\title{
Basin-wide variations in Amazon forest structure and function are mediated by both soils and climate
}

\author{
C. A. Quesada ${ }^{1,2}$, O. L. Phillips ${ }^{1}$, M. Schwarz ${ }^{3}$, C. I. Czimczik $^{4}$, T. R. Baker ${ }^{1}$, S. Patiño ${ }^{1,4, \dagger}$, N. M. Fyllas ${ }^{1}$,
} M. G. Hodnett ${ }^{5}$, R. Herrera ${ }^{6}$, S. Almeida ${ }^{7, \dagger}$, E. Alvarez Dávila ${ }^{8}$, A. Arneth ${ }^{9}$, L. Arroyo ${ }^{10}$, K. J. Chao ${ }^{1}$, N. Dezzeo ${ }^{6}$, T. Erwin ${ }^{11}$, A. di Fiore ${ }^{12}$, N. Higuchi ${ }^{2}$, E. Honorio Coronado ${ }^{13}$, E. M. Jimenez ${ }^{14}$, T. Killeen ${ }^{15}$, A. T. Lezama ${ }^{16}$, G. Lloyd ${ }^{17}$, G. López-González ${ }^{1}$, F. J. Luizão ${ }^{2}$, Y. Malhi ${ }^{18}$, A. Monteagudo ${ }^{19,20}$, D. A. Neill ${ }^{21}$, P. Núñez Vargas ${ }^{19}$, R. Paiva ${ }^{2}$, J. Peacock ${ }^{1}$, M. C. Peñuela ${ }^{14}$, A. Peña Cruz ${ }^{20}$, N. Pitman ${ }^{22}$, N. Priante Filho ${ }^{23}$, A. Prieto ${ }^{24}$, H. Ramírez ${ }^{16}$, A. Rudas $^{24}$, R. Salomão ${ }^{7}$, A. J. B. Santos ${ }^{2,25,{ }^{\dagger}, \text { J. Schmerler }}{ }^{4}$, N. Silva ${ }^{26}$, M. Silveira ${ }^{27}$, R. Vásquez ${ }^{20}$, I. Vieira ${ }^{7}$, J. Terborgh ${ }^{22}$, and J. Lloyd ${ }^{1,28}$

${ }^{1}$ School of Geography, University of Leeds, LS2 9JT, UK

${ }^{2}$ Instituto Nacional de Pesquisas da Amazônia, Manaus, Brazil

${ }^{3}$ Ecoservices, 07743 Jena, Germany

${ }^{4}$ Max-Planck-Institut fuer Biogeochemie, Jena, Germany

${ }^{5}$ Centre for Ecology and Hydrology, Wallingford, UK

${ }^{6}$ Instituto Venezolano de Investigaciones Científicas, Caracas Venezuela

${ }^{7}$ Museu Paraense Emilio Goeldi, Belém, Brazil

${ }^{8}$ Jardin Botanico de Medellin, Medellin, Colombia

${ }^{9}$ Karlsruhe Institute of Technology, Institute for Meteorology and Climate Research,Garmisch-Partenkirchen, Germany

${ }^{10}$ Museo Noel Kempff Mercado, Santa Cruz, Bolivia

${ }^{11}$ Smithsonian Institution, Washington, DC 20560-0166, USA

${ }^{12}$ Department of Anthropology, New York University, New York, NY 10003, USA

${ }^{13}$ IIAP, Apartado Postal 784, Iquitos, Peru

${ }^{14}$ Universidad Nacional de Colombia, Leticia, Colombia

${ }^{15}$ Centre for Applied Biodiversity Science, Conservation International, Washington DC, USA

${ }^{16}$ Faculdad de Ciencias Forestales y Ambientales, Univ. de Los Andes, Merida, Venezuela

${ }^{17}$ Integer Wealth Management, Camberwell, Australia

${ }^{18}$ School of Geography and the Environment, University of Oxford, Oxford, UK

${ }^{19}$ Herbario Vargas, Universidad Nacional San Antonio Abad del Cusco, Cusco, Peru

${ }^{20}$ Proyecto Flora del Perú, Jardin Botanico de Missouri, Oxapampa, Peru

${ }^{21}$ Herbario Nacional del Ecuador, Quito, Ecuador

${ }^{22}$ Centre for Tropical Conservation, Duke University, Durham, USA

${ }^{23}$ Depto de Fisica, Universidade Federal do Mato Grosso, Cuiabá, Brazil

${ }^{24}$ Instituto de Ciencias Naturales, Universidad Nacional de Colombia, Bogotá, Colombia

${ }^{25}$ Depto de Ecologia, Universidade de Brasilia, DF, Brazil

${ }^{26}$ Empresa Brasileira de Pesquisas Agropecuárias, Belém, Brazil

${ }^{27}$ Depto de Ciências da Natureza, Universidade Federal do Acre, Rio Branco, Brazil

${ }^{28}$ Centre for Tropical Environmental and Sustainability Science (TESS) and School of Earth and Environmental Sciences, James Cook University, Cairns, Queensland 4878, Australia

$\dagger$ deceased

Correspondence to: J. Lloyd (jon.lloyd@jcu.edu.au)

Received: 18 December 2008 - Published in Biogeosciences Discuss.: 8 April 2009

Revised: 6 March 2012 - Accepted: 12 April 2012 - Published: 22 June 2012 
Abstract. Forest structure and dynamics vary across the Amazon Basin in an east-west gradient coincident with variations in soil fertility and geology. This has resulted in the hypothesis that soil fertility may play an important role in explaining Basin-wide variations in forest biomass, growth and stem turnover rates.

Soil samples were collected in a total of 59 different forest plots across the Amazon Basin and analysed for exchangeable cations, carbon, nitrogen and $\mathrm{pH}$, with several phosphorus fractions of likely different plant availability also quantified. Physical properties were additionally examined and an index of soil physical quality developed. Bivariate relationships of soil and climatic properties with above-ground wood productivity, stand-level tree turnover rates, above-ground wood biomass and wood density were first examined with multivariate regression models then applied. Both forms of analysis were undertaken with and without considerations regarding the underlying spatial structure of the dataset.

Despite the presence of autocorrelated spatial structures complicating many analyses, forest structure and dynamics were found to be strongly and quantitatively related to edaphic as well as climatic conditions. Basin-wide differences in stand-level turnover rates are mostly influenced by soil physical properties with variations in rates of coarse wood production mostly related to soil phosphorus status. Total soil $\mathrm{P}$ was a better predictor of wood production rates than any of the fractionated organic- or inorganic-P pools. This suggests that it is not only the immediately available $\mathrm{P}$ forms, but probably the entire soil phosphorus pool that is interacting with forest growth on longer timescales.

A role for soil potassium in modulating Amazon forest dynamics through its effects on stand-level wood density was also detected. Taking this into account, otherwise enigmatic variations in stand-level biomass across the Basin were then accounted for through the interacting effects of soil physical and chemical properties with climate. A hypothesis of selfmaintaining forest dynamic feedback mechanisms initiated by edaphic conditions is proposed. It is further suggested that this is a major factor determining endogenous disturbance levels, species composition, and forest productivity across the Amazon Basin.

\section{Introduction}

There is a coincident, semi-quantitative correlation between the above-ground coarse wood production of tropical forests $\left(W_{\mathrm{P}}\right)$ and soil type observed across the Amazon Basin that has been attributed to variations in soil fertility (Malhi et al., 2004). But what controls Amazonian forest productivity and function, either at the Basin-wide scale or regionally, remains to be accurately determined.

Stem turnover, viz. the rate in which trees die and are recruited into a forest population, also varies across the Ama- zon Basin (Phillips et al., 2004) with an east-west gradient coinciding with gradients of soil fertility and geology as first described by Sombroek (1966) and Irion (1978). An average turnover rate of $1.4 \% \mathrm{a}^{-1}$ is observed in the infertile eastern and central areas whilst an average turnover rate of $2.6 \% \mathrm{a}^{-1}$ occurs in the more fertile west and south-west portion of the Basin. This pattern has resulted in the hypothesis that soil nutrient status may play an important role in explaining the almost two-fold difference in stem turnover rates between the western and central-eastern areas (Phillips et al., 2004; Stephenson and van Mantgen, 2005).

Nevertheless, in addition to soil nutrient status per se, soil physical properties such as a limited rooting depth, poor drainage, low water holding capacity, the presence of hardpans, bad soil structure and/or topographic position have also long been known to be important potential limitations to forest growth; directly or indirectly influencing tree mortality and turnover rates across both temperate and tropical forest ecosystems (Arshad et al., 1996; Dietrich et al., 1996; Gale and Barfod, 1999; Schoenholtz et al., 2000; Ferry et al., 2010).

Variations in soil chemical and physical properties across the Amazon Basin both tend to correlate with variations in soil age and type of parent material (Quesada et al., 2011). Specifically, highly weathered soils are generally of depths several metres above the parent material and usually have very good physical conditions as a result of millennia of soil development (Sanchez, 1987). On the other hand, the more fertile soils in Amazonia are generally associated with lower levels of pedogenesis with the parent material still a source of nutrients. Alternatively, they may occur as a consequence of bad drainage and/or deposition of nutrients by flood waters (Irion, 1978; Herrera et al., 1978; Quesada et al., 2011). In both cases a high soil cation and phosphorus status would be expected to be associated with non-optimal soil physical conditions (Quesada et al., 2010), the latter with a potential to have an adverse impact on many aspects of tree function (Schoenholtz et al., 2000).

This gives rise to the idea that the previously identified relationships found between soil chemical status and stem turnover rates (Phillips et al., 2004; Russo et al., 2005; Stephenson and van Mantgen, 2005; Stephenson et al., 2011) might at least to some extent be indirect, actually reflecting additional physical constraints in more fertile soils: or at least a combination of soil chemical and physical factors. Other forest properties such as wood density, production rates and above-ground biomass might also be influenced in this way.

In any case, relationships between tropical forest dynamics and/or structure and soil chemical conditions remain enigmatic. For example, the reported effects of soil properties on tropical forest above-ground biomass have been contradictory: Some studies have found interactions between a range of measures of soil fertility and above- ground biomass (Laurance et al., 1999; Roggy et al., 1999; Paoli et al., 2008; Slik et al., 2010), but most have found little or no relationship with 
a range of measures of soil nutrients (Proctor et al., 1983; Clark and Clark 2000; Chave et al., 2001; DeWalt and Chave, 2004; Baraloto et al., 2011).

Stand-to-stand variation in Amazon forest structure and dynamics at a Basin-wide scale can potentially be due to three interacting factors. First, tropical tree taxa are not distributed randomly across the Amazon Basin, but rather show spatial patterning attributable to both biogeographic and edaphic/climatic effects. Included in the former category are differences between different taxa in their geographical origins and subsequent rates of diversification and dispersion (e.g. Richardson et al., 2001; Fine et al., 2005; Hammond, 2005; ter Steege et al., 2010) with these phenomena then potentially interacting with the second factor, viz. a tendency for particular taxa to associate with certain soils and/or climatic regimes (Phillips et al., 2003; Butt et al., 2008; Honorio Coronado et al., 2009; Higgins et al., 2011; Toledo et al., 2011a). As different tree species have different structural and demographic traits such as intrinsic growth rates, lifetimes and maximum heights (Keeling et al., 2008; Baker et al., 2009), both local and large-scale patterns in tropical forest tree growth, stature and dynamics might simply be related to differences in species composition. Indeed, stand level wood density variations are usually considered to occur in this way (Baker et al., 2004a).

If, even in part, forest structure and/or dynamics effects are mediated through the association of certain taxa with particular soils and/or climate (for example, intrinsically faster growing species associating with more fertile soils) then this second component can be considered as an environmental effect, but potentially with a biogeographic contribution related to the regional species mix.

It is also probable that soils or climate exert direct effects on forest dynamics independent of species composition or associations and this gives rise to a third (purely environmental) component of variation: For example, trees grow faster when essential nutrients are more abundant as suggested, for example by long-term fertilization trials (e.g. Wright et al., 2011). Similarly, results from artificial imposition of long-term soil water deficits suggest that under less favourable precipitation regimes stand-level growth rates are reduced (Costa et al., 2010).

Overlaying and underlying the above are large-scale spatial patterns in the potential environmental drivers of forest structure and dynamics themselves. For example, temperature, precipitation and soil type all vary across the Amazon Basin in a non-random manner (Malhi and Wright, 2004; Quesada et al., 2011).

We thus examine here in some detail the relationship between Amazon forest soil physical and chemical conditions and forest turnover rates, above-ground coarse wood production, average plot wood density and above-ground biomass, also attempting to take into account the above spatial patterning effects which may potentially operate at a different range of scales for different processes. We use both previously pub- lished data (Phillips et al., 2004; Malhi et al., 2004; Baker et al., 2004a; Baker et al., 2009) and newly calculated estimates of these parameters from the RAINFOR database (Peacock et al., 2007; López-González et al., 2011) with all estimates used obtained prior to the onset of the 2005 Amazon drought. Our statistical approach is based on eigenfunction spatial analysis (Griffith and Peres-Neto, 2006; Peres-Neto and Legendre, 2010). Although usually applied to help understand the factors underlying species distributions, these techniques may also be applied to aggregated ecosystem properties, as for example in a study of anuran body size in relation to climate in the Brazilian Cerrado (Olalla-Tárraga et al., 2009).

\section{Material and methods}

\subsection{Study sites}

From the soils dataset of Quesada et al. (2010), a subset of 59 primary forest plots located across the Amazon Basin was used in the analysis here. The selected sites had all requisite forest parameters and complete soil data available with the following sites excluded for this analysis: MAN-03, MAN04, MAN-05, TAP-04, TIP-05, and CPP-01 (no forest data available); CAX-06, SUC-03, SCR-04, and CAX-04 (incomplete soil data) and SUM-06 (excluded as it is a submontane forest above $500 \mathrm{~m}$ altitude).

\subsection{Soil sampling and determination of chemical and physical properties}

Soil sampling and determination methods are described in detail in Quesada et al. $(2010,2011)$ and are thus only briefly summarised here.

For each one-hectare plot, five to twelve soil cores were collected and soil retained over the depths $0-0.05,0.05-0.10$, $0.10-0.20,0.20-0.30,0.30-0.50,0.50-1.00,1.00-1.50$ and $1.50-2.00 \mathrm{~m}$ using an undisturbed soil sampler (Eijkelkamp Agrisearch Equipment BV, Giesbeek, The Netherlands).

Each plot also had one soil pit dug to a depth of $2.0 \mathrm{~m}$ (or until an impenetrable layer was reached) with samples collected from the pit walls at the same depths as above for bulk density and particle size analysis determinations. All sampling was done following a standard protocol (see http://www.geog.leeds.ac.uk/projects/rainfor/pages/ manuals_eng.html) in such a way as to account for spatial variability within the plot.

Soil samples were air dried, usually in the field, and then once back in the laboratory, had roots, detritus, small rocks and particles over $2 \mathrm{~mm}$ removed. Samples were then analysed for: $\mathrm{pH}$ in water at 1:2.5 and with exchangeable aluminium, calcium, magnesium, potassium and sodium viz. $[\mathrm{Al}]_{\mathrm{E}},[\mathrm{Ca}]_{\mathrm{E}},[\mathrm{Mg}]_{\mathrm{E}},[\mathrm{K}]_{\mathrm{E}}$ and $[\mathrm{Na}]_{\mathrm{E}}$, determined by the silver-thiourea method (Pleysier and Juo, 1980). Complete phosphorus fractionations (modified from Hedley et al., 1982), and carbon and nitrogen determinations (Pella, 1990; 
Nelson and Sommers, 1996) were also undertaken. Results from the top soil layer $(0-0.3 \mathrm{~m})$ are presented. The phosphorus pools identified (as in Quesada et al., 2010) were "plant available phosphorus", $[\mathrm{P}]_{\mathrm{a}}$, this being the sum of the resin extracted and (inorganic + organic) bicarbonate extracted pools; "total extractable phosphorus", $[\mathrm{P}]_{\mathrm{ex}}$, this being $[\mathrm{P}]_{\mathrm{a}}$ plus the $\mathrm{NaOH}$ extracted (inorganic + organic) pool together with that extracted by $1 \mathrm{M} \mathrm{HCl}$; and "total phosphorus", $[\mathrm{P}]_{\mathrm{t}}$, this being that extracted through a digestion of the soil in hot acid. In this analysis we also consider separately the inorganic component of $[\mathrm{P}]_{\mathrm{ex}}$, this being referred to as $[\mathrm{P}]_{\mathrm{i}}$ and with the associated organic component denoted $[\mathrm{P}]_{\mathrm{o}}$. As potential predictors of forest dynamics, we also considered the sum of the individual extractable base cations (viz. the "sum of bases"), this being denoted as $\Sigma_{\mathrm{B}}$, as well as the effective cation exchange capacity $\left(I_{\mathrm{E}}=\Sigma_{\mathrm{B}}+[\mathrm{Al}]_{\mathrm{E}}\right)$.

For quantifying the magnitude of limiting soil physical properties, a score table was developed and sequential scores assigned to the different levels of physical limitations. This was done using the soil pit descriptions that had been made at each site (details in Quesada et al., 2010) with this then providing the requisite information on soil depth, soil structure quality, topography, and anoxic conditions in a semiquantitative format. These data were also summated to give two indexes of soil physical quality $(\Pi)$. One $\left(\Pi_{1}\right)$, was created by adding up the soil depth, structure, topography and anoxic scores, and the other $\left(\Pi_{2}\right)$ by summation of the soil depth, structure and topography scores only. It has already been observed that $\Pi_{1}$ is strongly related to a soil's weathering extent, reflecting broad geographical patterns of soil physical properties in Amazonia (Quesada et al., 2010). Differentiating $\Pi_{1}$ and $\Pi_{2}$ is the absence of a presumed effect of anoxia in the latter, as might be expected if physiological adaptions to water-logging (Joly, 1991; Parolin et al., 2004) are important in maintaining the function of tropical trees in such environments.

Soil bulk density profiles (sampled from the soil walls) were used as an aid in soil structure score grading along with data on particle size distribution obtained using the Boyoucos method (Gee and Bauder, 1986).

Available soil water content $\left(\theta^{*}\right)$ was determined as a function of potential evaporation, depth of root system (as noted from soil pit descriptions), and by an estimation of soil available water content based on the particle size pedotransfer functions given by Hodnett and Tomasella (2002). For this analysis, $\theta^{*}$ was integrated to the maximum rooting depth for each area or integrated to four meters where roots were not observed to be constrained in any way. This was then modelled to vary following daily rainfall inputs and losses estimated by potential evaporation, with the duration (months) of $\theta^{*}<0.2$ estimated using standard soil "water bucket" calculations.

\subsection{Climatic data}

Mean annual temperature $\left(T_{\mathrm{A}}\right)$ and precipitation $\left(P_{\mathrm{A}}\right)$ data are as in Malhi et al. (2004) and Patiño et al. (2009), with estimates of incoming solar radiation $\left(R_{\mathrm{a}}\right)$ derived taken from the $0.5^{\circ}$ resolution University of East Anglia Observational Climatology (New et al., 2002). Dry season precipitation $\left(P_{\mathrm{D}}\right)$ is defined here as the average monthly precipitation occurring during the driest quarter of the year.

\subsection{Forest structure and dynamics}

Biomass per unit area $(B)$ was estimated by applying a single allometric relationship derived for the central Amazon near Manaus (Chambers et al., 2001) to each tree and summing the estimated biomass of each tree estimated over the plot area, taking into account species differences in wood density (Baker et al., 2004a). Thus, one factor that is not accounted for is spatial variation in allometry (i.e. the tree height and biomass supported for a given tree basal area) as this allometric equation uses tree diameter and tree wood density only. For most plots all trees were identified to species, either in the field or by collecting voucher specimens for comparison with herbarium samples. Higher-order taxonomy follows the Angiosperm Phylogeny Group (1998).

To control for any long-term changes in forest behaviour (e.g. Baker et al., 2004b; Phillips et al., 1998; Lewis et al. 2004a), variations in census dates were minimised. All forest properties reported here predate the 2005 drought event which impacted forest biomass, productivity, and forest mortality (Phillips et al., 2009).

Above-ground coarse wood carbon production in stems and branches $\left(W_{\mathrm{P}}\right)$ is as defined by Malhi et al. (2004) viz. the rate at which carbon is fixed into above-ground coarse woody biomass structures, including boles, limbs and branches but excluding fine litter production (i.e. not including leaves, reproductive structures and twigs) and estimated on the basis of the biomass gain rates recorded in all stems $\geq 0.1 \mathrm{~m}$ diameter in our plots, with small adjustments for census-interval effects (Malhi et al., 2004; Phillips et al., 2009).

Stand level turnover rates $(\varphi)$ reflect the rate with which trees move through a population (the flux); because this is estimated relative to the number of trees in the population (the pool) it reflects the mean proportion of trees entering and leaving the population per year. Annual mortality and recruitment rates were separately estimated using standard procedures that use logarithmic models which assume a constant probability of mortality and recruitment through each inventory period (Swaine et al., 1987; Phillips et al., 1994, 2004) with trees identified as "standing dead" for the first time being included in the mortality estimates. To reduce noise associated with measurement difficulties over short periods and small areas, turnover rates for each period were represented by the mean of recruitment and mortality and are our best estimates of long-term mean stand turnover rates. As for $W_{\mathrm{P}}$ 
we accounted for census-interval effects using standard approaches (Lewis et al., 2004b).

The final dataset as analysed here consists of 59 plots with measurements of $B$ (all of these with estimates of stand-level wood density), of which 55 had $\varphi$ and 53 had $W_{P}$ measurements also available.

\subsection{Statistical methods}

\subsubsection{Theoretical considerations}

Analyses of ecological processes are usually done using multiple regressions in which a desired response variable is regressed against sets of environmental variables (see Paoli et al., 2008 for a recent example). However, the lack of independence between pairs of observations across geographical space (spatial autocorrelation) in situations such as ours results in the need for more complex strategies for data analyses (Legendre, 1993). This is because spatial autocorrelation - for example due to plots being located close to each other having essentially the same temperature and precipitation generates redundant information and a subsequent overestimation of actual degrees of freedom (Dutilleul, 1993). Therefore, autocorrelation in multiple regression residuals results in the underestimation of standard errors of regression coefficients, consequently inflating Type I errors.

A related issue is the "red shift" effect, identified by Lennon (2000) where it is claimed that the probability of detecting a "false" correlation between autocorrelated response variable and any set of predictors is much greater for strongly autocorrelated predictors, even if spatial patterns are independent. Thus there is a likely over-representation of covariates with stronger spatial autocorrelation when using model selection procedures for which this is not taken into account (Lennon, 2000). This suggests that when a response variate and a predictor variate are characterised by spatial autocorrelation at a similar scale (as can be detected with the aid of a Moran's I correlogram for example: Legendre and Legendre, 1998), then even if not causatively related, there is an increased chance of a false association being suggested. This may be particularly the case for spatially interpolated covariates such as temperature and, to a lesser extent, precipitation, where a high degree of spatial autocorrelation is all but inevitable (Lennon, 2000). In such a situation, a relatively high level of spatial structuring in regression residuals need not necessarily be expected and therefore the absence of residual spatial autocorrelation may not necessarily be indicative of an unbiased OLS fit.

Models that incorporate the spatial structures into regression model parameterisations provide one means by which to address these problems (Diniz-Filho and Bini, 2005), with the significance of pre-selected OLS predictors usually decreasing once the inherent spatial dependencies of the variates of interest are taken into account (Bini et al., 2009). Conversely, once spatial autocorrelation is accounted for in a re- gression model the importance of predictors without spatial structure may actually increase (Bini et al., 2009). The inclusion of spatial structures does, however, have the potential to lead to a de-emphasis of (usually) larger scale relationships, some of which may be causative (Diniz-Filho et al., 2003; Beale et al., 2010) and there is no "black and white" rule for spatial structure identification and inclusion into statistical models and with different approaches sometimes giving very different results (Bini et al., 2009; Beale et al., 2010).

\subsubsection{Identification of spatial components}

To aid the detection of spatial structures in the data, Moran's I correlograms (Legendre and Legendre, 1998) were first estimated for each variable of interest. Spearman correlations were then adjusted to account for spatial autocorrelation, following Dutilleul (1993) with modified degrees of freedom and probability $(p)$ values.

Eigenvector-based spatial filtering (extracted by Principal Component of Neighbor Matrices: PCNM, Borcard and Legendre, 2002) was then used to help understand the observed spatial patterns in forest structure and dynamics. The selected filters were subsequently used in multiple least-squares regressions specifically designed to account for the potential presence of both environmental and geographical effects.

Three different variants of Spatial EigenVector Mapping (SEVM) were used, these varying in the way in which the spatial filters were selected. This "sensitivity analysis" was undertaken because filter selection protocol has been shown to have a substantial impact on the regression coefficients associated with environmental variables and their significance (Bini et al., 2009). In the first SEVM-1 procedure, all filters with Moran's $I>0.1$ were selected. The second variant (SEVM-2) included only filters significantly correlated $(p<0.05)$ to the response variable. In the third, we included only spatial filters significantly correlated with residuals from the already selected OLS model of the response variable against environmental predictors (SEVM-3).

\subsubsection{Multivariate modelling}

Model selection was in all cases done on the basis of Akaike's Information Criterion ( $A I C)$. Initially, a full suite of models containing all possible combinations of climate and soil variables was examined, with all soil chemical parameters having been log-transformed prior to analysis due to their strongly skewed nature (Quesada et al., 2010). Subsequent considerations were limited to those variables appearing in models with an $A I C$ within 2 units of the best model fit; this reflecting a rule of thumb for selecting among models using an information-theoretic approach. Here models with an $A I C$ not more than 2 greater than the lowest $A I C$ model are considered equally likely to be the best model; thus needing to be given full credence when making any inferences about a system (Richards, 2005). Final model selection was 
with an additional criterion (also applied in the selection of the "best fit" model) that the soil or climate variables considered could not contain redundant information. For example, from the sequential extraction procedure used for phosphorus, "readily available P" (resin extracted P plus organic and inorganic bicarbonate extracted P) is a subset of "total P" (extracted in hot acid), and thus it makes little sense to include both in any model. Similarly, "sum of bases" $\left(\Sigma_{\mathrm{B}}\right)$ is the sum of $[\mathrm{Ca}]_{\mathrm{E}},[\mathrm{Mg}]_{\mathrm{E}},[\mathrm{K}]_{\mathrm{E}}$, and $[\mathrm{Na}]_{\mathrm{E}}$. Thus, although more than one base cation could potentially be included in the model, no model with one or more individual cations and $\Sigma_{\mathrm{B}}$ was permitted. In a similar manner, all significant soil physical variables were allowed for inclusion, but not along with the summated index terms, for which only one of $\Pi_{1}$ or $\Pi_{2}$ could be included in any given model. Treating climate predictors in the same way, we only considered models with a single precipitation term ( $\mathrm{viz}$. one or none of mean annual precipitation, dry season precipitation or $\theta^{*}<0.2$ ). Although the above criteria served to remove many models with a strong collinearity of predictors from consideration, an additional criterion for model retention was that variance inflation factors be $<5$ : Where alternative formulations meeting the above criterion were found to give a fit within 2.0 AIC units of the final selected model this is usually noted in the text, especially for the OLS model.

Regression coefficients for the final model fits are presented as standardised values, these giving the relative change in the dependent variable per unit standard deviation of each independent variable. Though potentially open to misinterpretation (Grace and Bollen, 2005), this provides a simple measure of the relative importance of the various factors accounting for the observed variation in forest structure and/or dynamics; the standardising factor being the variability (after transformation where appropriate) of the various candidate independent variables across the Amazon Basin as measured by our dataset. We also provide standard estimates of the level of significance of the independent covariates selected through the $A I C$ procedure, also noting that sometimes variables selected are not significant at the conventional $p \leq 0.05$. This is because information theoretical procedures such as Akaike AIC provide a holistic approach to ordering and selecting among competing models. They thus present a very different philosophical approach to conventional hypothesis testing, sometimes giving rise to very different conclusions to the piece-meal and potentially inconsistent outcomes that arise from applying multiple significance tests (Dayton, 2003).

One approach in incorporating spatial filters to account for spatial autocorrelation in OLS multiple regression is to first select the predictor variables using OLS and to then rerun the analysis but with the spatial filters also included. The probabilities of significance of the predictor variables are then adjusted accordingly (Bini et al., 2009). This approach is often taken because empirical simulations have shown that when OLS procedures are applied to spatially correlated datasets, standard errors (but not slope estimates) end up being biased (Hawkins et al., 2007). Nevertheless, as different predictor variables have different spatial structures, after the addition of any set of spatial filters as above, some predictors may actually have their significance increased compared to the OLS model (Bini et al., 2009), Thus, a model selection with filters included need not necessarily lead to the same predictor variables being selected as would have been found using an OLS procedure in the first place (Diniz-Filho et al., 2008). For the SEVM-01 and SEVM-02 models, we therefore undertook two analyses. One where the selected filters were simply added to the OLS result (the results are shown in brackets in Tables 2, 4, 6 and 8) as well as a separate lowest AIC model selection where all candidate environmental variables and the pre-selected filters were put into the mix for inclusion into the lowest $A I C$ model (shown in bold).

\subsubsection{Variance partitioning}

We also used information from our PCNM analyses to partition the variation in a data set into environmental, spatial and residual components, including an estimate of the variance shared by both environment and space (Peres-Neto et al., 2006). This procedure is, unfortunately, not straightforward. This is because it is necessary to perform a model selection procedure in order to reduce the number of spatial predictors so that significant unique environmental predictors have a greater chance of being identified (Peres-Neto and Legendre, 2010). As suggested by Beale et al. (2010), in doing this analysis we therefore selected only those filters that were significantly correlated $(p>0.05)$ with the response variable (i.e. the SEVM-02 spatial filters). These were then examined in a multiple regression context along with the environmental variables selected by the OLS procedure for the same variable. Bocard and Legendre (2002) provide details of the underlying theory behind this procedure.

All statistical analyses were undertaken using the software "Spatial Analysis in Macroecology - SAM" (Rangel et al., 2006).

\section{Results}

\subsection{Forest structure and dynamics in the geographic space}

Figure 1 shows the geographical distribution of average plot wood density, tree turnover rates, above-ground biomass, and coarse wood productivity. In all cases forest structure and dynamics are strongly conditioned by spatial location. For instance, the estimated average plot wood density $\left(\varrho_{\mathrm{w}}\right)$ ranges from 0.49 to $0.73 \mathrm{~g} \mathrm{~cm}^{-3}$ with higher wood density stands in central, eastern and northern Amazonia, and the lower wood density species more prevalent in the western forests. 

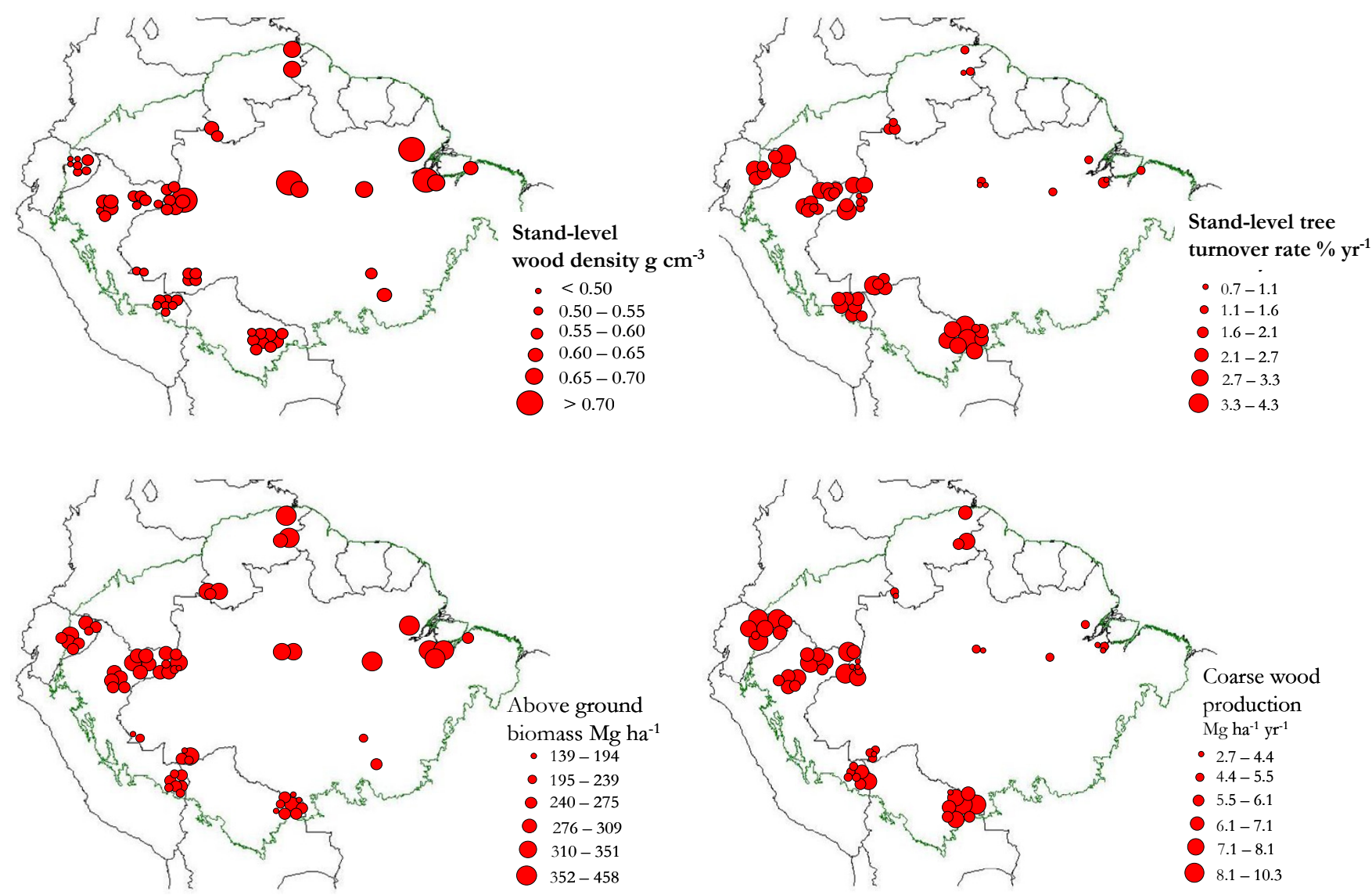

Fig. 1. Geographical distribution of stand-level wood density $\left(\varrho_{\mathrm{W}}\right)$, stand-level tree turnover rates $(\varphi)$, above-ground biomass $(B)$ and aboveground coarse wood production $\left(W_{\mathrm{P}}\right)$ across the Amazon Basin. Size of circles represents relative magnitudes.

Tree turnover rates also vary substantially across the Amazon Basin, ranging from 0.7 to $4.3 \% \mathrm{a}^{-1}$. As has been reported before (Phillips et al., 2004) values are generally higher in the western areas of Amazonia whilst much lower rates occur in central and eastern sedimentary areas as well as in the north part (Guyana Shield). This geographical pattern is similar to that of coarse wood production, which also varies with a similar pattern ranging from 2.7 to $10.3 \mathrm{Mg} \mathrm{ha}^{-1} \mathrm{a}^{-1}$, being noticeably higher in the proximity of the Andean cordillera, intermediary in the Guyana Shield area, and lowest in the central and eastern Amazonian areas (Malhi et al., 2004). By contrast, above-ground biomass is higher in the eastern and central areas as well as in the north, but it also has an east-west gradient with lower above-ground biomass occurring in western and south-western areas (Baker et al., 2004a; Malhi et al., 2006). Above-ground biomass (trees $\geq 0.1 \mathrm{~m}$ diameter at breast height) ranged from 139 to $458 \mathrm{Mg} \mathrm{ha}^{-1}$ across our dataset.

Though the relationships are different, all measured forest parameters correlated with latitude and longitude and with Moran's I correlograms (Fig. 2) demonstrating wood density, tree turnover rate, coarse wood production and biomass to all be positively spatially autocorrelated at distances of $900-1200 \mathrm{~km}$, then becoming negatively autocorrelated.

Many of the candidate soil and climate descriptors were also spatially structured (Supplement, Fig. S11). In particular, the precipitation measures and many of the soil physical constraint metrics showed high positive Moran's $I$ at short distances $(100 \mathrm{~km})$, steadily declining to negative values beyond around $1000 \mathrm{~km}$. This pattern was different for the soil chemical characteristics which, although having a positive Moran's $I$ at short distances $(100 \mathrm{~km})$ showed no systematic pattern beyond that. As well as showing a positive correlation at short distances, mean annual temperature $\left(T_{\mathrm{A}}\right)$ showed a second high Moran's $I$ around $2500 \mathrm{~km}$ with a strong negative Moran's $I$ at an intermediate distance of $2000 \mathrm{~km}$. This is probably a consequence of the Amazon Basin being circumvented by mountain ranges on its northern, southern and western sides and with much of our lowland sampling being towards the more distal portion of the Basin in the east. Together with the strong indications of spatial autocorrelation for the studied dependent variables (Fig. 2), these results suggest significant spatial structuring of the predictor variables, confirming a need to adopt adequate strategies to 

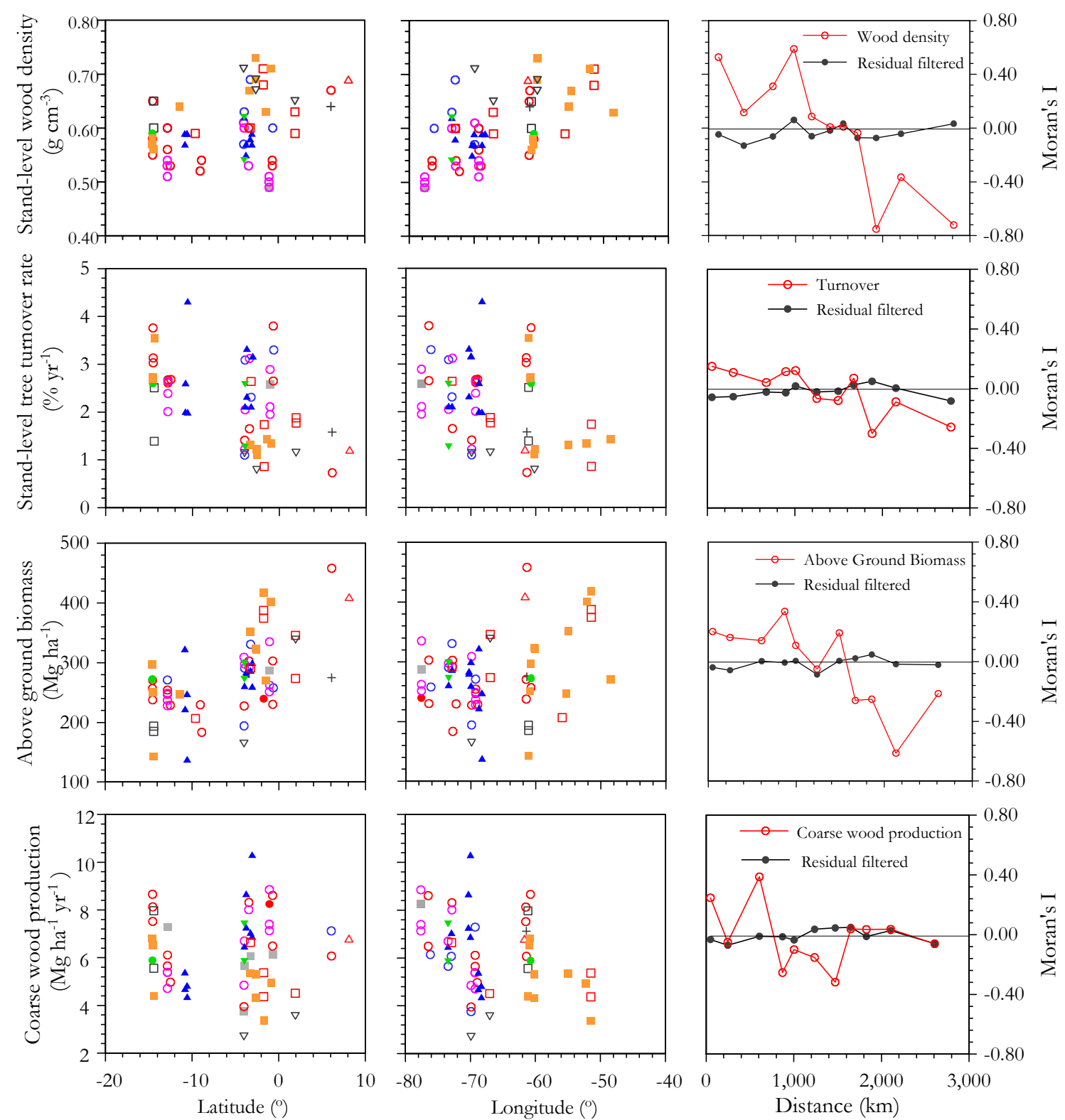

$\begin{array}{lllllllllllll}\nabla & \text { Arenosols } \square & \text { Ferralsols } & \Delta & \text { Lixisols } & \Delta & \text { Plinthosols } & \square & \text { Umbrisols } & \bullet & \text { Andosols } & \circ & \text { Gleysols } \\ \nabla & \text { Podzols } \square & \text { Acrisols } & \bullet & \text { Nitisols } & \circ & \text { Alisols } & \circ & \text { Cambisols } \backsim & \text { Fluvisols } & + & \text { Leptosols }\end{array}$

Fig. 2. Correlations of stand-level wood density, tree turnover, above-ground coarse wood production and above-ground biomass with the geographic space. Moran's I correlograms are also given showing spatial autocorrelation but with spatial filters able to effectively remove its effect from regression residuals.

perform statistical analysis on what is clearly a dataset of non-independent observations (Sect. 2.5.1)

Indeed, regressing all spatial filters for which Moran's $I>$ 0.1 from our SEVM-01 models (see Sect. 2.5.2) and using estimates of $R^{2}$ to estimate the proportion of variation that could be accounted for simply by "space" (Peres-Neto et al., 2006), we found that the selected spatial filters could on their own explain 0.6 of the variation in tree turnover rates, about 0.31 of the variation in coarse wood production, 0.61 of the variation in above-ground biomass, and 0.72 for the standlevel wood density variation. 
Table 1. Spearman's $\rho$ for relationships between above-ground coarse wood production and a range of soil and climate predictors. Probabilities $(p)$ are given with and without adjustment (adj) for degrees of freedom (df) according to Dutillieul (1993). Abbreviations used: $\Pi_{1}$ and $\Pi_{2}$ - first and second indices of soil physical conditions (Sect. 2.2); $[\mathrm{P}]_{\mathrm{ex}},[\mathrm{P}]_{\mathrm{a}},[\mathrm{P}]_{\mathrm{i}},[\mathrm{P}]_{\mathrm{o}},[\mathrm{P}]_{\mathrm{t}}-$ extractable, available, inorganic, organic, and total soil phosphorus pools; $[\mathrm{Ca}]_{\mathrm{E}},[\mathrm{Mg}]_{\mathrm{E}},[\mathrm{K}]_{\mathrm{E}},[\mathrm{Al}]_{\mathrm{E}}-$ exchangeable calcium, magnesium, potassium and aluminium concentrations; $I_{\mathrm{E}}$ - effective soil cation exchange capacity; $\theta^{*}<0.20$ - modelled number of months with soil water less than 0.2 of maximum available soil water content. Where $p \leq 0.050$ values are shown in bold.

\begin{tabular}{|c|c|c|c|c|}
\hline & Spearman's $\rho$ & $p$ value & $p$ value adj & df adj \\
\hline Sand fraction & 0.031 & 0.763 & 0.793 & 40 \\
\hline Clay fraction & 0.000 & 0.788 & 0.812 & 41 \\
\hline Silt fraction & 0.156 & 0.429 & 0.494 & 39 \\
\hline Soil depth score & 0.142 & 0.131 & 0.250 & 30 \\
\hline Soil structure score & 0.108 & 0.396 & 0.424 & 47 \\
\hline Topography score & 0.451 & $<0.001$ & 0.010 & 31 \\
\hline Anoxia score & 0.162 & 0.376 & 0.330 & 62 \\
\hline$\Pi_{1}$ & 0.380 & 0.007 & 0.037 & 31 \\
\hline$\Pi_{2}$ & 0.373 & 0.006 & 0.028 & 34 \\
\hline $\mathrm{pH}$ & 0.315 & 0.054 & 0.194 & 24 \\
\hline$[\mathrm{P}]_{\mathrm{ex}}$ & 0.430 & 0.002 & 0.026 & 26 \\
\hline$[\mathrm{P}]_{\mathrm{a}}$ & 0.409 & 0.004 & 0.047 & 26 \\
\hline$[\mathrm{P}]_{\mathrm{i}}$ & 0.371 & 0.019 & 0.090 & 27 \\
\hline$[\mathrm{P}]_{\mathrm{o}}$ & 0.459 & $<0.001$ & 0.010 & 26 \\
\hline$[\mathrm{P}]_{\mathrm{t}}$ & 0.451 & $<0.001$ & 0.017 & 27 \\
\hline Total $[\mathrm{N}]$ & 0.406 & 0.004 & 0.068 & 22 \\
\hline Total [C] & 0.126 & 0.232 & 0.394 & 27 \\
\hline $\mathrm{C}: \mathrm{N}$ ratio & -0.421 & 0.002 & 0.013 & 32 \\
\hline$[\mathrm{Ca}]_{\mathrm{E}}$ & 0.311 & 0.029 & 0.126 & 26 \\
\hline$[\mathrm{Mg}]_{\mathrm{E}}$ & 0.287 & 0.048 & 0.151 & 28 \\
\hline$[\mathrm{K}]_{\mathrm{E}}$ & 0.196 & 0.239 & 0.273 & 45 \\
\hline$[\mathrm{Al}]_{\mathrm{E}}$ & 0.121 & 0.694 & 0.720 & 43 \\
\hline Sum of bases & 0.287 & 0.040 & 0.146 & 27 \\
\hline$I_{\mathrm{E}}$ & 0.462 & 0.001 & 0.007 & 36 \\
\hline Mean annual temperature & -0.323 & 0.023 & 0.014 & 61 \\
\hline Mean annual precipitation & 0.195 & 0.208 & 0.318 & 33 \\
\hline Dry season precipitation & 0.258 & 0.015 & 0.187 & 16 \\
\hline$\theta^{*}<0.20$ & 0.062 & 0.518 & 0.657 & 25 \\
\hline Mean annual radiation & -0.054 & 0.465 & 0.635 & 22 \\
\hline
\end{tabular}

\subsection{Underlying causes of variation}

An understanding of biomass, productivity and turnover variation across a large area such as the Amazon Basin (Fig. 1) requires some knowledge of the "internal components" giving rise to the stand-to-stand variation. For example, a Basinwide gradient in $\varphi$ (which is expressed here as a proportion of the total tree population) could arise (in one extreme) from the same number of trees entering/leaving the population per unit area per year, but variable stand densities $(S)$. Or (in the other extreme) it could arise from an invariant $S$ and a variable number of trees entering/leaving the population per unit area per year. Similarly, stand-to-stand variations in $W_{\mathrm{P}}$ could be due to differences in average individual tree growth rates and/or different $S$. Likewise different stand biomasses $(B)$ can potentially arise through any combination of variability in $S$, basal area per tree $\left(A_{\mathrm{t}}\right)$ and wood density $\left(\varrho_{\mathrm{w}}\right)$ with significant covariances also possible.
A detailed study of these underlying components is not the purpose of this study, but for the interested reader we present an analysis of the component causes for the underlying variation in stand-level properties as Supplement. This shows that, although there is some variation in $S$, it is proportionally much less than either $A_{\mathrm{t}}$ or the average basal area growth rate per tree $\left(G_{\mathrm{t}}\right)$ and with stand level variability in basal areas and basal area growth rates mainly due to variations in $A_{\mathrm{t}}$ and $G_{\mathrm{t}}$, respectively. This is as opposed to variation in $S$. There is also no relationship between $S$ and either the average numbers of stems recruited/dying per unit area per year or $\varphi$ but with the latter two variables closely correlated (Fig. S1). Thus, almost all the variation in $\varphi$ in this study is due to differences in the number of trees recruited/dying per unit area per year. This is as opposed to variations in stem density. 

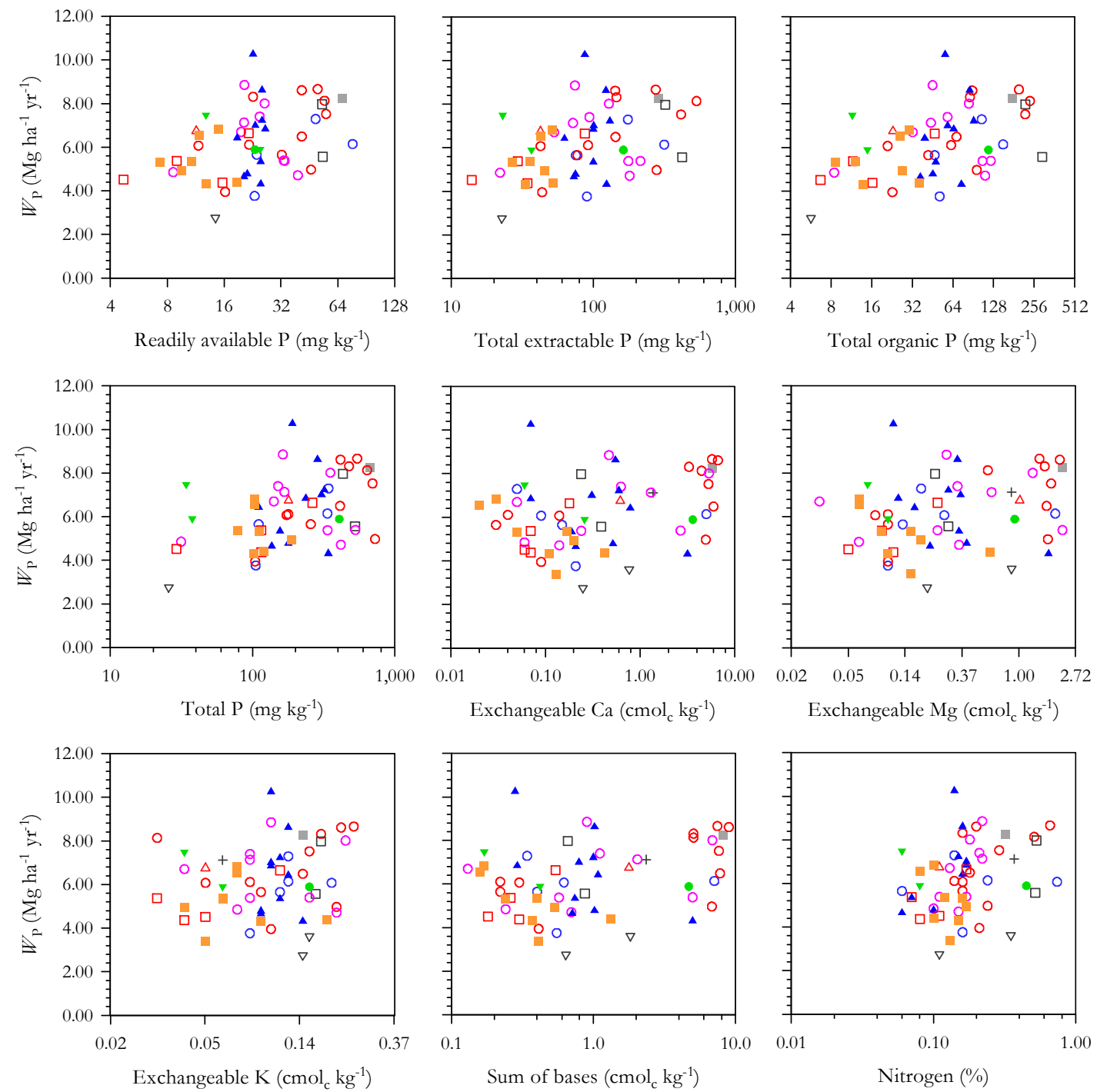

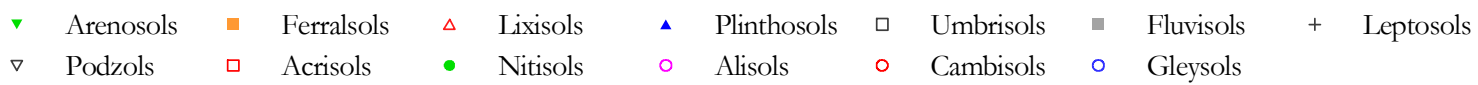

Fig. 3. Relationships between above-ground coarse wood production $\left(W_{\mathrm{P}}\right)$ and different soil nutrient measures.

\subsection{Coarse wood production}

Spatially adjusted Spearman's $\rho$ describing the relationships between $W_{\mathrm{P}}$ and the studied edaphic and climatic variables are shown in Table 1. Of the soil chemistry predictors, the best associations of $W_{\mathrm{P}}$ were with the various pools of phosphorus, with $\rho$ decreasing from 0.46 to 0.37 in the order $[\mathrm{P}]_{\mathrm{o}}>[\mathrm{P}]_{\mathrm{t}}>[\mathrm{P}]_{\mathrm{ex}}>[\mathrm{P}]_{\mathrm{a}}>[\mathrm{P}]_{\mathrm{i}}$. All correlations remained significant after adjustment of degrees of freedom for spatial autocorrelation (Table 1). Soil nitrogen was positively correlated and soil C:N ratio negatively correlated to $W_{\mathrm{P}}$, with soil exchangeable cations and $\Sigma_{\mathrm{B}}$ also of a limited positive influence. Effective cation exchange capacity was also remark- ably well correlated to $W_{\mathrm{P}}$. Relationships between soil chemistry parameters and $W_{\mathrm{P}}$ are plotted in Fig. 3. Noting that the validity of $I_{\mathrm{E}}$ as a fertility indicator is questionable due to the inclusion of aluminium into its calculation, sum of bases $\left(\Sigma_{\mathrm{B}}\right)$ was considered to be a better measure of cation availability and is thus plotted against $W_{\mathrm{P}}$ in Fig. 3 instead of the somewhat better-correlated $I_{\mathrm{E}}$. Overall, the most obvious relationships were between $W_{\mathrm{P}}$ and the various soil phosphorus measures. Soil physical properties had much less of a correlation with $W_{\mathrm{P}}$ than the soil chemical characteristics (Fig. 4). 

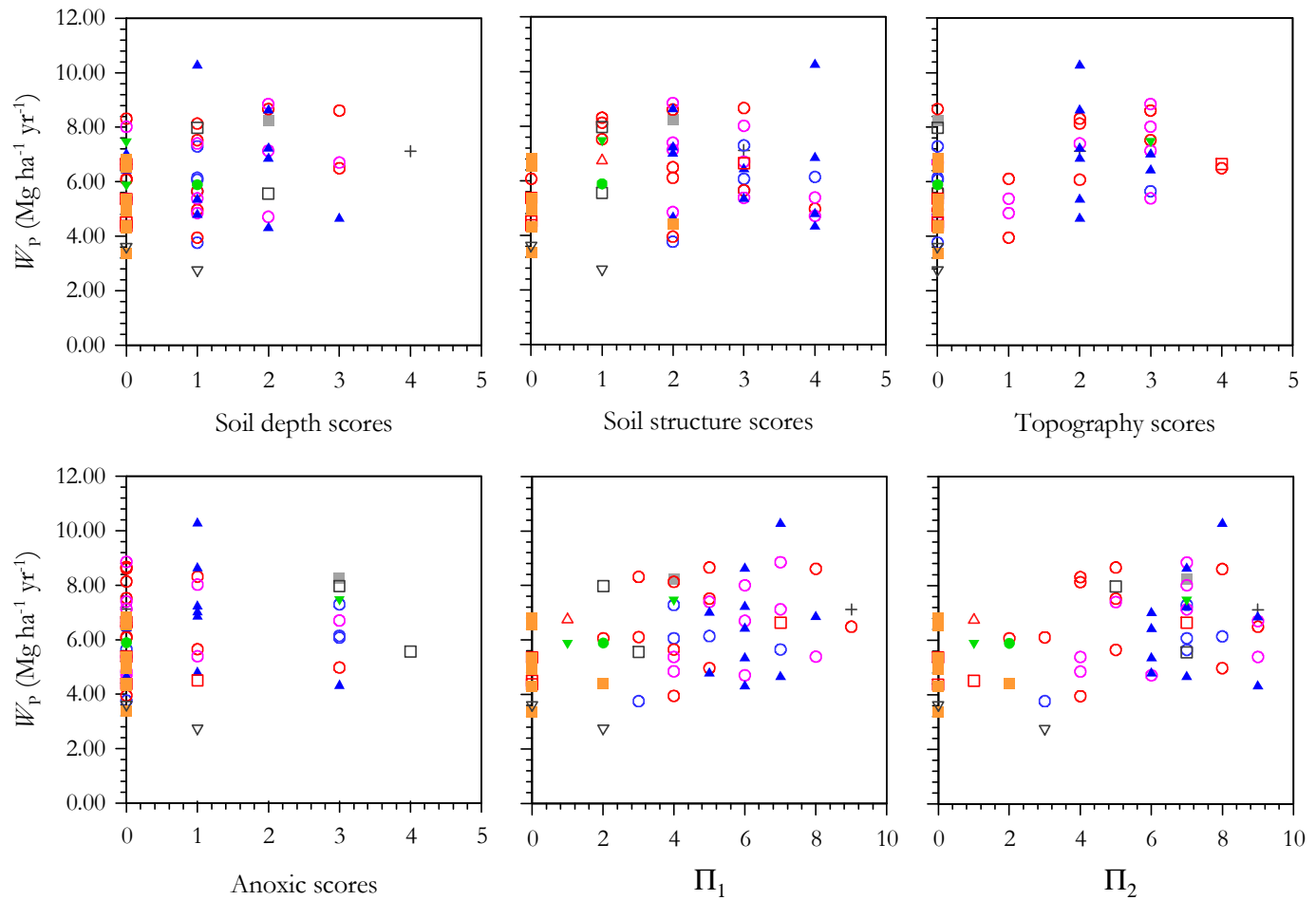

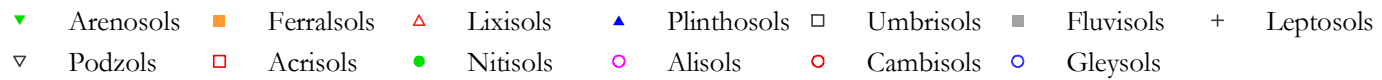

Fig. 4. Relationships between above-ground coarse wood production $\left(W_{\mathrm{P}}\right)$ and soil physical properties. For definitions of $\Pi_{1}$ and $\Pi_{2}$ see Sect. 2.2.

Of the climate variables, $T_{\mathrm{A}}$ showed only a relatively weak negative correlation with $W_{\mathrm{P}}$, and with dry-season precipitation, $P_{\mathrm{D}}$, showing a more consistent positive relationship than that observed for mean annual precipitation, $P_{\mathrm{A}}$ (Fig. 5); this is also evidenced by its higher Spearman's $\rho$. Nevertheless, neither of these measures were significant at $p \leq 0.10$ after an adjustment for the relevant degrees of freedom (Table 1). Nor was there an indication of a role for mean annual radiation variations across the Basin as an important modulator of $W_{\mathrm{P}}$, although we do also note that the fidelity of the radiation estimates used remains largely unknown for our study area.

Results of multiple regression analysis, with and without the inclusion of spatial filters are given in Table 2. All of $[\mathrm{K}]_{\mathrm{E}},[\mathrm{P}]_{\mathrm{t}}, T_{\mathrm{A}}$ and $P_{\mathrm{D}}$ were selected in the lowest AIC OLS model $\left(R^{2}=0.46\right)$ and with all four variables significant at $p<0.05$. The model selected with the lowest AIC criterion but with all spatial filters with a Moran's $I>0.1$ included (i.e. SEVM-01) was, however, substantially different. Although $[\mathrm{P}]_{\mathrm{t}}$ remained as a strong predictor term, $[\mathrm{Mg}]_{\mathrm{E}}$ replaced $[\mathrm{K}]_{\mathrm{E}}$ as the (negatively affecting) influential cation and with temperature and precipitation terms not selected $\left(R^{2}=0.48\right)$. For SEVM-02, where there was a solitary filter selected on the basis of a prior correlation with $W_{\mathrm{P}}$, then the results were more similar to the OLS case, but with, as for SEVM-01, $T_{\mathrm{A}}$ excluded $\left(R^{2}=0.46\right)$. For SEVM-03, there was no spatial filter found to be significantly correlated with the OLS model residuals. Thus the model presented is simply the OLS case.

Also shown in Table 2 are (in brackets) the model fits for the variables selected by the minimum AIC OLS models, but with the SEVM-01 or SEVM-02 filters also included. In most cases, the standardised coefficients $(\beta)$ and their level of significance were reduced in the presence of spatial filters and with these reductions being greatest for SEVM-01 (which has the more liberal spatial filter selection criteria). One notable exception to this pattern was $P_{\mathrm{D}}$ which had a greatly increased value in SEVM-01 as compared to the OLS/SEVM-03 and SEVM-02 models.

Of the OLS models with $\triangle A I C<2.0$ (and hence probably providing just as good a fit as the selected lowest $A I C$ model; Sect. 2.5.3) for both the OLS and SEVM-02 case, there were several models including $[\mathrm{K}]_{\mathrm{E}}$ or involving, either in addition or as replacements, $[\mathrm{Ca}]_{\mathrm{E}}$ and/or $[\mathrm{Mg}]_{\mathrm{E}}$ or $\Sigma_{\mathrm{B}}$. Contrary to the OLS case, however, there was no model with a $\triangle A I C<2.0$ that did not include at least one of the major soil base cations for SEVM-02. Irrespective of whether or not the spatial filter was employed, $[\mathrm{P}]_{\mathrm{t}}$ was a much better 

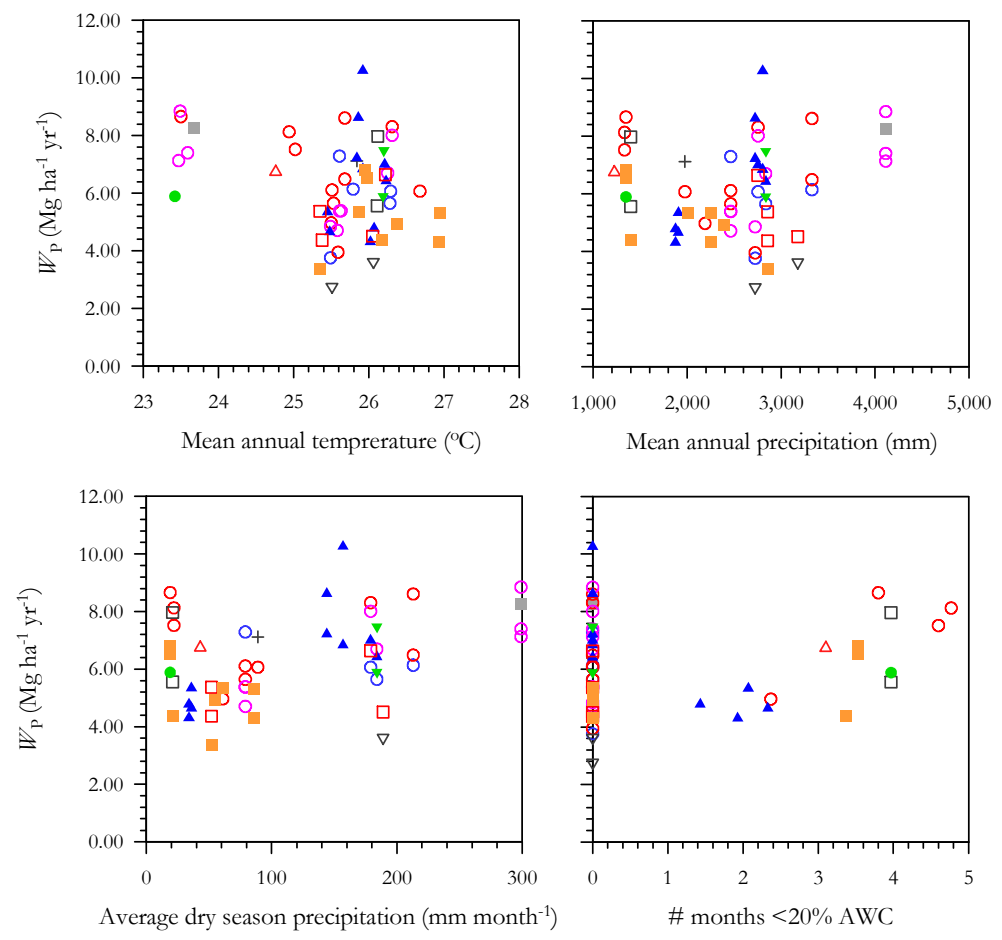

$\begin{array}{llllll}\nabla & \text { Arenosols } & \square & \text { Acrisols } & \Delta & \text { Plinthosols } \\ \nabla & \text { Podzols } & \triangle & \text { Lixisols } & \bigcirc & \text { Alisols } \\ \square & \text { Ferralsols } & \bullet & \text { Nitisols } & \square & \text { Umbrisols }\end{array}$

$$
\begin{array}{ll}
\circ & \text { Cambisols } \\
\square & \text { Fluvisols } \\
\circ & \text { Gleysols }
\end{array}
$$

Fig. 5. Relationships between above-ground coarse wood production $\left(W_{\mathrm{P}}\right)$ and climatic factors.

predictor of $W_{\mathrm{P}}$ than any other soil phosphorus pool; this being both in terms of the number of models with $\triangle A I C<2.0$ for which it was a component and in terms of having much higher standardised coefficients. A similar result was found for $P_{\mathrm{D}}$ which was a much more frequently selected predictor of $W_{\mathrm{P}}$ than was $P_{\mathrm{A}}$.

As shown in the Supplement (Eq. S5), $W_{\mathrm{P}}$ can be considered (to good approximation) as the product of basal area growth rate $\left(G_{\mathrm{B}}\right)$ and $\varrho_{\mathrm{w}}$. An analysis of soil and climate effects on the latter is presented in the next section and with a similar analysis for $G_{\mathrm{B}}$ provided in the Supplement. For $G_{\mathrm{B}}$ we found our selection procedure to imply similar climatic and edaphic factors as the best predictors for $W_{\mathrm{P}}$; this being the case both with and without the inclusion of spatial filters. Specifically, the OLS regression results indicate a role of $[\mathrm{P}]_{\mathrm{T}}, T_{\mathrm{A}}$ and $P_{\mathrm{A}}$ but with a less significant $\Pi_{2}$ term also selected (Supplement, Table S2). Interestingly, although mean annual radiation $\left(R_{\mathrm{a}}\right)$ did not appear as a significant predictor for $W_{\mathrm{P}}$, it turns out to be significant at $p=0.004$ for $G_{\mathrm{B}}$ in the model selection undertaken with SEVM-2 spatial filters but not for the OLS or other SEVM models. Also of note is the absence of any apparent influence of cations on $G_{\mathrm{B}}$. This contrasts with the negative effect of one of $[\mathrm{K}]_{\mathrm{E}}$ or $[\mathrm{Mg}]_{\mathrm{E}}$ on $W_{\mathrm{P}}$ as suggested by the multivariate regression results (Table 2).

\subsection{Wood density}

Spearman's $\rho$ with and without probability values and degrees of freedom adjusted for spatial autocorrelation are listed for relationships between measured edaphic and climatic variables and plot-level $\varrho_{\mathrm{w}}$ in Table 3. This shows $\varrho_{\mathrm{w}}$ to have negative associations with many soil nutrient characteristics and physical properties, as well as with climatic variables such as $T_{\mathrm{A}}, P_{\mathrm{A}}$ and $P_{\mathrm{D}}$. Relationships are shown further for edaphic predictors in Fig. 6 (soil chemistry) and Fig. 7 (soil physical properties). All soil phosphorus pools and base cation measures showed negative relationships with $\varrho_{\mathrm{w}}$ and with most soil physical properties also strongly related. Specifically, soil depth, soil structure and topography were all negatively correlated, but with anoxic conditions showing no clear relationship. The combined indexes of physical properties also had strong negative relationships with $\varrho_{\mathrm{w}}$, with $\Pi_{1}$ the most strongly correlated $(\rho=-0.66)$.

Figure 8 shows the relationship between average plot $\varrho_{\mathrm{w}}$ and the studied climate variables. There is some indication of a positive relationship with mean annual temperature and negative associations with both $P_{\mathrm{A}}$ and $P_{\mathrm{D}}$. Although the relationships with these precipitation metrics are not significant after the adjustment of their Spearman's $\rho$ probability values (Table 3). 
Table 2. Lowest AIC model fits for the prediction of coarse wood productivity with and without the use of spatial filters. For each variable, the upper line gives first the standardised coefficients $(\beta)$ and their level of significance $(p)$ from the best OLS model fit followed by (in brackets) the results when the same OLS model is applied with the preselected spatial filter included. Also shown in bold (second line) for each variable are the values of $\beta$ and $p$ obtained for the lowest $A I C$ model fit with the spatial filters included. Variables not included in any given model fit are denoted with a “-”. Variables: $[\mathrm{P}]_{\mathrm{t}}$; total soil phosphorus: $[\mathrm{K}]_{\mathrm{E}}$; exchangeable soil potassium: $[\mathrm{Mg}]_{\mathrm{E}}$; exchangeable soil magnesium: $T_{\mathrm{A}}$; mean annual air temperature: $P_{\mathrm{D}}$; dry season precipitation. The numbering of the spatial filters is inconsequential.

\begin{tabular}{|c|c|c|c|c|c|c|c|c|}
\hline \multirow{3}{*}{$\log [\mathrm{P}]_{\mathrm{t}}$} & \multicolumn{2}{|c|}{ OLS } & \multicolumn{2}{|c|}{ SEVM-1 } & \multicolumn{2}{|c|}{ SEVM-2 } & \multicolumn{2}{|c|}{ SEVM-3 } \\
\hline & $\beta$ & $p$ & $\beta$ & $p$ & $\beta$ & $p$ & $\beta$ & $p$ \\
\hline & 0.503 & $<0.001$ & $\begin{array}{c}(0.437) \\
\mathbf{0 . 6 2 1}\end{array}$ & $\begin{array}{l}(0.004) \\
<\mathbf{0 . 0 0 1}\end{array}$ & $\begin{array}{c}(0.451) \\
\mathbf{0 . 4 6 8}\end{array}$ & $\begin{array}{l}(0.002) \\
<\mathbf{0 . 0 0 1}\end{array}$ & 0.503 & $<0.001$ \\
\hline $\log [\mathrm{K}]_{\mathrm{E}}$ & -0.275 & 0.046 & $\begin{array}{c}(-0.330) \\
-\end{array}$ & $\begin{array}{c}(0.035) \\
-\end{array}$ & $\begin{array}{c}(-0.333) \\
-\mathbf{0 . 3 1 5}\end{array}$ & $\begin{array}{c}(0.016) \\
\mathbf{0 . 0 2 3}\end{array}$ & -0.275 & 0.046 \\
\hline $\log [\mathrm{Mg}]_{\mathrm{E}}$ & - & - & $\begin{array}{c}(-) \\
-\mathbf{0 . 4 2 7}\end{array}$ & $\begin{array}{c}(-) \\
0.015\end{array}$ & - & - & - & - \\
\hline$T_{\mathrm{A}}$ & -0.369 & 0.005 & $\begin{array}{c}(-0.271) \\
-\end{array}$ & $\begin{array}{c}(0.236) \\
-\end{array}$ & $\begin{array}{c}(-0.209) \\
-\end{array}$ & $\begin{array}{c}(0.200) \\
-\end{array}$ & -0.369 & 0.005 \\
\hline$P_{\mathrm{D}}$ & 0.508 & $<0.001$ & $\begin{array}{c}(1.004) \\
-\end{array}$ & $\begin{array}{c}(0.113) \\
-\end{array}$ & $\begin{array}{c}(0.445) \\
\mathbf{0 . 3 4 4}\end{array}$ & $\begin{array}{c}(<0.001) \\
\mathbf{0 . 0 0 4}\end{array}$ & 0.508 & $<0.001$ \\
\hline Filter 1 & - & - & $\begin{array}{c}(-0.533) \\
\mathbf{0 . 3 8 3}\end{array}$ & $\begin{array}{c}(0.371) \\
\mathbf{0 . 0 0 2}\end{array}$ & - & - & - & - \\
\hline Filter 2 & - & - & $\begin{array}{c}(-0.043) \\
-\mathbf{0 . 0 4 4}\end{array}$ & $\begin{array}{c}(0.754) \\
\mathbf{0 . 6 9 3}\end{array}$ & - & - & - & - \\
\hline Filter 3 & - & - & $\begin{array}{c}(0.211) \\
\mathbf{0 . 4 5 4}\end{array}$ & $\begin{array}{l}(0.279) \\
<\mathbf{0 . 0 0 1}\end{array}$ & $\begin{array}{c}(0.292) \\
\mathbf{0 . 4 1 3}\end{array}$ & $\begin{array}{c}(0.063) \\
\mathbf{0 . 0 0 2}\end{array}$ & - & - \\
\hline Filter 4 & - & - & $\begin{array}{c}(0.145) \\
-\mathbf{0 . 1 0 8}\end{array}$ & $\begin{array}{c}(0.430) \\
\mathbf{0 . 3 3 0}\end{array}$ & - & - & - & - \\
\hline Filter 5 & - & - & $\begin{array}{c}(0.080) \\
-\mathbf{0 . 0 2 7}\end{array}$ & $\begin{array}{c}(0.558) \\
\mathbf{0 . 8 0 4}\end{array}$ & - & - & - & - \\
\hline$A I C$ & & & $\begin{array}{r}(18 \\
18\end{array}$ & & $\begin{array}{r}(17 \\
17\end{array}$ & $\begin{array}{l}.10) \\
.29\end{array}$ & & 14 \\
\hline
\end{tabular}

The best OLS regression fit (Table 4) was for a model having $\Pi_{1},[\mathrm{~K}]_{\mathrm{E}}$ and $T_{\mathrm{A}}$ as predictors, with this model yielding an $R^{2}$ of 0.59 . Within this model, the $T_{\mathrm{A}}$ and $\Pi_{1}$ effects were highly significant ( $p=0.002$ and $p<0.001$, respectively), but with the negative $[\mathrm{K}]_{\mathrm{E}}$ effect much less so $(p=0.12)$.

In contrast to $W_{\mathrm{P}}$, inclusion of spatial filters through SEVM-01 or SEVM-02 resulted in different soil and climate variables being selected by the minimum $A I C$ criterion, with $[\mathrm{K}]_{\mathrm{E}}$ replaced by $[\mathrm{Mg}]_{\mathrm{E}}$ and $T_{\mathrm{A}}$ replaced by $P_{\mathrm{D}}$ in both these models. Plant available phosphorus ([P $]_{\mathrm{a}}$ : see Sect. 2.2$)$ was also selected in the lowest AIC SEVM-01 model and with this model also not including $\Pi_{1}$.
Two of the eight potential eigenvector filters were correlated with the OLS model residuals and, when added to the OLS regression model to give SEVM-3, these caused some change to the OLS result. Although the $T_{\mathrm{A}}$ and $\Pi_{1}$ effects did not show large changes in significance levels $(p=0.004$ and $p \leq 0.001$, respectively), for $[\mathrm{K}]_{\mathrm{E}}$ this was much reduced at only $p=0.61$. The effect of adding these spatial filters was much less than for those added through the SEVM-01 and SEVM-02 procedures for which $T_{\mathrm{A}}$ ended up being the only environmental term selected by both models, and with $\Pi_{1}$ still significant in SEVM-02.

Examining alternative models: for the OLS case a substitution of $\Pi_{1}$ with $\Pi_{2}$ caused an increase in the $A I C$ of only 0.37 
Table 3. Spearman's $\rho$ for relationships between stand-level wood density and a range of soil and climate predictors. Probabilities $(p)$ are given with and without adjustment (adj) for degrees of freedom (df) according to Dutillieul (1993). Abbreviations used: $\Pi_{1}$ and $\Pi_{2}-$ first and second indices of soil physical conditions (Sect. 2.2); $[\mathrm{P}]_{\mathrm{ex}},[\mathrm{P}]_{\mathrm{a}},[\mathrm{P}]_{\mathrm{i}},[\mathrm{P}]_{\mathrm{o}},[\mathrm{P}]_{\mathrm{t}}-$ extractable, available, inorganic, organic and total soil phosphorus pools; $[\mathrm{Ca}]_{\mathrm{E}},[\mathrm{Mg}]_{\mathrm{E}},[\mathrm{K}]_{\mathrm{E}},[\mathrm{Al}]_{\mathrm{E}}$ - exchangeable calcium, magnesium, potassium and aluminium concentrations; $I_{\mathrm{E}}-$ effective soil cation exchange capacity; $\theta^{*}<0.20$ - modelled number of months with soil water less than 0.2 of maximum available soil water content. Where $p \leq 0.050$ values are shown in bold.

\begin{tabular}{|c|c|c|c|c|}
\hline Variable & Spearman's $\rho$ & $p$ value & $p$ value adj & $\mathrm{df}$ adj \\
\hline Sand fraction & 0.069 & 0.536 & 0.520 & 55 \\
\hline Clay fraction & 0.038 & 0.125 & 0.058 & 78 \\
\hline Silt fraction & -0.430 & $<0.001$ & 0.064 & 16 \\
\hline Soil depth score & -0.450 & $<0.001$ & 0.040 & 17 \\
\hline Soil structure score & -0.523 & $<0.001$ & 0.052 & 11 \\
\hline Topography score & -0.520 & $<0.001$ & 0.121 & 10 \\
\hline Anoxia & -0.142 & 0.265 & 0.337 & 38 \\
\hline$\Pi_{1}$ & -0.662 & $<0.001$ & 0.036 & 8 \\
\hline$\Pi_{2}$ & -0.542 & $<0.001$ & 0.045 & 7 \\
\hline $\mathrm{pH}$ & -0.333 & 0.057 & 0.071 & 45 \\
\hline$[\mathrm{P}]_{\mathrm{ex}}$ & -0.552 & 0.007 & 0.104 & 19 \\
\hline$[\mathrm{P}]_{\mathrm{a}}$ & -0.538 & $<0.001$ & 0.076 & 16 \\
\hline$[\mathrm{P}]_{\mathrm{i}}$ & -0.497 & 0.008 & 0.073 & 24 \\
\hline$[\mathrm{P}]_{\mathrm{o}}$ & -0.535 & 0.014 & 0.140 & 19 \\
\hline$[\mathrm{P}]_{\mathrm{t}}$ & -0.470 & $<0.001$ & 0.031 & 20 \\
\hline Total $[\mathrm{N}]$ & -0.330 & 0.263 & 0.436 & 25 \\
\hline Total $[\mathrm{C}]$ & 0.019 & 0.680 & 0.766 & 27 \\
\hline $\mathrm{C}: \mathrm{N}$ ratio & 0.633 & $<0.001$ & 0.025 & 9 \\
\hline$[\mathrm{Ca}]_{\mathrm{E}}$ & -0.518 & $<0.001$ & 0.026 & 21 \\
\hline$[\mathrm{Mg}]_{\mathrm{E}}$ & -0.551 & $<0.001$ & 0.019 & 22 \\
\hline$[\mathrm{K}]_{\mathrm{E}}$ & -0.457 & $<\mathbf{0 . 0 0 1}$ & 0.041 & 17 \\
\hline$[\mathrm{Al}]_{\mathrm{E}}$ & 0.086 & 0.987 & 0.990 & 31 \\
\hline Sum of bases & -0.552 & $<0.001$ & 0.022 & 21 \\
\hline$I_{\mathrm{E}}$ & -0.489 & $<0.001$ & 0.048 & 14 \\
\hline Mean annual temperature & 0.499 & $<0.001$ & 0.007 & 26 \\
\hline Mean annual precipitation & -0.257 & 0.006 & 0.296 & 8 \\
\hline Dry season precipitation & -0.300 & $<\mathbf{0 . 0 0 1}$ & 0.304 & 5 \\
\hline$\theta^{*}<0.20$ & -0.167 & 0.828 & 0.928 & 9 \\
\hline Mean annual radiation & -0.007 & 0.762 & 0.871 & 17 \\
\hline
\end{tabular}

(data not shown), suggesting that both measures of soil physical properties were equally good predictors of stand level wood density variations. Indeed, for the seven valid OLS models with $\triangle A I C \leq 2$, all included $\Pi_{1}$. All these models also included $T_{\mathrm{A}}$ with six of these models also including one or more exchangeable cations. Phosphorus and precipitation measures on the other hand were not selected in any OLS model with an $\triangle A I C \leq 2$. Examining models in SEVM-1 and SEVM-2 with $\triangle A I C \leq 2$, we found that some measure of precipitation and $\Pi_{1}$ were present in most models. Only SEVM-1 models included a phosphorus term, whilst at least one soil cation term was present in all models and with $[\mathrm{Mg}]_{\mathrm{E}}$ selected in most models.

We can have some confidence in soil physical conditions having an important role in the modulation of stand level wood density as $\Pi_{1}$ was found to be a significant predictor in most cases with a high level of statistical significance. The roles for temperature and precipitation are, however, much more ambiguous. Although there is some suggestion for trees with lower wood densities associating with soils of a higher cation status, it is not clear through which cation(s) this effect is mediated.

\subsection{Stem turnover rates}

Spatially adjusted Spearman's $\rho$ describing the relationship between $\varphi$ and the measured edaphic/environmental factors showed many significant soil chemistry correlations $(p<$ $0.05)$. These involved not only the various soil phosphorus pools (organic, readily available, total extractable, total and inorganic $\mathrm{P}$, in decreasing order of correlation), but also $[\mathrm{Ca}]_{\mathrm{E}},[\mathrm{Mg}]_{\mathrm{E}}$ and $[\mathrm{K}]_{\mathrm{E}}$, the combined base cation measure $\left(\Sigma_{\mathrm{B}}\right)$, and effective cation exchange capacity $\left(I_{\mathrm{E}}\right)$. Soil nitrogen was also relatively well correlated to tree turnover rates with soil C:N ratio negatively correlated (Table 5). Relationships between soil chemical parameters and stand turnover 

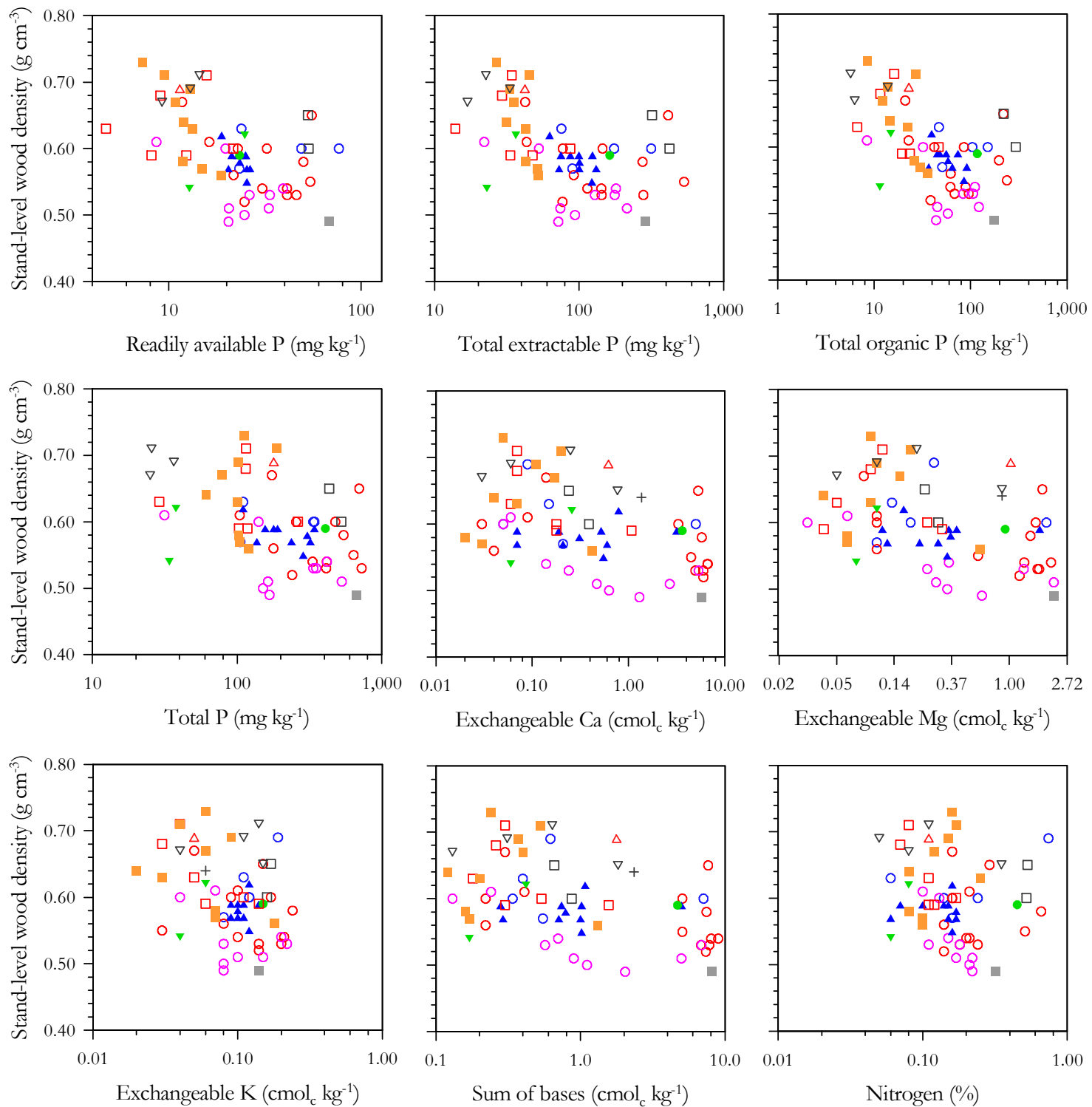

$\begin{array}{llll}\nabla & \text { Arenosols } & \square & \text { Acrisols } \\ \nabla & \text { Podzols } & \Delta & \text { Lixisols } \\ \square & \text { Ferralsols } & \bullet & \text { Nitisols }\end{array}$

$\begin{array}{llll}\triangle & \text { Plinthosols } & \circ & \text { Cambisols } \\ \circ & \text { Alisols } & \square & \text { Fluvisols } \\ \square & \text { Umbrisols } & \circ & \text { Gleysols }\end{array}$

Fig. 6. Relationships between average stand wood density and different soil nutrient measures.

rate (Fig. 9) confirm that Amazon forest stand dynamics are well correlated with many measures of soil nutrient status.

Individual soil physical property scores were also associated with variations in $\varphi$, with soil structure and soil depth having the highest $\rho$. Relationships are shown in Fig. 10. Soil depth, structure and topography show some relationship with tree turnover rates but with no clear pattern evident for soil anoxic conditions. Both indexes of soil physical properties were also strongly related to tree turnover rates. Climatic pre- dictors on their own were, however, only loosely associated with variations in $\varphi$ (Fig. 11).

The results of multiple regression analysis with and without the inclusion of spatial filters are given in Table 6 . The OLS model selected $\left(R^{2}=0.65\right)$ included $\Pi_{2}, P_{\mathrm{A}}$ and $\Sigma_{\mathrm{B}}$ as predictors, although the effect of $\Sigma_{\mathrm{B}}$ on $\varphi$ was only significant at $p=0.06$. Neither $\Sigma_{\mathrm{B}}$ nor $P_{\mathrm{A}}$ were, however, selected as part of SEVM-01 or SEVM-02, but with soil physical properties still suggested as being important through the 

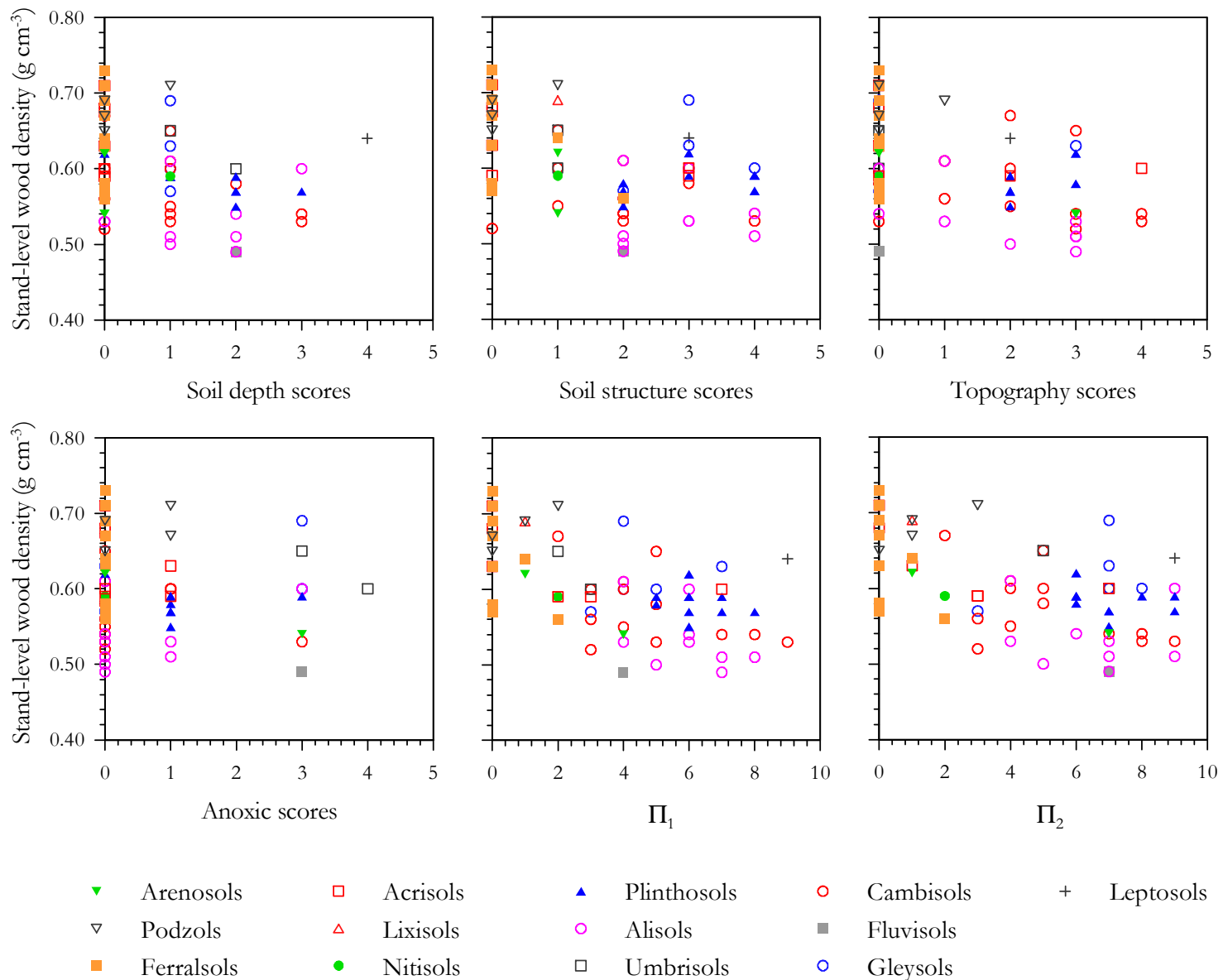

+ Leptosols

- Ferralsols $\bullet$ Nitisols

口 Umbrisols

- Gleysols

Fig. 7. Relationships between wood density and soil physical properties.For definitions of $\Pi_{1}$ and $\Pi_{2}$ see Sect. 2.2.

selection of one of $\Pi_{1}$ or $\Pi_{2}$ in both models. A negative effect of dry season precipitation of stand-level turnover rates was also suggested through the selection of $P_{\mathrm{D}}$ in SEVM-02.

When the SEVM-01 and SEVM-02 filters were added to the OLS model, only $\Pi_{1}$ retained significance at $p<0.05$. This drastic response contrasted with the SEVM-03 procedure where the standardised coefficients and their levels of significance were only slightly reduced for both $\Pi_{2}$ and $P_{\mathrm{A}}$. There was, however, a much more substantial reduction in apparent significance for $\Sigma_{\mathrm{B}}$ in SEVM-03 $(p=0.210)$.

Examining the 28 alternative OLS models with $\triangle A I C \leq$ 2.0, all models had either $\Pi_{1}$ or $\Pi_{2}$ as a significant predictor along with one significant precipitation measure (either $P_{\mathrm{A}}$ or $\left.P_{\mathrm{D}}\right)$ and a measure of soil cations and/or phosphorus as alternative or additional predictors (13 models had some measure of cations included, while some form of phosphorus was present in 10 models). Likewise for potentially alternative models under SEVM-02, one of $\Pi_{1}$ or $\Pi_{2}$ was always present. Taken together, these results suggest an unequivocal role of soil physical properties in driving tree turnover rates in Amazonia, but with amount and distribution of precipitation also important.

\subsection{Stand biomass}

Spearman's $\rho$ with and without $p$ values and degrees of freedom adjusted for spatial autocorrelation are listed for $B$ in Table 7 . Forest biomass was generally negatively correlated to both soil cation and phosphorus measurements (Fig. 12), with the best correlations amongst the soil chemistry parameters being the various soil phosphorus pools, which varied from $\rho=-0.48$ to $\rho=-0.28$. Exchangeable cations also had negative correlations with $B$, with $[\mathrm{K}]_{\mathrm{E}}$ and $[\mathrm{Mg}]_{\mathrm{E}}$ showing the stronger relationships $(\rho=-0.45$ and $\rho=-0.31$ respectively). Correlations with both soil phosphorus pools and exchangeable cations remained significant $p \leq 0.05$ after correction for spatial autocorrelation.

Soil physical properties varied in their ability to correlate with $B$. Soil depth and structure were the best correlated factors, with biomass decreasing as depth and structure scores increased (Fig. 13). Topography on the other hand had a weak but positive correlation with $B$, although $B$ does seem to decline once topography becomes very steep. Anoxic conditions also had a negative but weak correlation with $B$, as did both indexes of physical properties. Correlations between 

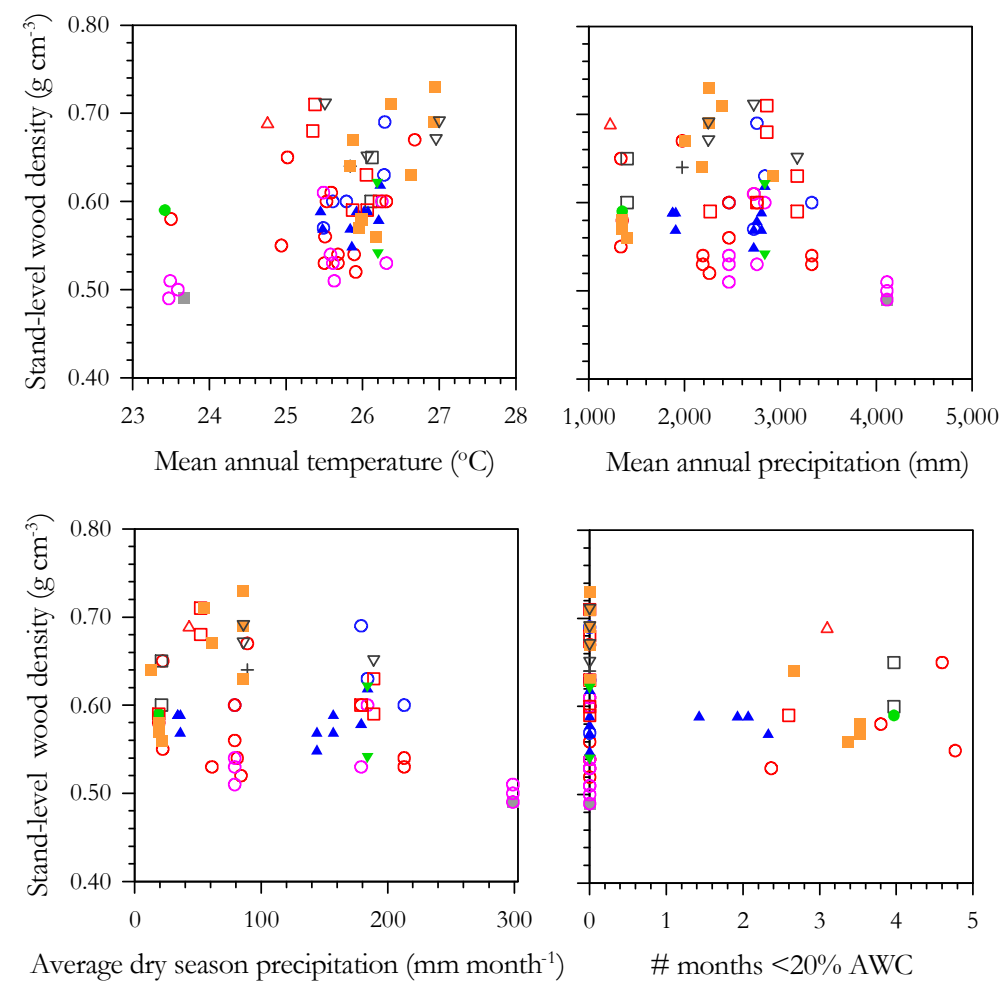

Average dry season precipitation $\left(\mathrm{mm} \mathrm{month}^{-1}\right)$

\# months $<20 \%$ AWC

$\begin{array}{llllllll}\nabla & \text { Arenosols } & \square & \text { Acrisols } & \Delta & \text { Plinthosols } & \circ & \text { Cambisols } \\ \nabla & \text { Podzols } & \triangle & \text { Lixisols } & \circ & \text { Alisols } & \square & \text { Fluvisols } \\ \square & \text { Ferralsols } & \bullet & \text { Nitisols } & \square & \text { Umbrisols } & \circ & \text { Gleysols }\end{array}$

Fig. 8. Relationships between stand wood density and climatic factors.

physical properties and $B$ remained marginally significant after spatial correction $(p \leq 0.10)$ with the exception of topography and $\Pi_{1}(p>0.15$ : Table 7$)$.

Above-ground biomass was also positively correlated with $T_{\mathrm{A}}, P_{\mathrm{A}}$ and $P_{\mathrm{D}}$ and strongly negatively correlated with the number of months for which $\theta^{*}<0.2$. These relationships between $B$ and climatic variables are shown in Fig. 14. This suggests some response to rainfall amount as well as to its distribution during the dry season.

The results for multiple regression models with and without the addition of spatial filters are given in Table 8 . The best OLS model retained $[\mathrm{P}]_{\mathrm{t}},[\mathrm{K}]_{\mathrm{E}}, P_{\mathrm{D}}$ and $\Pi_{2}$ as predictors for $B$, with an overall $R^{2}$ of 0.38 . Of note is the change in sign for $[\mathrm{P}]_{\mathrm{t}}$ with a positive relationship with $B$ being suggested by the multivariate model as compared to a negative (albeit non-significant) association with $B$ when considered on its own (Table 7, Table 8, Fig. 12).

The selection of filters through the SEVM-1 and SEVM-2 procedures resulted in two filters selected by SEVM-1 and three filters selected by SEVM-2. When the SEVM-01 filters were applied, the lowest $A I C$ model $\left(R^{2}=0.65\right)$ included only $[\mathrm{Ca}]_{\mathrm{E}}$ and with none of the OLS variables selected. Only $[\mathrm{K}]_{\mathrm{E}}$ was included in the lowest AIC SEVM-02 model
$\left(R^{2}=0.53\right)$. Consistent with the large effects of the filters in these models, none of the OLS-selected variables remained significant when the filters from either SEVM-01 or SEVM02 were included in a new model fit.

Regression with the two filters selected by the SEVM-3 procedure had varying effects on the levels of significance of the OLS predictors. Although total soil phosphorus had its significance level improved from $p=0.02$ to $p<0.01$ and $P_{\mathrm{D}}$ had no significant change, $[\mathrm{K}]_{\mathrm{E}}$ had its significance level reduced from $p=0.003$ to $p=0.023$ and with $\Pi_{2}$ also being much less significant after filter addition $(p=0.106)$. The inclusion of these two filters improved the overall model fit substantially with an $R^{2}=0.51$ as compared to 0.38 for the OLS fit.

Only three alternative OLS models with $\triangle A I C \leq 2$ were found; these being very similar to the best model, but with the difference of $[\mathrm{Ca}]_{\mathrm{E}}$ appearing in addition to $[\mathrm{K}]_{\mathrm{E}}$ in the second lowest $A I C$ model and $T_{\mathrm{A}}$ appearing in addition to $P_{\mathrm{D}}$ in the third model.

Stand-level biomass can be considered as the product of basal area $A_{\mathrm{B}}, \varrho_{\mathrm{w}}$ and some allometric constant (Supplement; Eq. S4) and the relationship between $B, \varrho_{\mathrm{w}}$ and $A_{\mathrm{B}}$ are shown in the Supplement (Fig. S2). This shows 
Table 4. Lowest $A I C$ model fits for the prediction of stand wood density with and without the use of spatial filters. For each variable, the upper line gives first the standardised coefficients $(\beta)$ and their level of significance $(p)$ from the best OLS model fit, followed by the results (in brackets) when the same OLS model is applied with the preselected spatial filter included. Also shown in bold (second line) for each variable are the values of $\beta$ and $p$ obtained for the lowest $A I C$ model fit with the spatial filters included. Variables not included in any given model fit are denoted with a “-”. Variables: $\Pi_{1}$; Quesada et al (2010)'s first index of soil physical properties; $[\mathrm{P}]_{\mathrm{a}}$; readily available soil phosphorus: $[\mathrm{K}]_{\mathrm{E}}$; exchangeable soil potassium: $[\mathrm{Mg}]_{\mathrm{E}}$; exchangeable soil magnesium: $[\mathrm{P}]_{\mathrm{a}}$; plant available phosphorus: $T_{\mathrm{A}}$; mean annual air temperature: $P_{\mathrm{D}}$; dry season precipitation. The numbering of the spatial filters is inconsequential.

\begin{tabular}{|c|c|c|c|c|c|c|c|c|}
\hline & \multicolumn{2}{|c|}{ OLS } & \multicolumn{2}{|c|}{ SEVM-1 } & \multicolumn{2}{|c|}{ SEVM-2 } & \multicolumn{2}{|c|}{ SEVM-3 } \\
\hline & $\beta$ & $p$ & $\beta$ & $p$ & $\beta$ & $p$ & $\beta$ & $p$ \\
\hline$\Pi_{1}$ & -0.495 & $<0.001$ & $\begin{array}{c}(-0.167) \\
-\end{array}$ & $\begin{array}{c}(0.295) \\
-\end{array}$ & $\begin{array}{c}(-0.291) \\
\mathbf{- 0 . 2 5 7}\end{array}$ & $\begin{array}{c}(0.036) \\
\mathbf{0 . 0 3 0}\end{array}$ & -0.496 & $<0.001$ \\
\hline $\log [K]_{\mathrm{E}}$ & -0.175 & 0.121 & $\begin{array}{c}(-0.063) \\
-\end{array}$ & $\begin{array}{c}(0.561) \\
-\end{array}$ & $\begin{array}{c}(-0.062) \\
-\end{array}$ & $\begin{array}{c}(0.567) \\
-\end{array}$ & -0.054 & 0.611 \\
\hline $\log [\mathrm{Mg}]_{\mathrm{E}}$ & - & - & $\begin{array}{c}(-) \\
-\mathbf{0 . 3 3 0}\end{array}$ & $\begin{array}{c}(-) \\
<\mathbf{0 . 0 0 1}\end{array}$ & $\begin{array}{c}(-) \\
-\mathbf{0 . 2 2 3}\end{array}$ & $\begin{array}{c}(-) \\
0.011\end{array}$ & - & - \\
\hline $\log [\mathrm{P}]_{\mathrm{a}}$ & - & - & $\begin{array}{c}(-) \\
0.201\end{array}$ & $\begin{array}{c}(-) \\
0.093\end{array}$ & & - & - & - \\
\hline$T_{\mathrm{A}}$ & 0.321 & 0.002 & $\begin{array}{c}(0.211) \\
-\end{array}$ & $\begin{array}{c}(0.048) \\
-\end{array}$ & $\begin{array}{c}(0.260) \\
-\end{array}$ & $\begin{array}{c}(0.005) \\
-\end{array}$ & 0.270 & 0.004 \\
\hline$P_{\mathrm{D}}$ & - & - & $\begin{array}{c}(-) \\
-\mathbf{0 . 8 2 8}\end{array}$ & $\begin{array}{c}(-) \\
<\mathbf{0 . 0 0 1}\end{array}$ & $\begin{array}{c}(-) \\
-0.654\end{array}$ & $\begin{array}{c}(-) \\
<\mathbf{0 . 0 0 1}\end{array}$ & - & - \\
\hline Filter 1 & - & - & $\begin{array}{c}(0.248) \\
-\mathbf{0 . 3 7 8}\end{array}$ & $\begin{array}{c}(0.039) \\
\mathbf{0 . 0 8 4}\end{array}$ & $\begin{array}{c}(0.172) \\
-\mathbf{0 . 3 9 9}\end{array}$ & $\begin{array}{c}(0.127) \\
\mathbf{0 . 0 2 3}\end{array}$ & - & - \\
\hline Filter 2 & - & - & $\begin{array}{c}(-0.210) \\
-\mathbf{0 . 2 7 0}\end{array}$ & $\begin{array}{l}(0.028) \\
<\mathbf{0 . 0 0 1}\end{array}$ & - & - & - & - \\
\hline Filter 3 & - & - & $\begin{array}{c}(0.441) \\
\mathbf{0 . 7 0 3}\end{array}$ & $\begin{array}{c}(<0.001) \\
<\mathbf{0 . 0 0 1}\end{array}$ & $\begin{array}{c}(0.377) \\
\mathbf{0 . 5 0 6}\end{array}$ & $\begin{array}{c}(<0.001) \\
<\mathbf{0 . 0 0 1}\end{array}$ & 0.296 & 0.005 \\
\hline Filter 4 & - & - & $\begin{array}{c}(0.139) \\
\mathbf{0 . 1 0 3}\end{array}$ & $\begin{array}{c}(0.110) \\
\mathbf{0 . 2 3 0}\end{array}$ & - & - & - & - \\
\hline Filter 5 & - & - & $\begin{array}{c}(0.011) \\
\mathbf{0 . 0 8 0}\end{array}$ & $\begin{array}{c}(0.900) \\
\mathbf{0 . 2 4 7}\end{array}$ & - & - & - & - \\
\hline Filter 6 & - & - & $\begin{array}{c}(-0.079) \\
\mathbf{0 . 1 1 7}\end{array}$ & $\begin{array}{c}(0.365) \\
\mathbf{0 . 2 3 5}\end{array}$ & - & - & - & - \\
\hline Filter 7 & - & - & $\begin{array}{c}(0.211) \\
\mathbf{0 . 1 7 3}\end{array}$ & $\begin{array}{c}(0.120) \\
\mathbf{0 . 0 3 5}\end{array}$ & $\begin{array}{c}(0.185) \\
0.136\end{array}$ & $\begin{array}{c}(0.035) \\
\mathbf{0 . 0 9 7}\end{array}$ & - & - \\
\hline Filter 8 & - & - & $\begin{array}{c}(0.096) \\
-\mathbf{0 . 0 1 2}\end{array}$ & $\begin{array}{c}(0.256) \\
\mathbf{0 . 8 6 7}\end{array}$ & - & - & 0.173 & 0.049 \\
\hline$A I C$ & -17 & 667 & $\begin{array}{l}(-1 \\
-1\end{array}$ & $\begin{array}{l}.31) \\
.19\end{array}$ & $\begin{array}{l}(-18 \\
\mathbf{- 1 9}\end{array}$ & $\begin{array}{l}169) \\
875\end{array}$ & -18 & 405 \\
\hline
\end{tabular}


Table 5. Spearman's $\rho$ for relationships between stand-level turnover rates and a range of soil and climate predictors. Probabilities $(p)$ are given with and without adjustment (adj) for degrees of freedom (df) according to Dutillieul (1993). Abbreviations used: $\Pi_{1}$ and $\Pi_{2}-$ first and second indices of soil physical conditions (Sect. 2.2); $[\mathrm{P}]_{\mathrm{ex}},[\mathrm{P}]_{\mathrm{a}},[\mathrm{P}]_{\mathrm{i}},[\mathrm{P}]_{\mathrm{o}},[\mathrm{P}]_{\mathrm{t}}-$ extractable, available, inorganic, organic and total soil phosphorus pools; $[\mathrm{Ca}]_{\mathrm{E}},[\mathrm{Mg}]_{\mathrm{E}},[\mathrm{K}]_{\mathrm{E}},[\mathrm{Al}]_{\mathrm{E}}-$ exchangeable calcium, magnesium, potassium, and aluminium concentrations; $I_{\mathrm{E}}-$ effective soil cation exchange capacity; $\theta^{*}<0.20$ - modelled number of months with soil water less than 0.2 of maximum available soil water content. Where $p \leq 0.050$ values are shown in bold.

\begin{tabular}{|c|c|c|c|c|}
\hline Variable & Spearman's $\rho$ & $p$ value & $p$ value adj & df adj \\
\hline Sand fraction & -0.141 & 0.243 & 0.250 & 52 \\
\hline Clay fraction & 0.095 & 0.876 & 0.885 & 46 \\
\hline Silt fraction & 0.272 & 0.034 & 0.064 & 41 \\
\hline Soil depth score & 0.381 & 0.001 & 0.008 & 35 \\
\hline Soil structure score & 0.526 & $<\mathbf{0 . 0 0 1}$ & 0.002 & 29 \\
\hline Topography score & 0.311 & 0.040 & 0.125 & 30 \\
\hline Anoxia score & 0.183 & 0.082 & 0.089 & 52 \\
\hline$\Pi_{1}$ & 0.527 & $<0.001$ & 0.002 & 25 \\
\hline$\Pi_{2}$ & 0.554 & $<0.001$ & 0.001 & 25 \\
\hline $\mathrm{pH}$ & 0.332 & 0.004 & 0.022 & 35 \\
\hline$[\mathrm{P}]_{\mathrm{ex}}$ & 0.559 & $<0.001$ & 0.002 & 27 \\
\hline$[\mathrm{P}]_{\mathrm{a}}$ & 0.561 & $<0.001$ & 0.003 & 26 \\
\hline$[\mathrm{P}]_{\mathrm{i}}$ & 0.469 & $<0.001$ & 0.009 & 29 \\
\hline$[\mathrm{P}]_{\mathrm{o}}$ & 0.568 & $<0.001$ & 0.001 & 27 \\
\hline$[\mathrm{P}]_{\mathrm{t}}$ & 0.489 & $<0.001$ & 0.001 & 33 \\
\hline Total $[\mathrm{N}]$ & 0.252 & 0.051 & 0.119 & 35 \\
\hline Total $[\mathrm{C}]$ & -0.077 & 0.880 & 0.899 & 39 \\
\hline $\mathrm{C}: \mathrm{N}$ ratio & -0.570 & $<0.001$ & $<0.001$ & 33 \\
\hline$[\mathrm{Ca}]_{\mathrm{E}}$ & 0.336 & $<0.001$ & 0.003 & 41 \\
\hline$[\mathrm{Mg}]_{\mathrm{E}}$ & 0.449 & $<0.001$ & 0.001 & 40 \\
\hline$[\mathrm{K}]_{\mathrm{E}}$ & 0.442 & $<\mathbf{0 . 0 0 1}$ & 0.009 & 32 \\
\hline$[\mathrm{Al}]_{\mathrm{E}}$ & 0.036 & 0.812 & 0.828 & 45 \\
\hline Sum of bases & 0.368 & $<0.001$ & 0.002 & 39 \\
\hline$I_{\mathrm{E}}$ & $\mathbf{0 . 5 8 7}$ & $<0.001$ & $<0.001$ & 42 \\
\hline Mean annual temperature & -0.145 & 0.101 & 0.179 & 36 \\
\hline Mean annual precipitation & -0.06 & 0.626 & 0.773 & 19 \\
\hline Dry season precipitation & -0.046 & 0.915 & 0.956 & 15 \\
\hline$\theta^{*}<0.20$ & 0.265 & 0.027 & 0.189 & 19 \\
\hline Mean annual radiation & 0.128 & 0.792 & 0.855 & 26 \\
\hline
\end{tabular}

that although there is some variability in $\varrho_{\mathrm{w}}$, it is differences in $A_{\mathrm{B}}$ that to a large extent drive the variations in $B$, except at very high values. Similar analyses to those done for $B$ here, $v i z$. an examination of driving variables with and without spatial autocorrelation issues, is therefore also given for $A_{\mathrm{B}}$ in Table S2. This shows similar results to have been attained for $A_{\mathrm{B}}$ as was the case for $B$, especially for the OLS and SEVM03 models.

\subsection{Partitioning of environmental versus spatial components of variation}

Figure 15 shows the partitioning of the variation in $W_{\mathrm{P}}, \varrho_{\mathrm{w}}$, $\varphi$ and $B$ as Venn diagrams. Only in the case of $W_{\mathrm{P}}$ was the environmental component (a) greater than the shared component (b) and in all cases this shared component was greater than that attributable solely to the spatial component (c). Notably small fractions of the variation were attributable solely to space in the case of $W_{\mathrm{P}}$ and solely to environment for $B$. Although the spatial fraction was slightly higher, this result did not differ greatly when the SEVM-01 filters were used instead of those from SEVM-02 (not shown). The high degree of overlap between the environmental and spatial components is consistent with the observation that, when considered on their own, either the spatial filters (Sect. 3.1) or the hypothesised environmental drivers (including those associated with soils: see OLS results in Tables 2, 4,6 and 8) can be good predictors of all four stand characteristics. With the exception of $W_{\mathrm{P}}$, this gives rise to the difficult to interpret shared (b) component usually being the dominant source of variation. 

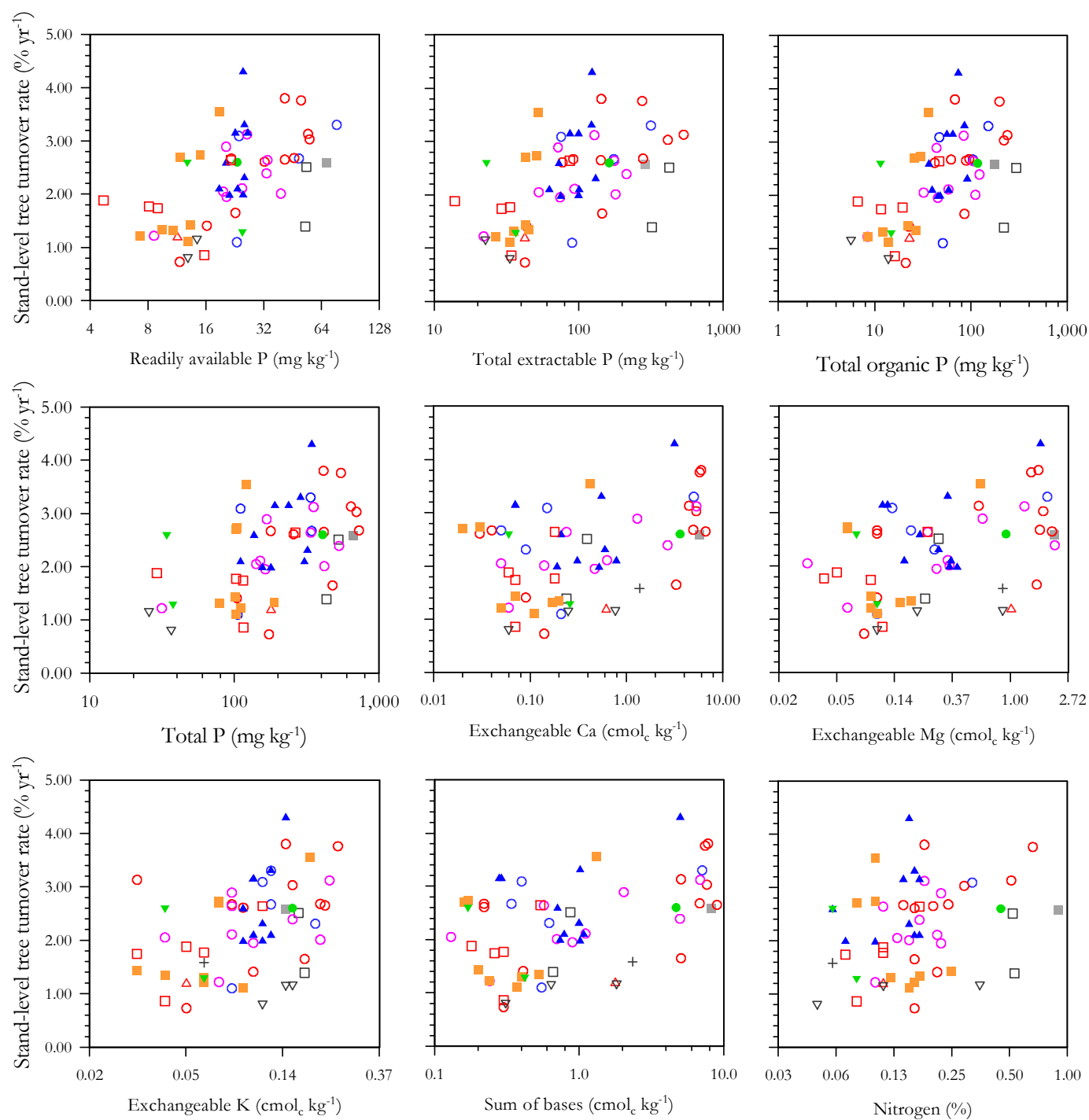

$\nabla$ Arenosols $\square$ Ferralsols $\triangle$ Lixisols

^ Plinthosols $\square \quad$ Umbrisols

- Fluvisols

$+\quad$ Leptosols

$\nabla$ Podzols $\square$ Acrisols $\quad$ Nitisols

○ Alisols

○ Cambisols

Gleysols

Fig. 9. Relationships between tree turnover rates and different soil fertility parameters.

\section{Discussion}

\subsection{Spatial structures and spatial autocorrelation}

Implied roles for the examined climatic and edaphic predictors in modulating Amazon forest structure and dynamics depended to a large degree on the assumptions made as to the causes for the strong spatial patterning in response variables observed. Complicating this matter, effects of spatial filter inclusion were not predictable, with the magnitude of model differences in terms of variables selected, changes in values of standardised coefficients, and associated levels of signifi- cance depending on the stand-level property examined. This is likely a consequence of differences in the relative magnitudes of the proportion of the variation in the response variable attributable to environment versus space, and in particular the proportion of the variation that is "shared" (Fig. 15).

Some reasons for the different results from these different approaches in dealing with (or ignoring) spatial structures and spatial autocorrelation should relate, at least in part, to their different underlying assumptions. For example, OLS assumes that there are no spatial issues to be considered. Or in the words of Diniz-Filho et al. (2003), "That the relationship is considered at the overall spatial scale under study". 

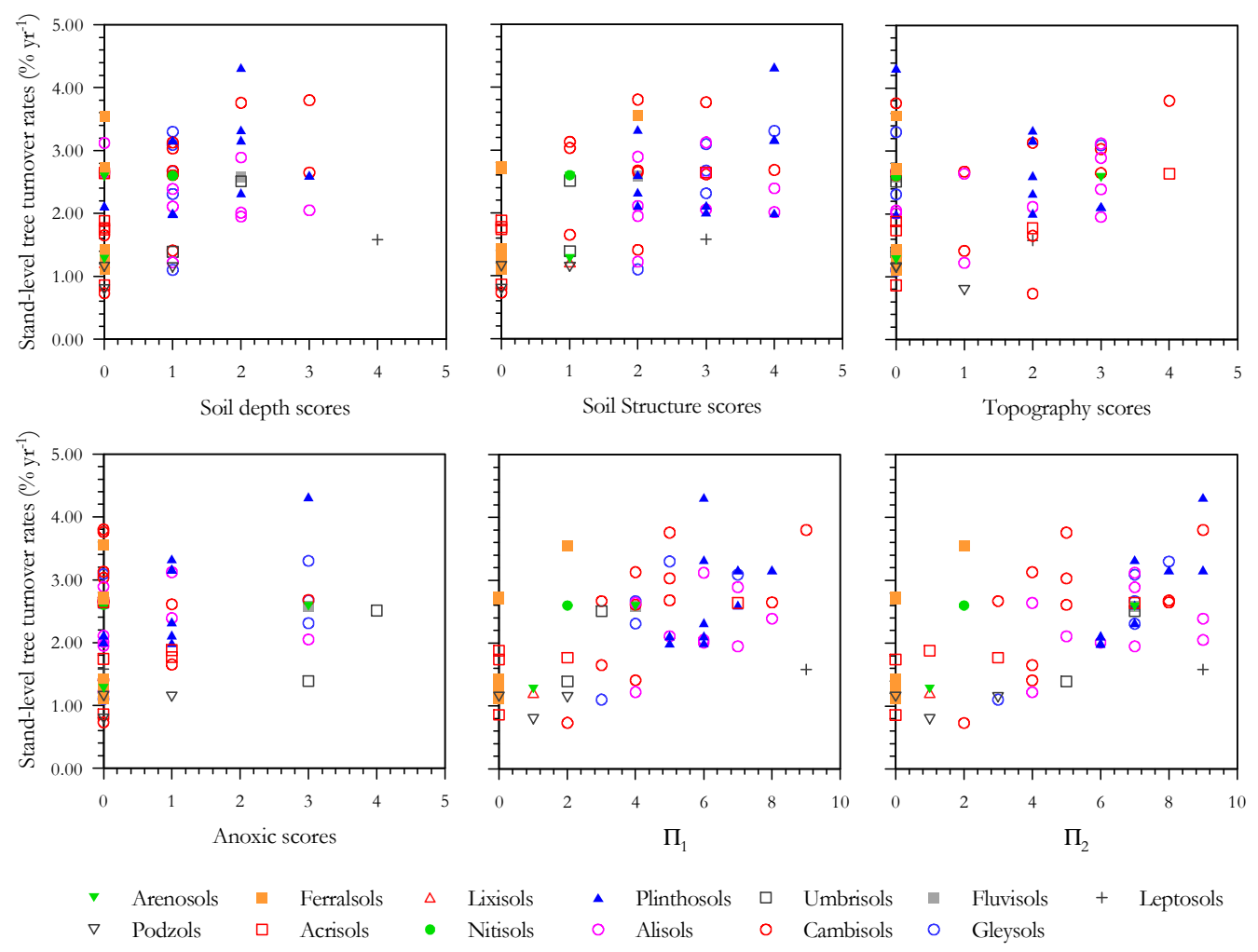

$\checkmark$ Arenosols $\square$ Ferralsols $\triangle$ Lixisols

- Plinthosols $\square$ Umbrisols

Nitisols

- Alisols

○ Cambisols ○ Gleysols

Fig. 10. Relationships between tree turnover rates and soil physical properties. For definitions of $\Pi_{1}$ and $\Pi_{2}$ see Sect. 2.2 .

As a variant of this, the SEVM-03 approach is roughly comparable to the criterion adopted by Griffith and Peres-Neto (2006) where only eigenvectors that minimise Moran's $I$ in regression residuals are included (Bini et al., 2009). This effectively then assumes that all spatial structures in the dataset which are not correlated with model residuals must be caused by the predictor variables.

On the other hand, model selections through SEVM-01 and SEVM-02 represent an approach where unidentified spatial processes are considered an alternative explanation for the observed geographical variations in stand properties. In the case of SEVM-01, with filters first selected on the basis of their Moran's $I$ and then put forward for selection in a model also including environmental variables, then as pointed out by Diniz-Filho et al. (2008) a fundamental tautology exists. This is because the dependent variable has already been used to select the independent variable against which it is subsequently tested. It could be argued therefore, that SEVM-01 effectively involves a null hypothesis that all observed variation in the response variable can be accounted for through endogenous spatial processes alone and that none of it is related to the studied climatic and edaphic variables.

This is not necessarily a nonsense proposition. For example, many physiological and structural traits related to Amazon forest growth and mortality have strong phylogenetic associations (Baker et al., 2004a; Fyllas et al., 2009, 2012;
Patiño et al., 2009, 2012) and likewise, many of the major Amazon families and genera have distinct geographical distributions, at least some of which have historical causes (Hammond, 2005; ter Steege et al., 2010). Indeed, with some authors arguing that the forests of the Guyana Shield were separated from the rest of the Amazon forest during the Last Glacial Maximum (Anhuf et al., 2006) then if so, the tree species occupying part of the eastern Amazon forest region must have migrated from the north-east or western areas of the Basin to replace what was a savanna-type vegetation sometime over the last 20000 or so years. Likewise, Bolivian forests at the southern edge of the Amazon Basin (some of which were sampled as part of this study), have only appeared in the last 3000 years or so in association with a southward movement of the Inter Tropical Convergence Zone (Mayle et al., 2000). As the climate became moister, the species now in these forests probably migrated from pre-existing areas of gallery forest to occupy areas then occupied by savanna. Such species patterns with a historical basis could potentially manifest themselves through effects not only on stand level wood density and/or biomass (where strong large-scale spatial patterns were observed) but with other stand parameters such as growth and turnover rates potentially influenced as well. The SEVM-01 approach effectively assumes that this is the case because spatial filters are preselected on the basis of their correlation with the observed 

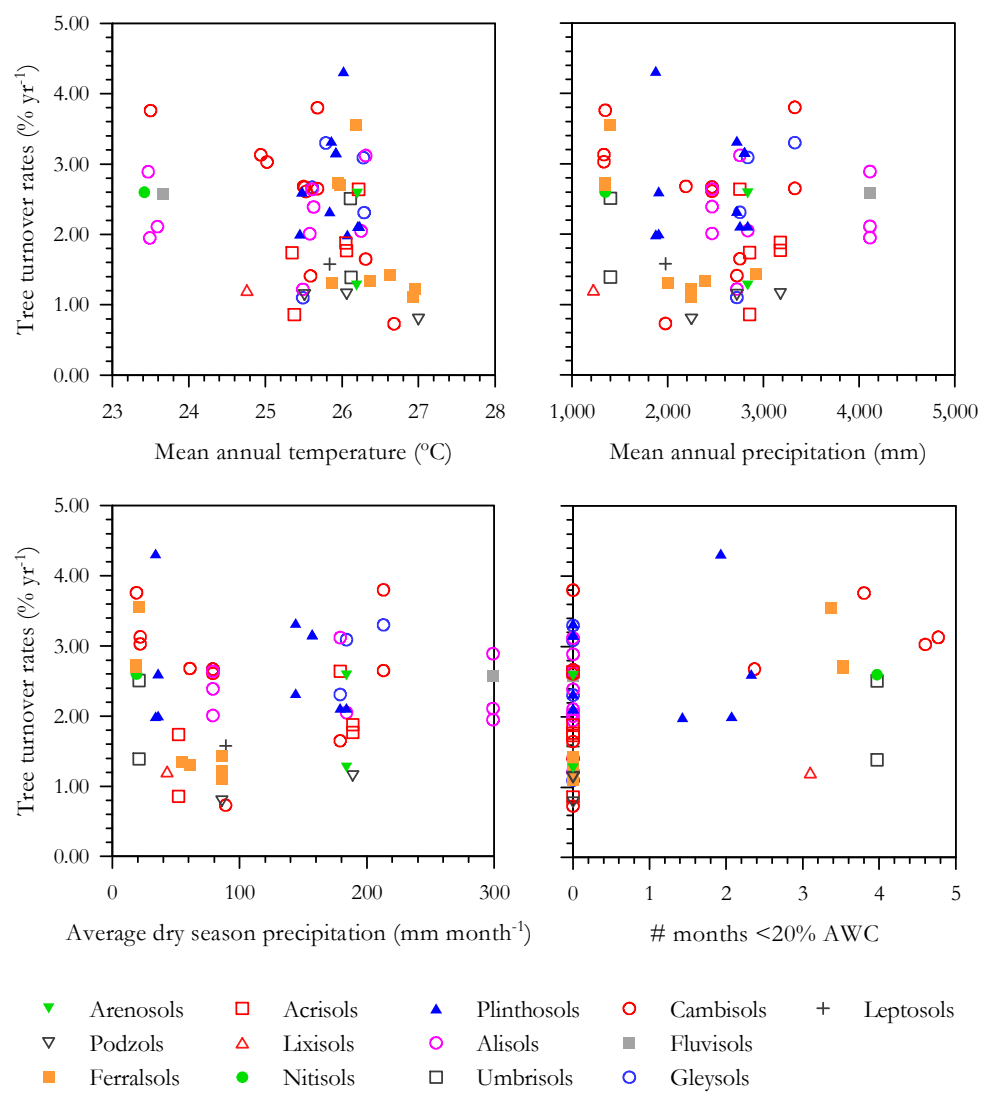

Fig. 11. Relationships between tree turnover rates and climatic factors.

spatial structure. This then means that most of the shared variation attributable to both space and environment (Fig. 15) is preapportioned to the former and with the importance of environmental variables consequently minimised.

In an approach weighted much more towards the already selected environmental predictors, SEVM-3 can be viewed as an OLS affiliated procedure which corrects for spatial autocorrelation in residuals such as might be expected if closely aligned sites had similar properties, this non-independence of observations effectively giving rise to pseudoreplication (Hurlbert, 1984).

For the intermediate SEVM-2, only spatial filters significantly correlated with the response variable are selected. Thus environmental drivers, endogenous biogeographic processes and missing (unobserved) predictors (which are themselves spatially structured) can all be considered to potentially be the causes of the patterns observed. Here the tendency is thought to be for SEVM-02 to still, however, reduce the importance of the more broadly structured predictor variables of true consequence (Bini et al., 2009; Beale et al., 2010). This is consistent with greatly reduced or omitted effects of variables that incorporate strong spatial structures (Supplement S11). For example there were often very different implied effects for $T_{\mathrm{A}}$ or $P_{\mathrm{D}}$ in SEVM-02 as compared to the OLS or SEVM-03 models (Tables 2, 4, 6 and 8). Nevertheless, it also needs to be considered that that these variables have very high degrees of autocorrelation, having been derived from interpolated fields in the first place and thus with a very high potential to be "red shift" variables (Sect. 2.5.1).

From the above considerations, it is clear that there is no simple "fix" to the question of how to deal with the strong spatial signatures evident in our data (Figs. 1 and 2) and thus, following Bini et al. (2009), in considering our results we compare the inferences from the various approaches, looking not only to the degree of consistency in parameter selection, coefficient values and associated levels of significance, but also considering the different assumptions associated with the various SEVM models applied.

\subsection{Forest growth rates: above-ground coarse wood production}

Results from Sect. 3.3 pointed to various measures of soil chemistry and climate as potential factors affecting $W_{\mathrm{P}}$; the most unambiguous of which was total soil phosphorus which was included as a significant positive descriptor variable in all multivariate models (Table 2). This was not surprising as phosphorus is generally considered the most likely nutrient to limit tropical forest productivity (Vitousek, 1982, 
Table 6. Lowest AIC model fits for the prediction of stand turnover rate with and without the use of spatial filters. For each variable, the upper line gives first the standardised coefficients $(\beta)$ and their level of significance $(p)$ from the best OLS model fit followed by the results (in brackets) when the same OLS model is applied with the preselected spatial filter included. Also shown in bold (second line) for each variable are the values of $\beta$ and $p$ obtained for the lowest $A I C$ model fit with the spatial filters included. Variables not included in any given model fit are denoted with a “-”. Variables: $\Pi_{2}$; Quesada et al. (2010)'s second index of soil physical properties: $\Pi_{1}$; Quesada et al. (2010)'s first index of soil physical properties; $\Sigma_{\mathrm{B}}$; soil total sum of bases: $P_{\mathrm{A}}$; mean annual precipitation: $P_{\mathrm{D}}$; dry season precipitation. The numbering of the spatial filters is inconsequential.

\begin{tabular}{|c|c|c|c|c|c|c|c|c|}
\hline & \multicolumn{2}{|c|}{ OLS } & \multicolumn{2}{|c|}{ SEVM-1 } & \multicolumn{2}{|c|}{ SEVM-2 } & \multicolumn{2}{|c|}{ SEVM-3 } \\
\hline & $\beta$ & $p$ & $\beta$ & $p$ & $\beta$ & $p$ & $\beta$ & $p$ \\
\hline$\Pi_{2}$ & 0.568 & $<0.001$ & $\begin{array}{c}(0.509) \\
\mathbf{0 . 6 0 3}\end{array}$ & $\begin{array}{l}(0.008) \\
<\mathbf{0 . 0 0 1}\end{array}$ & $\begin{array}{c}(0.483) \\
-\end{array}$ & $\begin{array}{c}(0.008) \\
-\end{array}$ & 0.462 & $<0.001$ \\
\hline$\Pi_{1}$ & - & - & - & - & $\begin{array}{c}(-) \\
0.561\end{array}$ & $\begin{aligned} & (-) \\
< & <0.001\end{aligned}$ & - & - \\
\hline$\Sigma_{\mathrm{B}}$ & 0.225 & 0.057 & $\begin{array}{c}(0.126) \\
-\end{array}$ & $\begin{array}{c}(0.271) \\
-\end{array}$ & $\begin{array}{c}(0.140) \\
-\end{array}$ & $\begin{array}{c}(0.233) \\
-\end{array}$ & 0.144 & 0.210 \\
\hline$P_{\mathrm{A}}$ & -0.233 & 0.038 & $\begin{array}{c}(-0.096) \\
-\end{array}$ & $\begin{array}{c}(0.654) \\
-\end{array}$ & $\begin{array}{c}(-0.211) \\
-\end{array}$ & $\begin{array}{c}(0.059) \\
-\end{array}$ & -0.206 & 0.052 \\
\hline$P_{\mathrm{D}}$ & - & - & - & - & $\begin{array}{c}(-) \\
-0.297\end{array}$ & $\begin{array}{c}(-) \\
\mathbf{0 . 0 0 9}\end{array}$ & - & - \\
\hline Filter 1 & - & - & $\begin{array}{c}(0.137) \\
\mathbf{0 . 2 6 2}\end{array}$ & $\begin{array}{c}(0.477) \\
\mathbf{0 . 0 1 7}\end{array}$ & - & - & - & - \\
\hline Filter 2 & - & - & $\begin{array}{c}(0.041) \\
\mathbf{0 . 0 7 7}\end{array}$ & $\begin{array}{c}(0.776) \\
\mathbf{0 . 5 7 1}\end{array}$ & $\begin{array}{c}(0.024) \\
\mathbf{0 . 0 3 8}\end{array}$ & $\begin{array}{c}(0.867) \\
\mathbf{0 . 7 6 9}\end{array}$ & - & - \\
\hline Filter 3 & - & - & $\begin{array}{c}(-0.290) \\
\mathbf{- 0 . 3 2 5}\end{array}$ & $\begin{array}{c}(0.022) \\
\mathbf{0 . 0 0 7}\end{array}$ & $\begin{array}{c}(-0.298) \\
\mathbf{- 0 . 4 0 5}\end{array}$ & $\begin{array}{l}(0.019) \\
<\mathbf{0 . 0 0 1}\end{array}$ & -0.305 & 0.009 \\
\hline Filter 4 & - & - & $\begin{array}{c}(0.098) \\
\mathbf{0 . 1 6 4}\end{array}$ & $\begin{array}{c}(0.496) \\
\mathbf{0 . 1 1 1}\end{array}$ & - & - & - & - \\
\hline Filter 5 & - & - & $\begin{array}{c}(-0.117) \\
\mathbf{- 0 . 1 2 1}\end{array}$ & $\begin{array}{c}(0.279) \\
\mathbf{0 . 1 9 9}\end{array}$ & - & - & - & - \\
\hline Filter 6 & - & - & $\begin{array}{c}(-0.106) \\
-\mathbf{0 . 1 0 6}\end{array}$ & $\begin{array}{c}(0.291) \\
\mathbf{0 . 2 5 9}\end{array}$ & - & - & - & - \\
\hline Filter 7 & - & - & $\begin{array}{c}(-0.165) \\
\mathbf{- 0 . 1 0 9}\end{array}$ & $\begin{array}{c}(0.091) \\
\mathbf{0 . 2 6 8}\end{array}$ & - & - & - & - \\
\hline Filter 8 & - & - & $\begin{array}{c}(-0.158) \\
\mathbf{- 0 . 1 8 2}\end{array}$ & $\begin{array}{c}(0.130) \\
\mathbf{0 . 0 5 7}\end{array}$ & & & & \\
\hline$A I C$ & & 324 & $\begin{array}{r}(11 \\
\mathbf{1 1}\end{array}$ & & $\begin{array}{r}(11 \\
\mathbf{1 0}\end{array}$ & & & 3.37 \\
\hline
\end{tabular}


Table 7. Spearman's $\rho$ for relationships between above-ground biomass and a range of soil and climate predictors. Probabilities ( $p$ ) are given with and without adjustment (adj) for degrees of freedom (df) according to Dutillieul (1993). Abbreviations used: $\Pi_{1}$ and $\Pi_{2}-$ first and second indices of soil physical conditions (Sect. 2.2); $[\mathrm{P}]_{\mathrm{ex}},[\mathrm{P}]_{\mathrm{a}},[\mathrm{P}]_{\mathrm{i}},[\mathrm{P}]_{\mathrm{o}},[\mathrm{P}]_{\mathrm{t}}-$ extractable, available, inorganic, organic and total soil phosphorus pools; $[\mathrm{Ca}]_{\mathrm{E}},[\mathrm{Mg}]_{\mathrm{E}},[\mathrm{K}]_{\mathrm{E}},[\mathrm{Al}]_{\mathrm{E}}$ - exchangeable calcium, magnesium, potassium and aluminium concentrations; $I_{\mathrm{E}}-$ effective soil cation exchange capacity; $\theta^{*}<0.20$ - modelled number of months with soil water less than 0.2 of maximum available soil water content. Where $p \leq 0.050$ values are shown in bold.

\begin{tabular}{lrrrr}
\hline Variable & Spearman's $\rho$ & $p$ value & $p$ value adj & df adj \\
\hline Sand & 0.161 & 0.346 & 0.293 & 62 \\
Clay & -0.045 & 0.463 & 0.411 & 63 \\
Silt & -0.343 & 0.017 & 0.071 & 29 \\
Soil depth & $-\mathbf{0 . 3 4 1}$ & $\mathbf{0 . 0 1 9}$ & 0.072 & 16 \\
Soil structure & $-\mathbf{0 . 3 5 5}$ & $<\mathbf{0 . 0 0 1}$ & 0.067 & 29 \\
Topography & 0.162 & 0.570 & 0.664 & 46 \\
Anoxic & $-\mathbf{0 . 1 8 4}$ & $\mathbf{0 . 0 2 4}$ & $\mathbf{0 . 0 3 0}$ & $\mathbf{1 9}$ \\
$\Pi_{1}$ & $-\mathbf{0 . 2 2 1}$ & $\mathbf{0 . 0 3 0}$ & 0.188 & 18 \\
$\Pi_{2}$ & $-\mathbf{0 . 2 8 3}$ & $\mathbf{0 . 0 0 4}$ & 0.088 & 32 \\
pH & -0.255 & 0.158 & 0.123 & 48 \\
$\mathrm{P}_{\mathrm{ex}}$ & $-\mathbf{0 . 4 7 2}$ & $\mathbf{0 . 0 0 2}$ & $\mathbf{0 . 0 1 6}$ & $\mathbf{3 0}$ \\
$\mathrm{P}_{\mathrm{a}}$ & $-\mathbf{0 . 4 8 3}$ & $<\mathbf{0 . 0 0 1}$ & $\mathbf{0 . 0 0 4}$ & $\mathbf{3 0}$ \\
$\mathrm{P}_{\mathrm{i}}$ & $-\mathbf{0 . 4 1 8}$ & $\mathbf{0 . 0 0 4}$ & $\mathbf{0 . 0 2 4}$ & $\mathbf{3 3}$ \\
$\mathrm{P}_{\mathrm{O}}$ & $-\mathbf{0 . 4 3 8}$ & $\mathbf{0 . 0 0 3}$ & $\mathbf{0 . 0 2 3}$ & $\mathbf{3 0}$ \\
$\mathrm{P}_{\mathrm{t}}$ & -0.279 & 0.156 & 0.199 & 43 \\
Total [N] & -0.198 & 0.102 & 0.095 & 52 \\
Total $[\mathrm{C}]$ & -0.018 & 0.524 & 0.615 & 31 \\
C:N ratio & 0.345 & 0.033 & 0.160 & 22 \\
{$[\text { Ca }]_{\mathrm{E}}$} & $-\mathbf{0 . 2 5 5}$ & $\mathbf{0 . 0 8 0}$ & $\mathbf{0 . 0 1 8}$ & $\mathbf{9 1}$ \\
[Mg]E & $-\mathbf{0 . 3 0 8}$ & $\mathbf{0 . 0 5 0}$ & $\mathbf{0 . 0 3 5}$ & $\mathbf{5 8}$ \\
[K] $]_{\mathrm{E}}$ & $-\mathbf{0 . 4 4 9}$ & $<\mathbf{0 . 0 0 1}$ & $\mathbf{0 . 0 0 3}$ & $\mathbf{2 6}$ \\
[Al] & 0.105 & 0.764 & 0.758 & 52 \\
Sum of bases & $-\mathbf{0 . 2 9 4}$ & $\mathbf{0 . 0 4 7}$ & $\mathbf{0 . 0 1 5}$ & $\mathbf{7 5}$ \\
$I_{\mathrm{E}}$ & -0.187 & 0.146 & 0.177 & 30 \\
Mean annual temperature & 0.135 & 0.774 & 0.818 & 10 \\
Mean annual precipitation & 0.276 & 0.246 & 0.641 & 13 \\
Dry season precipitation & 0.257 & 0.459 & 0.711 & 11 \\
$\theta^{*}<0.20$ & $-\mathbf{0 . 3 1 4}$ & $\mathbf{0 . 0 3 0}$ & 0.307 & 43 \\
Mean annual radiation & -0.122 & 0.472 & 0.689 & 18 \\
\hline & & & &
\end{tabular}

1984, 2004; Cuevas and Medina, 1986; Vitousek and Sanford, 1986; Silver, 1994; Reich et al., 1995; MacGrath et al., 2001; Paoli and Curran, 2007). This idea is conceptually attractive because $\mathrm{P}$ is almost exclusively supplied by parent material and tropical forest soils are often of considerable age (Crews et al., 1995; Quesada et al., 2010, 2011). In addition, the evolution of soils during weathering is thought to reduce plant-available $\mathrm{P}$ pools either by parent material weathering and leaching and/or modification to the chemical state of both organic and inorganic $\mathrm{P}$ towards non-available forms such as the $\mathrm{P}$ occluded by $\mathrm{Fe}$ and $\mathrm{Al}$ oxides (Walker and Syers, 1976). Because $P$ is essential for ATP and sugar phosphates, a deficiency of this nutrient could potentially limit photosynthesis and thus community level primary production (Raaimakers et al., 1995; Crews et al., 1995; Herbert and Fownes, 1995; Raich et al., 1996; Kitayma et al., 2004; Domingues et al., 2010).
It was not, however, expected that it would be the total phosphorus pool which was best correlated with $W_{\mathrm{P}}$ as it is generally considered that soil phosphorus exists across a range of states of greatly varying degrees of plant availability (Sattel and Morris, 1992; Crews et al., 1995; Lloyd et al., 2001, Quesada et al., 2010). In particular we note that "readily available P" (the sum of the resin and bicarbonate $\mathrm{P}$ fractions), although often considered as being the best indication of the amount of soil P available to plants (Cross and Schlesinger, 1995; Johnson et al., 2003), was not selected as a variable in our multivariate regression analysis; either with or without spatial filters included. Indeed, the ability of the various $\mathrm{P}$ pools to explain variations in $W_{\mathrm{P}}$ increased with the inclusion of more stable, slow turnover forms of $\mathrm{P}$. This suggests that it is not only the immediately available $\mathrm{P}$ forms, but probably the entire $\mathrm{P}$ pool that is interacting with forest growth on longer timescales (Silver, 1994). This is most likely due to a transiting through buffer pools to the 

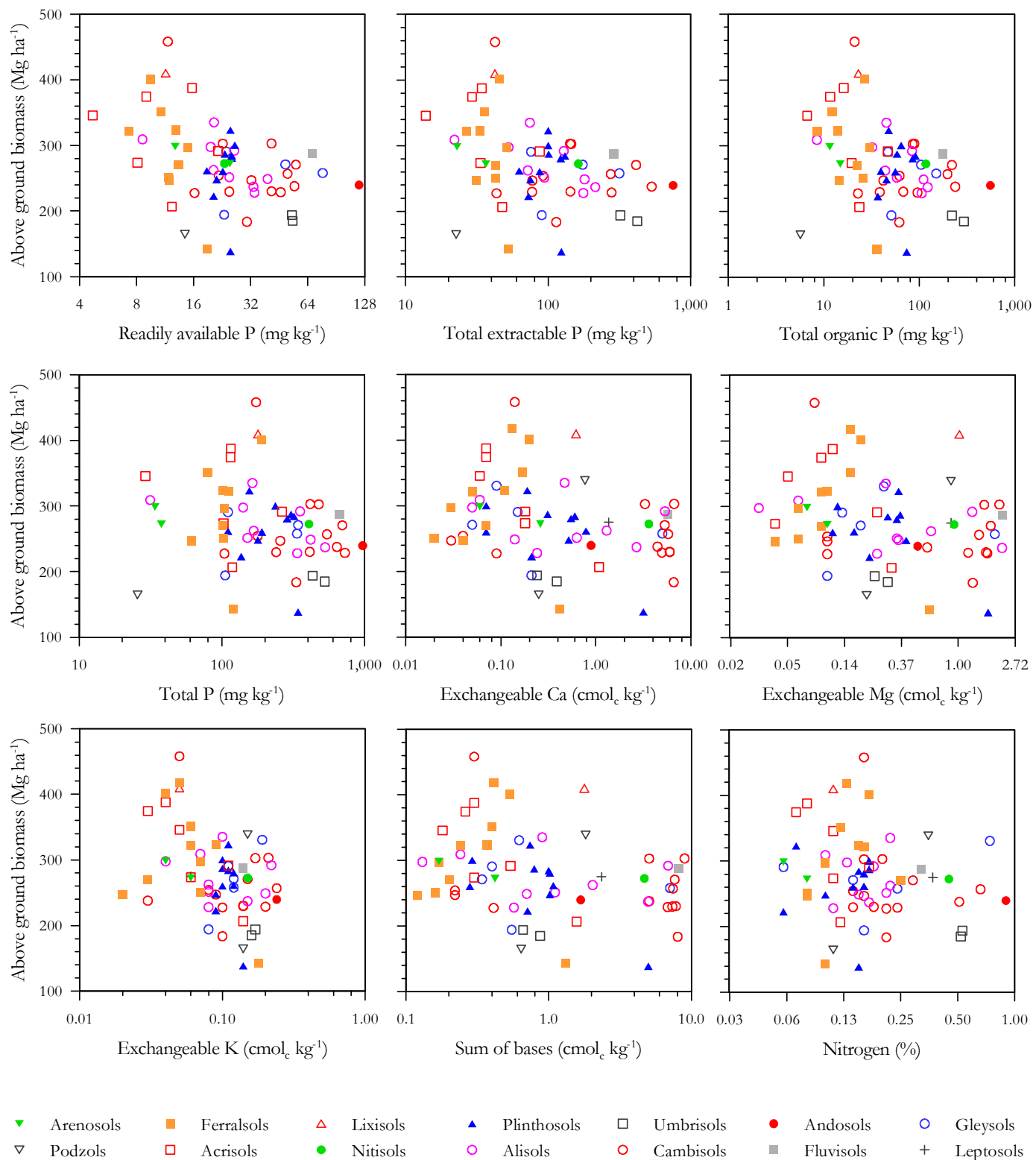

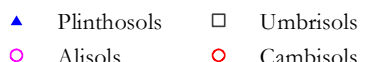

- Andosols

Fluvisols + Gleysols

Fig. 12. Relationships between above-ground biomass and different soil fertility parameters.

immediately available forms (Tiessen et al., 1984; Hinsinger, 2001), and/or due to the effect of mycorrhizal infections (Alexander, 1989). Mycorrhizal associations raise the affinity of infected roots for P in solution, lowering its threshold concentration to absorption (Mosse et al., 1973) and leading to more desorption of $\mathrm{P}$ from the labile pools. Mycorrhizal associations can also induce the release phosphorus that is adsorbed by iron oxides and otherwise unavailable to plant roots (Alexander, 1989).

In agreement with the results reported here, Kitayama et al. (2000), showed that total extractable P (total-residual) was a better predictor of $\mathrm{P}$ availability for tropical forest in Borneo as compared to just the more readily plant-accessible pools. As discussed in detail in Quesada et al. (2010), there is also evidence that the more stable phosphorus fractions may become available for plants when $\mathrm{P}$ is in relatively short supply (Adepetu and Corey, 1976; Tiessen et al., 1984; Gahoonia et al., 1992; Sattell and Morris, 1992; Hedley et al., 1994; Saleque and Kirk, 1995; Magid et al., 1996; Hinsinger and Gilkes, 1996; Trolove et al., 1996; Zoysa et al., 1997, 1998, 1999; Guo and Yost, 1998; Bertrand et al., 1999; Frossard et al., 2000).

An important consequence of the total soil phosphorus pool being the best predictor of variations in $W_{\mathrm{P}}$ is that the importance of phosphorus as prime modulator of tropical forest growth rate variations may have been underestimated in 

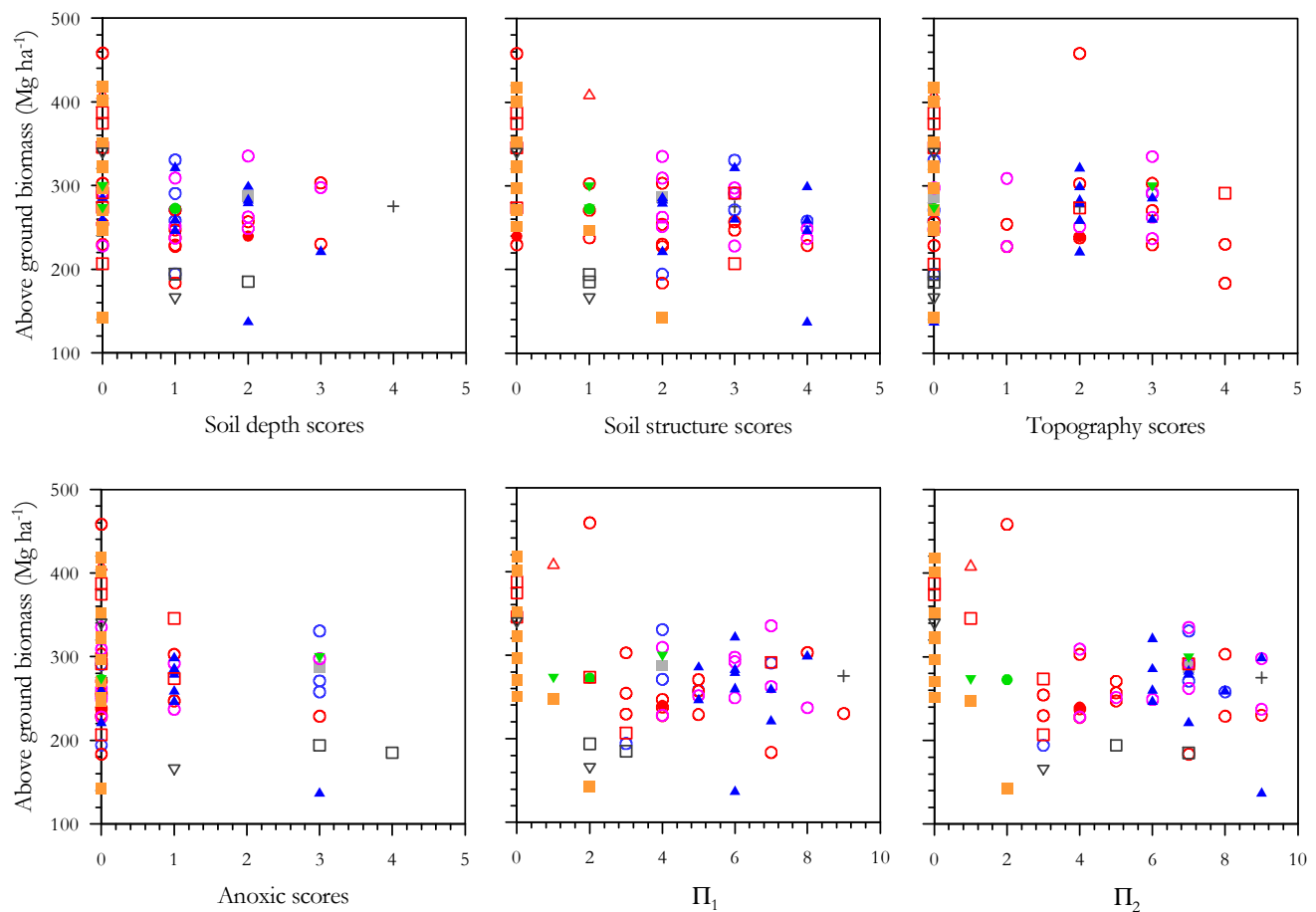

$\begin{array}{llll}\nabla & \text { Arenosols } & \square & \text { Acrisols } \\ \nabla & \text { Podzols } & \triangle & \text { Lixisols } \\ \square & \text { Ferralsols } & \bullet & \text { Nitisols }\end{array}$
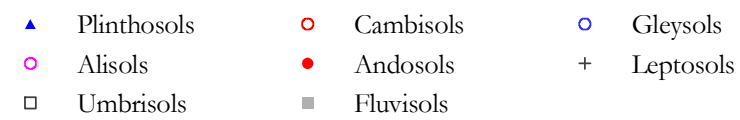

Fig. 13. Relationships between above-ground biomass and soil physical properties. For definitions of $\Pi_{1}$ and $\Pi_{2}$ see Sect. 2.2 .

studies which have taken into account only the more immediately available forms of phosphorus in the soil solution. Moreover, even when the same extraction procedure is used, analytical method may also substantially influence the apparent amount of this element present in the more labile pools, further confounding interpretations. For example, using a modified Olsen procedure for bicarbonate-extractable soil phosphorus, Hart and Cornish (2009) obtained ca. 50\% higher values when analysing samples by inductively coupled plasma spectrometry (ICP) rather than the traditional colourimetric method. This is probably due to organic-P being represented only in the former.

Despite such complications, when examining variation within a $15 \mathrm{~km}^{2}$ area of Bornean rain forest, Paoli and Curran (2007) found Olsen-P analysed by ICP (therefore probably roughly equivalent to our "readily available P") to show a strong positive relationship with stand-level basal area and growth rates (litterfall+biomass). They then concluded that soil $\mathrm{P}$ supply was the main driver of spatial variation of above-ground net primary productivity in their study area (over which precipitation cannot have varied much).

By contrast, Toledo et al. (2011b), studying basal area increment productivity patterns for 165 Bolivian forests with an apparent variability in soil chemical properties similar to that found here, concluded that soil phosphorus and/or cation status was relatively unimportant in accounting for the differences observed, and with variations in precipitation regime considered the underlying cause of variations in $G_{\mathrm{B}}$. There may be several reasons for this difference between their study and ours. First, although covering a much smaller area than our study (less than 0.05 of South American tropical forest is in Bolivia), the study area of Toledo et al. (2011b) is also on the southern periphery of the Amazon Basin, with their study sites extending into the forest/savanna transition zone encompassing dry-deciduous (chiquitano) forest with a precipitation range of 1.1 to $2.2 \mathrm{ma}^{-1}$. This extends beyond the lower end of the precipitation range forming part of our study, which, nevertheless, also found dry-season precipitation to be an important factor accounting for variations in $W_{\mathrm{P}}$ (Table 2). It may then be that any phosphorus effects on productivity are simply swamped by precipitation effects towards the forested region periphery. Although we also suggest that the phosphorus availability metric used by Toledo et al. (2011b), viz. Olsen-P (which in their case may not have included any organic component) may not have been appropriate. With our dataset and calculating a Spearman's correlation for what would be our equivalent of that (resin + inorganic bicarbonate P), we obtain a $\rho$ of only 0.24 for the correlation with $W_{\mathrm{P}}$ with a probability (adjusted for spatial autocorrelation effects) of 0.14 . This is noticeably 

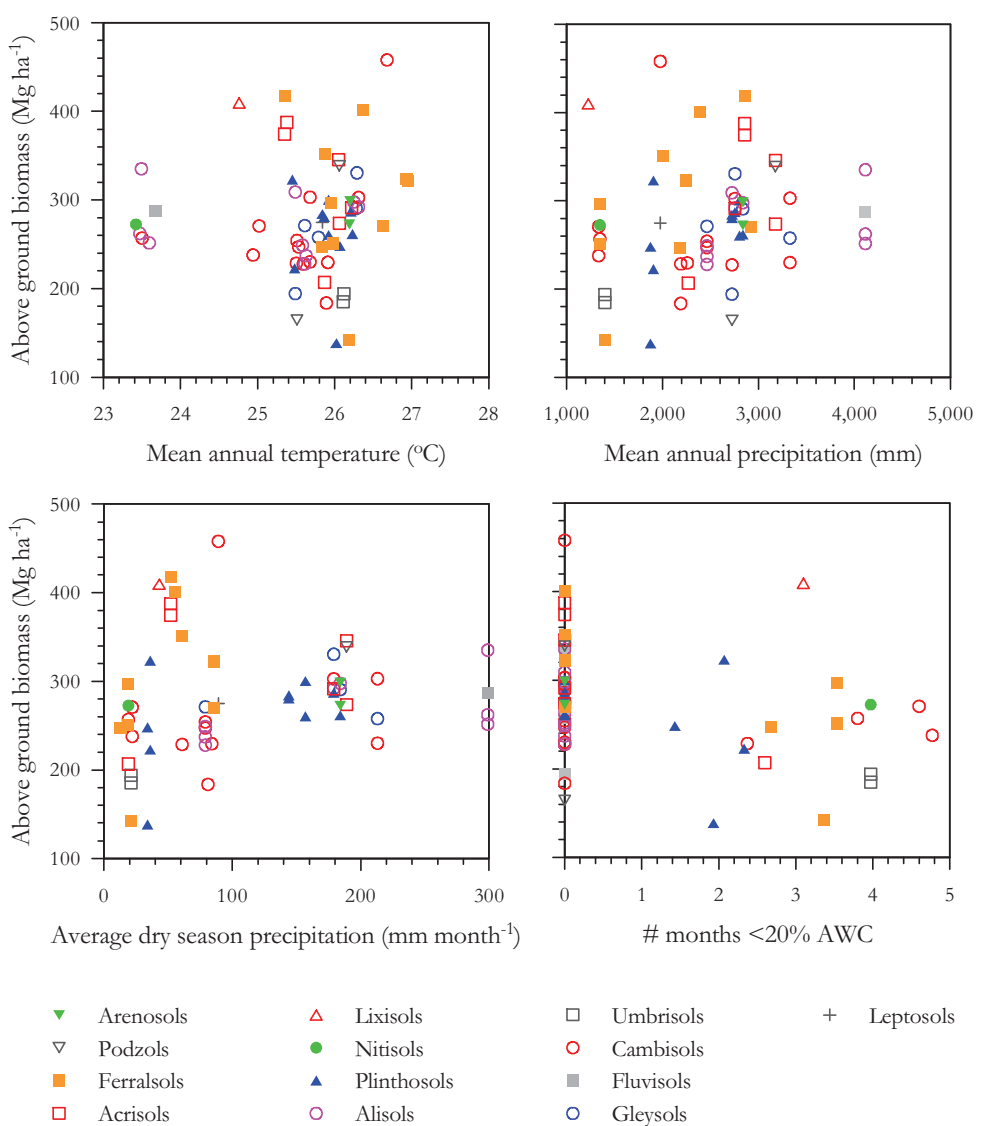

Fig. 14. Relationships between above-ground biomass and climatic factors.

worse than all our other P-availability measures, the highest of which is $\rho=0.45$ for $[\mathrm{P}]_{\mathrm{t}}$ and with an adjusted level of significance of 0.02 (Table 1). This highlights the importance of considering both extraction procedures and method of analysis when investigating relationships between soil chemical status and measures of ecosystem function.

A recent review of tropical forest function also reached a similar conclusion to that made here, viz. that total soil $\mathrm{P}$ is a good predictor of tropical forest productivity (Cleveland et al., 2011a). But this is hardly surprising as the bulk of the data used in that "pan-tropical" analysis is actually simply the RAINFOR dataset as used here, having been procured from Malhi et al. (2004) and the Supplement of Quesada et al. (2010), but with both these principal data sources inadvertently omitted from citation in the original publication (Cleveland et al., 2011b).

The means by which soils may exert their effects on moist tropical $W_{\mathrm{P}}$ were examined by Aragão et al. (2009) who found no large effects of soil chemical status on carbon allocation across a range of Amazon forests. This suggests that the $\mathrm{P}$ effect might be directly through higher rates of photosynthetic carbon assimilation (Domingues et al., 2010), an idea supported by the modelling analysis of Mercado et al. (2011) who, simulating stand level photosynthesis for a range of sites across the Basin using a model allowing for either nitrogen or phosphorus limitation of leaf-level $\mathrm{CO}_{2}$ assimilation rates (Gross Primary Production, $G_{\mathrm{P}}$ ), found a reasonably good relationship between the simulated $G_{\mathrm{P}}$ and $W_{\mathrm{P}}\left(R^{2}=0.30\right)$. For those simulations, canopy level nutrient values from the dataset detailed in Fyllas et al. (2009) were weighted by species abundance. This turned out to be important as plot-level means (ignoring abundances) gave a $R^{2}$ of only 0.16 . This difference is also probably why, their dataset being heavily influenced by our raw (non-abundance weighted) foliar nutrient data (Fyllas et al., 2009), Cleveland et al. (2011a) found a $R^{2}$ of only 0.09 when examining the relationship between above-ground net primary production and foliar [P].

Although the conclusion that phosphorus rather than nitrogen availability is the main factor influencing tropical forest productivity is consistent with biogeochemical theory, we do not here totally discount a role for nitrogen, at least in some cases. Nitrogen is, of course, generally accepted to be the nutrient most often limiting plant productivity for the vegetation of the temperate and boreal zones (e.g., Reich, 2012) and there is also good evidence that montane forests may in some cases have their productivity limited by this element (Tanner et al., 1998). In that context, we also note 
Table 8. Lowest AIC model fits for the prediction of stand biomass with and without the use of spatial filters. For each variable, the upper line gives first the standardised coefficients $(\beta)$ and their level of significance $(p)$ from the best OLS model fit followed by the results (in brackets) when the same OLS model is applied with the preselected spatial filter included. Also shown in bold (second line) for each variable are the values of $\beta$ and $p$ obtained for the lowest AIC model fit with the spatial filters included. Variables not included in any given model fit are denoted with a “_”. Variables: $\Pi_{2}$; Quesada et al (2010)'s second index of soil physical properties: $[\mathrm{P}]_{\mathrm{t}}$; total soil phosphorus: $[\mathrm{K}]_{\mathrm{E}}$; exchangeable soil potassium: $[\mathrm{Ca}]_{\mathrm{E}}$; exchangeable soil calcium: $P_{\mathrm{D}}$; dry season precipitation. The numbering of the spatial filters is inconsequential.

\begin{tabular}{|c|c|c|c|c|c|c|c|c|}
\hline & \multicolumn{2}{|c|}{ OLS } & \multicolumn{2}{|c|}{ SEVM-1 } & \multicolumn{2}{|c|}{ SEVM-2 } & \multicolumn{2}{|c|}{ SEVM-3 } \\
\hline & $\beta$ & $p$ & $\beta$ & $p$ & $\beta$ & $p$ & $\beta$ & $p$ \\
\hline$\Pi_{2}$ & -0.445 & 0.005 & $\begin{array}{c}(-0.192) \\
-\end{array}$ & $\begin{array}{c}(0.302) \\
-\end{array}$ & $\begin{array}{c}(-0.161) \\
-\end{array}$ & $\begin{array}{c}(0.292) \\
-\end{array}$ & -0.247 & 0.106 \\
\hline $\log [\mathrm{P}]_{t}$ & 0.350 & 0.021 & $\begin{array}{c}(0.183) \\
-\end{array}$ & $\begin{array}{c}(0.213) \\
-\end{array}$ & $\begin{array}{c}(0.191) \\
-\end{array}$ & $\begin{array}{c}(0.181) \\
-\end{array}$ & 0.358 & 0.009 \\
\hline $\log [K]_{E}$ & -0.432 & 0.003 & $\begin{array}{c}(-0.151) \\
-\end{array}$ & $\begin{array}{c}(0.247) \\
-\end{array}$ & $\begin{array}{c}(-0.238) \\
-\mathbf{0 . 1 8 1}\end{array}$ & $\begin{array}{c}(0.075) \\
\mathbf{0 . 1 1 0}\end{array}$ & -0.302 & 0.023 \\
\hline $\log [\mathrm{Ca}]_{\mathrm{E}}$ & - & - & $\begin{array}{c}(-) \\
-\mathbf{0 . 2 7 4}\end{array}$ & $\begin{array}{c}(-) \\
\mathbf{0 . 0 3 4}\end{array}$ & - & - & - & - \\
\hline$P_{\mathrm{D}}$ & 0.428 & 0.001 & $\begin{array}{c}(-0.794) \\
-\end{array}$ & $\begin{array}{c}(0.151) \\
-\end{array}$ & $\begin{array}{c}(0.153) \\
-\end{array}$ & $\begin{array}{c}(0.247) \\
-\end{array}$ & 0.385 & 0.002 \\
\hline Filter 1 & - & - & $\begin{array}{c}(-0.927) \\
\mathbf{- 0 . 1 6 7}\end{array}$ & $\begin{array}{c}(0.086) \\
\mathbf{0 . 0 7 9}\end{array}$ & - & - & - & - \\
\hline Filter 2 & - & - & $\begin{array}{c}(-0.172) \\
-\mathbf{0 . 1 9 4}\end{array}$ & $\begin{array}{c}(0.101) \\
\mathbf{0 . 0 3 0}\end{array}$ & - & - & - & - \\
\hline Filter 3 & - & - & $\begin{array}{c}(0.403) \\
\mathbf{0 . 3 1 5}\end{array}$ & $\begin{array}{l}(0.002) \\
<\mathbf{0 . 0 0 1}\end{array}$ & $\begin{array}{c}(0.274) \\
\mathbf{0 . 3 1 0}\end{array}$ & $\begin{array}{c}(0.023) \\
\mathbf{0 . 0 0 2}\end{array}$ & - & - \\
\hline Filter 4 & - & - & $\begin{array}{c}(0.524) \\
\mathbf{0 . 5 4 9}\end{array}$ & $\begin{array}{c}(<0.001) \\
<\mathbf{0 . 0 0 1}\end{array}$ & $\begin{array}{c}(0.421) \\
\mathbf{0 . 4 6 7}\end{array}$ & $\begin{array}{l}(0.002) \\
<\mathbf{0 . 0 0 1}\end{array}$ & 0.394 & 0.003 \\
\hline Filter 5 & - & - & $\begin{array}{c}(0.509) \\
\mathbf{0 . 2 5 6}\end{array}$ & $\begin{array}{c}(0.010) \\
\mathbf{0 . 0 0 4}\end{array}$ & $\begin{array}{c}(0.224) \\
\mathbf{0 . 2 6 2}\end{array}$ & $\begin{array}{c}(0.032) \\
\mathbf{0 . 0 0 8}\end{array}$ & - & - \\
\hline Filter 6 & - & - & $\begin{array}{c}(-0.062) \\
-\mathbf{0 . 0 5 6}\end{array}$ & $\begin{array}{c}(0.515) \\
\mathbf{0 . 5 2 0}\end{array}$ & - & - & - & - \\
\hline Filter 7 & - & - & $\begin{array}{c}(0.095) \\
\mathbf{0 . 1 2 3}\end{array}$ & $\begin{array}{c}(0.330) \\
\mathbf{0 . 1 7 0}\end{array}$ & - & - & - & - \\
\hline Filter 8 & - & - & $\begin{array}{l}(0.015) \\
-\mathbf{0 . 2 6 8}\end{array}$ & $\begin{array}{c}(0.930) \\
\mathbf{0 . 0 0 4}\end{array}$ & - & - & -0.257 & 0.014 \\
\hline$A I C$ & 639 & & $\begin{array}{r}(62 \\
62\end{array}$ & $\begin{array}{l}86) \\
.58\end{array}$ & $\begin{array}{r}(629 \\
623\end{array}$ & & 629 & \\
\hline
\end{tabular}

that the analysis of Mercado et al. (2011) has suggested that the productivity of lowland forests on some very young or very old Amazon forest soils may be more nitrogen than phosphorus limited; a contention also supported by soil and plant stable nitrogen isotope measurements (Quesada et al., 2010; Nardoto et al., 2012). With all three of the immediately just mentioned studies sharing many sites in common with those analysed here, it may then have been that with 

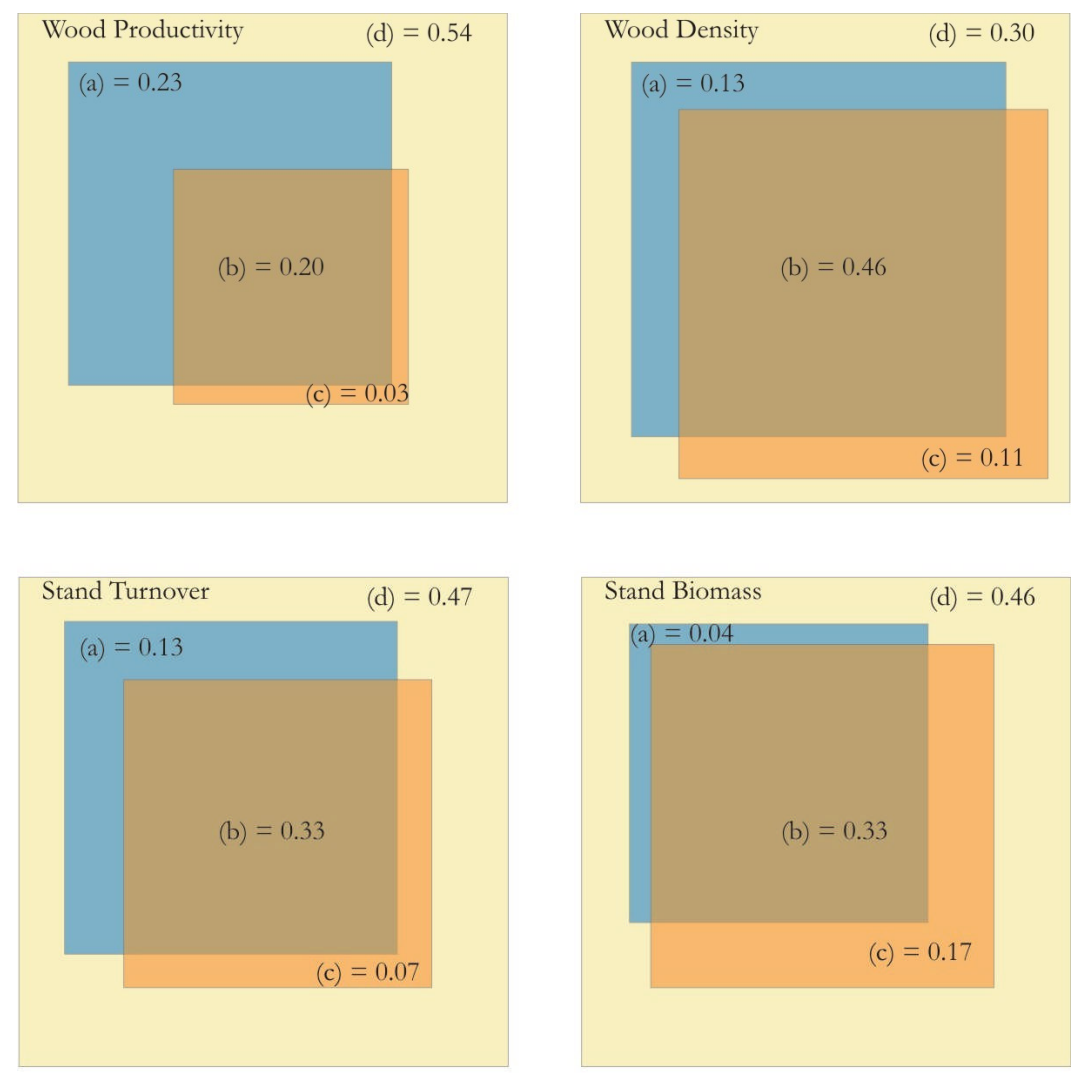

Fig. 15. Variation partitioning Venn diagrams representing the fractions of unique contribution of (a) environmental/edaphic and (c) spatial components to Basin-wide variations in Amazon forest above-ground wood productivity, stand-level wood density, stand tree turnover rates and biomass. Fraction (b) represents the shared variation between the environmental components and (d) the residual (unexplained) variations of the multiple regression model involving the OLS predictors and the SEVM-02 filters.

a more complex (probably discontinuous) paramaterisation our model fit may have been marginally improved with the inclusion of a soil nitrogen availability term. Nevertheless, the above mentioned evidence for $\mathrm{N}$-limitations exists only for a few sites (less than $10 \%$ of the dataset), and it is clear that total soil phosphorus was the key variable driving variations in $W_{\mathrm{P}}$ across the range of climate and soils encountered here.

There is little in our dataset to suggest a role for calcium or magnesium in influencing $W_{\mathrm{P}}$ or, as has been suggested by Schuur (2003), for there to be any general decline in tropical forest productivity with very high rainfall. Indeed, some of the highest $W_{\mathrm{P}}$ in our dataset are on high phosphorus soils in Ecuador where precipitation is also the highest (Fig. 1). We were, however, able to detect a decline in $W_{\mathrm{P}}$ as dryseason precipitation decreases for all cases except the very conservative SEVM-01 model.

Although the highly significant negative effect of higher mean annual temperatures on $W_{\mathrm{P}}$ in the OLS model could be taken to support the notion that tropical forests are already existing at or beyond their high-temperature threshold (Feeley et al., 2008; Clark et al., 2010), the significance of this term evaporated when the SEVM-01 or SEVM-02 models were applied. This is in contrast to the other three terms in the OLS model which were all substantially more robust to the addition of the spatial filters. Thus, especially as only one spatial filter was involved in SEVM-02, this may rather reflect $T_{\mathrm{A}}$ being somewhat a "red shift" variable whose importance at larger spatial scales was overestimated without the inclusion of this filter. On the other hand, if could also be that this large-scale negative temperature effect on Amazon forest productivity is real; being mediated, for example, through the effects of associated higher vapour pressure deficits in reducing average day-time stomatal conductances (Lloyd and Farquhar, 2008). This is obviously an important issue, but as noted by Beale et al. (2010), in many real-world situations it is impossible to know the true relationships between covariates and dependent variables (Miao et al., 2009). This is especially the case for ex post facto studies such as here with multiple variables strongly associated with each other and with relationships further confounded by significant spatial and/or temporal correlations (for an example of the latter see Clark et al., 2010). 
The negative effect of soil exchangeable potassium found in the OLS and SEVM-03 models was also found using the SEVM-02 procedure but with this soil cation effect manifesting as $[\mathrm{Mg}]_{\mathrm{E}}$ in SEVM-01. Noting that one of $[\mathrm{K}]_{\mathrm{E}}$ or $[\mathrm{Mg}]_{\mathrm{E}}$ was also negatively correlated with $\varrho_{\mathrm{w}}$ in its multivariate analysis (Table 4), but with no cation effect evident when growth was examined on a basal area as opposed to a dry-weight basis (Supplement, Table S2), it thus seems reasonable to argue that this effect occurs because stands on high cation status soils have, on average, a lower wood density. This is discussed further in Sect. 4.4.

Soil physical properties had much lower correlations with $W_{\mathrm{P}}$ than most of the soil fertility measures. Nevertheless, even though not being included in any of the minimum $A I C$ multivariate models, the topography scores did have a reasonable relationship with $W_{\mathrm{P}}$ (Table 1, Fig. 4). This potentially reflects a positive influence of topography on forest growth as crown illumination may be favoured on slopes. In addition, continuous erosion processes may aid the maintenance of mineral nutrient inputs, bringing less weathered soil layers to the proximity of soil surface and thus within the reach of nutrient absorbing roots at steeper sites.

\subsection{Tree turnover rates}

Variations in $\varphi$ were strongly correlated to soil fertility and soil-landscape physical conditions as well as to climatic variables such as amount and distribution of precipitation (Table 5; Figs. 9 to 11). Nevertheless, despite all soil phosphorus fractions and exchangeable base cations being strongly correlated with tree turnover rates when considered on their own, the only occasion a soil fertility parameter was included in a minimum $A I C$ multivariate model was for sum of bases $\left(\Sigma_{\mathrm{B}}\right)$ in the OLS model; and with it's level of significance there (already modest at $p=0.06$ ) reduced (to $p=0.21$ ) once the SEVM-03 filter was applied. By contrast, either $\Pi_{1}$ or $\Pi_{2}$ were selected as the dominant predictor in all four model types and at $p<0.001$. It thus seems clear that variations in Amazon forest $\varphi$ are driven mainly by variations in soil physical conditions.

These effects of adverse soil physical conditions in promoting high turnover rates may be mediated through a variety of mechanisms. For example, the proportion of trees which die standing, uprooted, and snapped is related to topographic position, slope angle, soil depth, soil shear strength, flooding and drought; though with biological effects such as herbivory and disease naturally important as well (Gale and Barford, 1999; Chao et al., 2008). Causes for tree uprooting are predominantly physical, due to bad soil anchorage, short soil depth, steep topography and slope position, storms and associated windthrow with - as "innocent bystanders" other trees also being broken or knocked over by the fall of neighbouring trees (Chao et al., 2009). On the other hand, standing death is most strongly related to biological agents such as senescence, diseases and competition for resources (Gale and Barfod, 1999; Gale, 2000; Gale and Hall, 2001).

Individual soil physical properties could influence tree turnover in many different ways. For instance, shallow soil depth implies a limited root space which often leads to short and stunted root systems, this most likely having a major influence on plant growth and survival (Arshad et al., 1996; Schoenholtz et al., 2000). This problem is often associated with steep topographies, which can greatly increase the probability of tree death by wind throw (Dietrich et al., 1996). In addition to possible constraints of nutrient supply due to limited rooting depth, hydrological constraints may also occur, either through a low drainage capacity or due to low water availability or seasonal drought (Arshad et al., 1996; Ferry et al., 2010). As well as occurring for young soils such as Leptosols and Cambisols, a shallow effective rooting depth should also occur in many soils which have large and shallow hardpans. Or soils that have severe structural problems such as massive and compact subsoil horizon. Hardpans are found all over the Amazon Basin and have different natures. The most common are continuous and hardened clusters of iron and aluminium oxides, often known as ironstones (hardened plinthite) and similar continuous gravel and rock layers. These layers can be a few centimetres or more than one metre thick, sometimes allowing roots to go through and sometimes not. The depth of occurrence and the nature of a hardpan are the best determinants of its capacity to limit plant growth (Sombroek, 1966). As is discussed below, although soil depth on its own was not significant in multiple regressions, it may have a strong effect on turnover rates through interactions with other soil properties.

Poor soil structure is another important factor affecting tree turnover, expected to lead to problems that are similar to those caused by a limited soil depth because both are physical impediments to root growth. Subsoil structure development occurs in line with the soil weathering process. Thus poor soil structure is generally a feature in soils of a low pedogenic status such as Gleysols and Regosols, also occurring in soils with argic horizons such as Alisols, Lixisols and Acrisols as a consequence of increasing clay contents with depth. Poor soil structure may also result in weak aeration in clay-rich soils, particularly when moist and with most of the pore space filled with water (Korning et al., 1994). Structural problems are also strongly related to hydrological constraints and water movement due to its relationship with soil porosity (in especially macro-porosity) which influences water infiltration as well as aeration (Arshad et al., 1996; Schoenholtz et al., 2000). Root proliferation is also impeded by high soil bulk densities $\left(D_{\mathrm{s}}\right)$ which are also a characteristic of soils with deficient structure. For example, inhibitions of root growth at $D_{\mathrm{s}} \geq 1.35 \mathrm{~g} \mathrm{~cm}^{-3}$ have been reported (Van Wambeke, 1992; Arshad et al., 1996), and these are probably the reason for high $D_{\mathrm{s}}$ having occasionally been linked to reductions in the productivity of tropical tree plantations (Dedecek et al., 2001; Hirai et al., 2003). 
Because geomorphological processes are strongly related to the pedogenetic status of tropical soils (Thomas, 1994), topography should be another factor closely associated with soil physical constraints. Soils with steep topography are usually shallow and thus mechanical instability is often a problem. For instance, Gale and Barfod (1999) reported that steep topography was an important factor influencing tree mortality in tropical forests due to its association with thin soils and strong lateral forces which favour tree uprooting. However, deep soils may also occur in steep areas and this has been shown to provide better tree anchorage and consequently lead to lower tree mortality rates in steep slopes, for example in the Manaus region of Brazil (Rocha et al., 2003). Lieberman and Lieberman (1987) reported that steep slopes may lead to a threshold in tree size above which the tree is much more probable to collapse. This was argued to be one factor explaining differences in mortality rates among forests at their Costa Rican sites.

Drainage capacity has two implications. Firstly, badly drained soils may become anoxic, which, depending on the severity, could exclude most plant species in areas where it occurs. Seasonally flooded soils are related to high rates of tree uprooting because anaerobic conditions inhibit deep root growth and tree anchorage is limited in hard subsoils (Gale and Barfod, 1999; Gale and Hall, 2001). Gale and Hall (2001) also showed that on poorly drained soils young trees tend to die standing, possibly suffering from anoxia, whilst larger trees tend to die uprooted; not having enough anchorage in soft waterlogged soils. On the other hand, rapidly draining soils such as white sands (Arenosols) may make plants more susceptible to soil water deficits in more seasonal areas. Soil texture is a less direct but important factor as it interacts with almost all processes of physical limitation. Considering soil depth for instance, sandier textures can increase problems of mechanical instability and drastically reduce water holding capacity.

In contrast to the other potential soil physical constraints studied, our data suggest little influence of anoxic conditions on turnover rates. This may be because it is only well-adapted species that tend to occur on soils under conditions of permanent water saturation (Parolin et al., 2004). Seasonal flooding or fluctuations of the water table can, however, increase stress and mortality rates (Cannel, 1979; Ferry et al., 2010). For this study such conditions affected only a small fraction of the study sites.

Although individual physical constraint scores gave important indications of their relationships with $\varphi$, it is also the case that only the most extreme conditions are likely to show a significant influence independently. As argued above, interactions among field characteristics are likely to occur, these increasing their effect on a tree community. A simple example is that tree mechanical instability caused by steep topography will be made worse when occurring in conjunction with shallow soil depth. Physical constraints should thus be considered jointly to allow for the interaction among such characteristics (Muchena, 1979). An approach to represent the interactions among factors, the $\Pi_{1}$, emerged as a good explanatory factor for $\varphi$. But it was a simplified index model consisting of soil depth, soil structure and topography only $\left(\Pi_{2}\right)$ that best described the influence of physical properties on $\varphi$.

Previous studies of $\varphi$ in Amazonia have resulted in the hypothesis that soil fertility plays an important role in explaining the almost two-fold difference in stem turnover rates between the western and central-eastern areas of Amazonia (Phillips et al., 2004; Stephenson and Van Mantgen, 2005). Although we also found univariate indices of soil nutrient availability to correlate with turnover rates as would be expected by that hypothesis (Table 5, Fig. 7), the main conclusion here must be that this is a mostly non-causal correlation resulting from the indirect associations between soil nutrient status and soil physical conditions (Quesada et al., 2010). Furthermore, as discussed in Sect. 4.6, the small $\Sigma_{\mathrm{B}}$ effect as suggested by the OLS model is most likely explainable in terms of cation effects on stand wood density indirectly affecting turnover rates.

Our analysis also suggests that there is an effect of low precipitation in increasing background stand-level turnover rates. Enhanced mortality events during episodic drought events are well documented for Southeast Asia (e.g., van Nieuwstadt and Sheil, 2005), but especially as the data period selected for analysis here preceded the 2005 Amazon drought (Sect. 2.4), this also suggests that, once effects of soil physical conditions are taken into account, "background" mortality rates are greater where dry-season soil water deficits are more common and/or severe. This is, perhaps, not surprising as such forests towards the periphery of the Basin must exist closer to their physiological limit, as suggested for example, by changes in tree height/diameter allometry (Feldpausch et al., 2011) and the reduction in $W_{P}$ with decreasing dry season precipitation (Table 2). This enhanced risk of mortality at lower $P_{\mathrm{D}}$ may be a consequence of a greater probability of hydraulic failure and/or unfavorable whole tree carbon balance and with significant interactions likely (McDowell, 2011).

\subsection{Wood density}

With the exception of SEVM-01, soil physical conditions emerged as the dominant control affecting stand level wood density, with $\Pi_{1}$ the best predictor (Table 4). Nevertheless, from an examination of individual correlations (Table 3), it is also clear that many of the measured soil nutrients were also negatively correlated with $\varrho_{\mathrm{w}}$.

Very little is known about below-ground processes for tropical forest trees and how they may vary with the wood density of a species, but in any case, the means by which the establishment and/or growth of low wood-density species should be directly favoured under conditions of a shallow soil depth, bad soil structural conditions, a steep topography 
and/or frequent anoxia is not readily apparent to us. We do, however, note that Neotropical deciduous forest tree species of a low wood density and high stem water contents (see below for the significance of the latter) are typically shallow rooted compared to co-occurring species with denser wood (Holbrook et al., 1995). Trees and palms with a low $\varrho_{\mathrm{w}}$ may thus be advantaged where soil rooting depth is limited and/or root development inhibited due to poor soil structure and/or anoxia.

In the main, though, we suggest that elevated disturbance regimes mediated through adverse soil physical conditions, as has already been shown to be a driving factor behind higher turnover rates (Sect. 4.3), also serve to favour low wood-density species. These are characterised by rapid height growth and a short-life cycle and thus should have a greater probability of reaching reproductive maturity under conditions where life expectancies are relatively short - as is likely to be the case on physically bad soils characterised by a high $\Pi_{1}$. This interaction between stand-level wood densities and turnover rates and its consequences for stand structure and species composition is considered further in Sect. 4.6.

Consistent with the implied effects of one or more soil cations reducing $W_{\mathrm{P}}$ but not basal area increment, either $[\mathrm{K}]_{\mathrm{E}}$ or $[\mathrm{Mg}]_{\mathrm{E}}$ was implied as having a negative association with $\varrho_{\mathrm{w}}$ (Table 4), including the majority of alternative models with a $\triangle A I C \leq 2.0$ (Sect. 3.4). Strong relationships between foliar potassium concentrations and branch xylem density $\left(\varrho_{\mathrm{x}}\right)$ of individual species, taken with inverse correlations between growing location effect on leaf level potassium and $\varrho_{\mathrm{x}}$ (Patiño et al., 2012), lead us to suggest that $[\mathrm{K}]_{\mathrm{E}}$ is the most likely candidate cation, especially as $\varrho_{\mathrm{w}}$ and $\varrho_{\mathrm{x}}$ are typically well correlated (Swenson and Enquist, 2008; Patiño et al., 2009; Sarmiento et al., 2011; but see also McCulloch et al., 2011). One ready explanation for this effect is that the stems of low wood density tropical tree species typically have a much higher water sapwood capacitance than their higher wood density counterparts (Meinzer et al., 2003; Scholz et al., 2007). This water store contributes to transpiration during the day when water supply from the roots cannot meet the atmospheric demand as modulated by the stomata (Meinzer et al., 2009), and with subsequent refilling at night involving both extracellular water exchange (i.e. in fibres, trachieds, vessels and intercellular spaces where the water is retained due to surface tension) and in living cells, such as the pith, the phloem, the extracambial region, and the sapwood (Holbrook, 1995). Importantly, it seems that many relatively low wood density tropical trees are characterised by extensive parenchymatic tissues located around the xylem with a likely role for these apparently specialised cells in stem water storage and release (Holbrook, 1995; Bochart and Pockman, 2005). It would therefore be expected that in order to maximise their capacitive efficiency, such cells would have substantial osmotic potential (thereby maximising the amount of water released per change in cellular water potential). As for foliar and root tissues (Leigh and Wyn Jones, 1984), potas- sium is a likely candidate to help serve this function as it is mobile, osmotically active, relatively abundant and relatively benign; and with already well documented positive effects on sapwood cambial activity (Fromm, 2010).

The idea that a greater abundance of low wood density species associated with high $[\mathrm{K}]_{\mathrm{E}}$ could result in a reduction in stand-level productivity (Sect. 4.3) does, however, go against the generally accepted dogma that, for seedlings at least, light-demanding, low-wood density species have the greatest relative biomass growth rates in all light environments (e.g. Kitajima, 1994; Poorter, 1999). That low wood density species may on average have lower $W_{\mathrm{P}}$ than their higher $\varrho_{\mathrm{w}}$ counterparts is, however, a notion consistent with the results of Keeling et al. (2008). Accounting for differences in light environment, they found that individual tree $W_{\mathrm{P}}$ tended to increase with $\varrho_{\mathrm{w}}$, especially on high fertility soils.

Keeling et al. (2008) suggested two possible explanations for this tendency which occurs despite low-wood density "pioneer" type species typically having higher photosynthetic rates per unit leaf area than their (generally) more shade-adapted, high-wood density counterparts (Riddoch et al., 1991; Raaimakers et al., 1995; Eshenbach et al., 1998; Nogueira et al., 2004). First, it was argued that carbon gain per tree may be reduced in low-wood density trees as (being unable to construct shade tolerant leaves) they typically have shallower canopies than is the case for their high-wood density counterparts. Second, it was suggested that low-density trees might have high rates of carbon losses due to processes such as high leaf turnover rates (perhaps also associated with high levels of herbivory) and/or high respiratory losses. Nevertheless, it is not clear if such extra carbon losses as suggested by the latter hypothesis would more than offset the higher absolute rates of carbon acquisition expected of low wood-density species (i.e. be higher in a relative as well as absolute sense). For example, higher respiration rates would in any case be expected for more physiologically active, faster growing species (van der Werf et al., 1994). Similarly, although leaf lifetimes may be significantly shorter for many low wood density "pioneer" types, other things being equal, it is the ratio of leaf construction costs to maximum photosynthetic rate that determines the optimal lifespan of a leaf (Ackerley, 1996). The latter should be appreciably lower for low wood density trees due to their typically having not only a lower leaf mass per unit area (Patiño et al., 2012), but also a lower construction cost per unit dry mass due to lower carbon contents (Fyllas et al., 2012). Thus, it is by no means clear that a species characterised by relatively short-lived leaves should have higher overall foliar construction costs as compared to a species whose leaves typically live longer.

There are, however, other characteristics of low-wood density trees that may be responsible for their apparent lower $W_{\mathrm{P}}$ despite high photosynthetic potential per unit leaf area. For example, although both low and high wood density trees can be constructed to provide the same structural support 
strength per unit dry mass (Anten and Schieving, 2010), low wood density species spread this structural support over larger cross sectional area and, with rates of tropical tree respiration tending to scale with either tree diameter or volume (Meir et al., 2002), this should then lead to higher rates of stem respiration per unit dry mass (Larjavaara and MullerLandau, 2010).

Low wood density "pioneer-type" trees are also characterised by high levels of fecundity (Bazzaz and Picket, 1980; Bazzaz, 1984) and although individual seed mass is often low (Swaine and Whitmore, 1988), this should be more than offset by higher seed numbers per unit canopy area (Moles and Westoby, 2005), resulting in a potentially high carbon cost of reproduction for such species. Further, although there is a large variation between species in terms of their relative size at the onset of maturity (RSOM: expressed as the tree height at first reproduction divided by the asymptotic maximal height: Thomas (1996)), this does not seem to relate to life-history strategies with RSOM independent of a species' gap dependence and thus (presumably) wood density. It therefore follows that, with a shorter lifetime on average than high wood density species (Chao et al., 2008), species with a low $\varrho_{\mathrm{w}}$ must allocate more carbon per year to reproduction in order to maintain the same life-time reproductive effort as longer-living, high- $\varrho_{\mathrm{w}}$ species. As is well documented for temperate zone species (Thomas, 2011) this increased reproductive effort may well be associated with a reduction in $W_{\mathrm{P}}$ (Bazzaz and Reekie, 1985; Davies and Ashton, 1999). Certainly the carbon allocated to reproductive effort can be considerable for pioneer species with Ackerly (1996), for example, estimating that as much as $20 \%$ of the annual net production of Cecropia should be consumed during the flowering process.

A greater proportional allocation of carbon to reproduction in shorter-lived, low wood density species is also consistent with the results of Chave et al. (2010) who, in analysing patterns of litterfall for South American tropical forests, observed that the annual investment into reproductive organs divided by the leaf litterfall increases with soil fertility; this also being consistent with the "ground level" observation of Gentry and Emmons (1987) of a higher relative abundance of understory trees/shrubs in flower in forests on more fertile soils. Although these observations can be interpreted as reflecting competition between reproductive versus vegetative structures for available nutrients, given the strong correlation between $\varrho_{\mathrm{w}}$ and soil nutrients in general (Table 5) it is, however, also consistent with a greater average allocation of carbon to reproduction in higher-turnover rate, low-wood density stands.

From the above discussion, it therefore seems that there are several possibilities accounting for significantly higher carbon costs being associated with low wood density species, the abundance of which we suggest is positively related to soil cation concentrations with the most likely cation involved being potassium. Our proposed reduction in $W_{\mathrm{P}}$ at- tributable to a lower stand-level $\varrho_{\mathrm{w}}$ (Sect. 4.3) is not, of course, at odds with the observation that lower $\varrho_{\mathrm{w}}$ stands also tend to have higher $W_{\mathrm{P}}$ (see Supplement Fig. S2). This is because stands with a higher soil cation status also have a higher phosphorus status and with the standardised coefficient for $[\mathrm{P}]_{\mathrm{t}}$ being nearly twice that for $[\mathrm{K}]_{\mathrm{E}}$. Indeed, examining bivariate relationships, the log-log scaling coefficient between $W_{\mathrm{P}}$ and basal area increment $\left(G_{\mathrm{B}}\right)$ is only 0.89 (Supplement, Sect. A; Fig. S2). This implies that any increase in stand-level $G_{\mathrm{B}}$ is accompanied by a less than commensurate increase in $W_{\mathrm{P}}$ - the opposite to what would be expected if low wood density species also had higher amounts of carbon available for stem growth on an annual basis. Similarly, the less negative scaling coefficient for $W_{\mathrm{P}}$ versus $\varrho_{\mathrm{W}}$ as opposed to $G_{\mathrm{B}}$ versus $\varrho_{\mathrm{w}}(-2.7$ vs. -3.2$)$ also suggests that there is a significant carbon cost associated with the low-wood density life-style. This trade-off presumably also explains why Mercado et al. (2011) found better correlations between modelled rates of gross primary productivity and $G_{\mathrm{B}}$ than was the case for $W_{\mathrm{P}}$ when simulating stem productivities for a range of tropical forests located across the Amazon Basin.

Although the above discussion has centered on the individual characteristics of low $\varrho_{\mathrm{w}}$ species, a second possibility is that community-level processes could be involved in causing the lower than expected $W_{\mathrm{P}}$ in low $\varrho_{\mathrm{w}}$ stands. That is to say, under the more dynamic and competitive conditions where low wood density stands generally occur (Sect. 4.5), the performance of the individual becomes more dependent on the characteristics of its neighbours and that this high level competition for light and soil resources leads to a tropical version of a "tragedy of the commons" sensu Hardin (1968). Here, as explained by Anten and During (2011) because plants interact and compete for light, an increase in the leaf area of one individual entails that this plant captures a greater fraction of the available light and its direct competitors therefore capture less. The net effect of this "evolutionary stable" (ES) strategy is that individuals dominating at the top of the canopy should have a leaf area index greater than that required to maximise their own growth rate, but with this reduction in the growth of the individual more than offset by the detrimental effect of the extra imposed shade on the photosynthetic productivity of competitors below (Schieving and Poorter, 1999; Lloyd et al., 2010): Allocation to increased resource acquisition thus benefits the individual that employs the strategy, but with the costs of this (increased shading in the canopy) shared by the whole population (Anten and During, 2011). And here we note that low-wood density tropical forest species are often (but not always) characterised by many of the traits suggested by Anten and During (2011) as being typical of ES stands, such as being taller (e.g. Poorter et al., 2010), having more horizontally projected leaves orientated so as to create a low ratio of self- to non-self-shading (Ashton, 1978; Ackerly, 1996; Kitajima et al., 2005; Posada et al., 2009), and a continuous production of new leaves (Ackerly, 1996; Wright, 1996) which are themselves of a short lifespan (Reich et al., 
2004) and with high nutrient resorption rates as senescence approaches (Reich et al., 1995).

Suggested roles for temperature and dry season precipitation in influencing wood density were ambiguous, with a positive effect of $T_{\mathrm{A}}$ on $\varrho_{\mathrm{w}}$ suggested by the OLS and SEVM-03 models, but with $P_{\mathrm{D}}$ selected by SEVM-01 and SEVM-02. This is similar to the situation discussed in Sect. 4.2 regarding $W_{\mathrm{P}}$. As for that case, interpretation depends on the extent to which the spatial structuring in $\varrho_{\mathrm{w}}$ is considered to be driven by environmental versus other processes. An increase in $\varrho_{\mathrm{w}}$ with $T_{\mathrm{A}}$ is certainly consistent with larger scale analyses (Swenson and Enquist, 2007) and is also apparent in the analysis of variations in $\varrho_{\mathrm{x}}$ across many of the same sites investigated here (Patiño et al., 2009). As well as potentially being a consequence of temperature effects on the viscosity of water (Roderick and Berry, 2001; Thomas et al., 2004), this may be due to the exposure of trees growing at warmer locations to higher-than-average vapour pressure deficits meaning that they have to adopt a more conservative water use strategy; with the higher $\varrho_{\mathrm{w}}$ and $\varrho_{\mathrm{x}}$ of such trees then being consistent with our understanding of current linkages between wood density and drought tolerance (Meinzer et al., 2009; Markesteijn et al., 2011). A similar explanation would also apply to the increase in $\varrho_{\mathrm{w}}$ with decreasing dry season precipitation as inferred by the SEVM-01 and SEVM02 models.

Finally we note that, unlike the other parameters here, our values of stand-level $\varrho_{\mathrm{w}}$ do not reflect direct measurements, but rather represent estimates based on a fixed value for each species based on literature reviews (Baker et al., 2004a; Chave et al., 2009). Although such an approach takes into account the strong phylogenetic associations underlying many of the observed variations in $\varrho_{\mathrm{w}}$ (Baker et al., 2004a; Swenson and Enquist, 2007), where the same species has been systematically examined across a range of sites it is also clear that soils and/or climate can in some circumstances significantly modulate $\varrho_{\mathrm{w}}$ (Omolodun et al., 1991; Hernández and Restrepo, 1995; Gonzalez and Fisher, 1998; Weber and Montes, 2008), a phenomenon that may be even more marked for $\varrho_{\mathrm{x}}$ (Patiño et al., 2009; 2012). Our approach has not taken this potential variation into account and this has almost certainly served to make the simulated spatial autocorrelation between sites greater than what it actually is. This effect should also flow on to the biomass calculations and must, at least in part, account for the unexpectedly high proportion of the variance for both $\varrho_{\mathrm{w}}$ and $B$ shared between the environmental/edaphic and spatial components (Fig. 15).

\subsection{Above-ground biomass}

Variations in forest biomass across the Amazon Basin were negatively correlated with many individual soil chemical and physical properties and it was therefore surprising that the minimum AIC model selected using the OLS criterion (Table 8 ) actually involved a positive effect for total soil phos- phorus. Moreover, this association with $[\mathrm{P}]_{\mathrm{t}}$ was with a relatively high standardised coefficient $(\beta=0.35)$ and a reasonably high level of significance $(p<0.021)$. If we trust the OLS results, this positive effect of a more eutric soil status in increasing stand biomass is, however, moderated by a negative effect of exchangeable potassium $(\beta=-0.43$; $p<$ 0.021 ) and with stand biomasses further reduced by adverse soil conditions (as evidenced by estimates of $\beta=0.45$ and $p<0.005$ for $\Pi_{2}$ : Sect. 3.6). The significance of these three contrasting soil variables was generally retained through the SEVM-03 procedure, but their role in affecting Amazon forest biomass disappeared when the more influential SEVM-01 or SEVM-02 filters were included. Although such a difference could be taken to simply mean that there is a large-scale endogenous structuring of $B$ that somehow overlaps with these soil variables (as well as $P_{\mathrm{D}}$ ) and that the OLS/SEVM03 results should simply be dismissed, there are two important issues that mitigate against a hasty dismissal of these OLS/SEVM-03 predictors.

First, the real problem is that although the proportion of variation attributed to the selected predictors is reasonable $\left(R^{2}=0.37\right)$, almost all of it is shared with the spatial component (Fig. 15), and thus the strong effect of the pre-selected filters in SEVM-01 and SEVM-02 in reducing the significance of the environmental predictors is all but inevitable. What needs to be considered then, is whether, in addition to the flow-on effect from the means of estimating $\varrho_{\mathrm{w}}$ mentioned above, it is possible that the strong endogenous patterning observed in $B$ might be attributable to some manifestation of the defining variables themselves.

Second, it is unlikely to be a coincidence that the selected model predictors are exactly what would be expected on the basis of those selected for the wood productivity and turnover models. Here we note that the steady state biomass of a stand should be related to both the rate at which new dry matter enters the above-ground carbon pool (i.e. $W_{\mathrm{P}}$ ) and the time it stays there; that is to say the mean residence time, $\tau$ (Lloyd and Farquhar, 1996). The latter should be related to $1 / \varphi$, but not exactly equal to it, unless trees of all size classes have the same probability of dying (Lloyd, 1999) which although not always the case (Muller-Landau et al. 2006) does seem to more or less hold for Amazon forest stands, especially in the higher turnover western portion of the Basin (Galbraith et al., 2012). Although not strictly linear in a mathematical sense, it can therefore be predicted that factors associated with $W_{\mathrm{P}}$, such as $[\mathrm{P}]_{\mathrm{t}}$ and $[\mathrm{K}]_{\mathrm{E}}$, should also predict $B$ and with their standardised coefficients of the same sign as for $W_{\mathrm{P}}$. Likewise, environmental variables associated with $\varphi$ such as $\Pi_{2}$ should also emerge as the selected predictors for $B$, but with the opposite sign as observed for their relationship with tree turnover rates. And this is exactly what the lowest AIC OLS model for biomass predicts, also with $P_{\mathrm{D}}$ positively associated with $B$ (as would also be expected from the $W_{\mathrm{P}}$ and $\varphi$ component model parameterisations). 


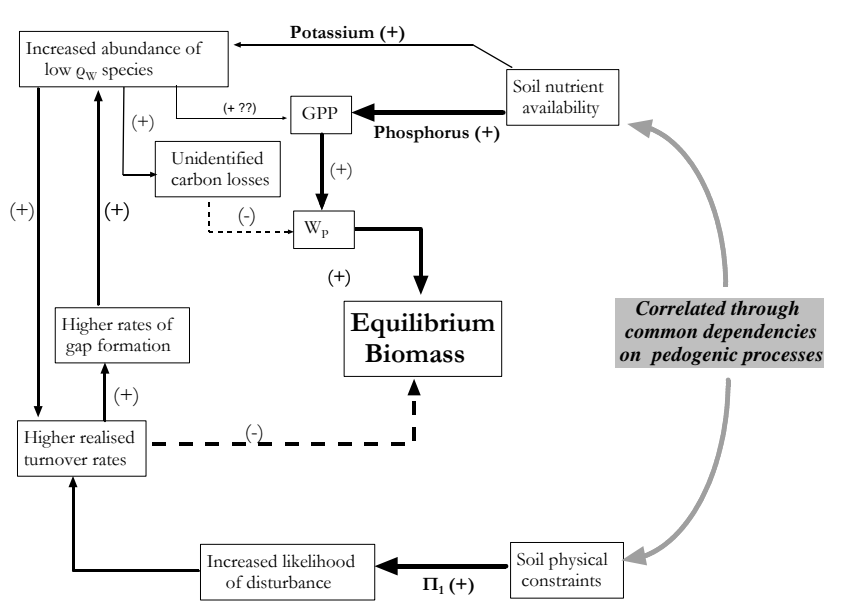

Fig. 16. Differential effects of soil nutrients and adverse soil physical conditions (as quantified through the empirical index $\Pi_{1}$ ) on above-ground coarse wood productivity $\left(W_{\mathrm{P}}\right)$ turnover rates and wood density $\left(\varrho_{\mathrm{w}}\right)$. GPP $=$ Gross Primary Productivity: the annual rate of carbon gain by the stand through photosynthesis.

It might therefore be concluded that the results of the OLS/SEVM-03 results are indeed reasonable and the apparent lack of any strong correlation between $B$ and any single variable is due to the interacting effects of soil nutrient status and soil physical conditions as is shown in Fig. 16. Here, rather than supposing there is some intrinsic property (or combination of properties) of fast-growing stands that results in their necessarily having a faster turnover rate (Stephenson et al., 2011), we see the tendency of turnover rates and growth rates to be correlated as a consequence of the almost inevitable relationship between soil physical constraints and soil nutrient availability (Quesada et al., 2010). These two fundamental soil characteristics are thus seen as acting primarily on turnover rates and production rates respectively. Although naturally we do not exclude, for example, standlevel differences in growth/defence tradeoffs being modulated directly by soil fertility and with variations in these then affecting mortality rates. Another way in which soil fertility could affect stand turnover directly, is through mechanisms such as favouring the presence of intrinsically faster growing taxa which are likely also characterised by a shorter lifespan. Conversely, harsh soil physical conditions could influence forest growth rates through increased turnover rates $(\varphi)$, this then causing a change to the structure of the forest and with more available light interception in gaps than for more "stable" forests with tall, closed canopies. Such an effect is incorporated as part of the feedback loops which as discussed in Sect. 4.6 may also be critical in influencing the differences in stand-level species composition observed across the Basin (e.g., Honorio Coronado et al., 2009).
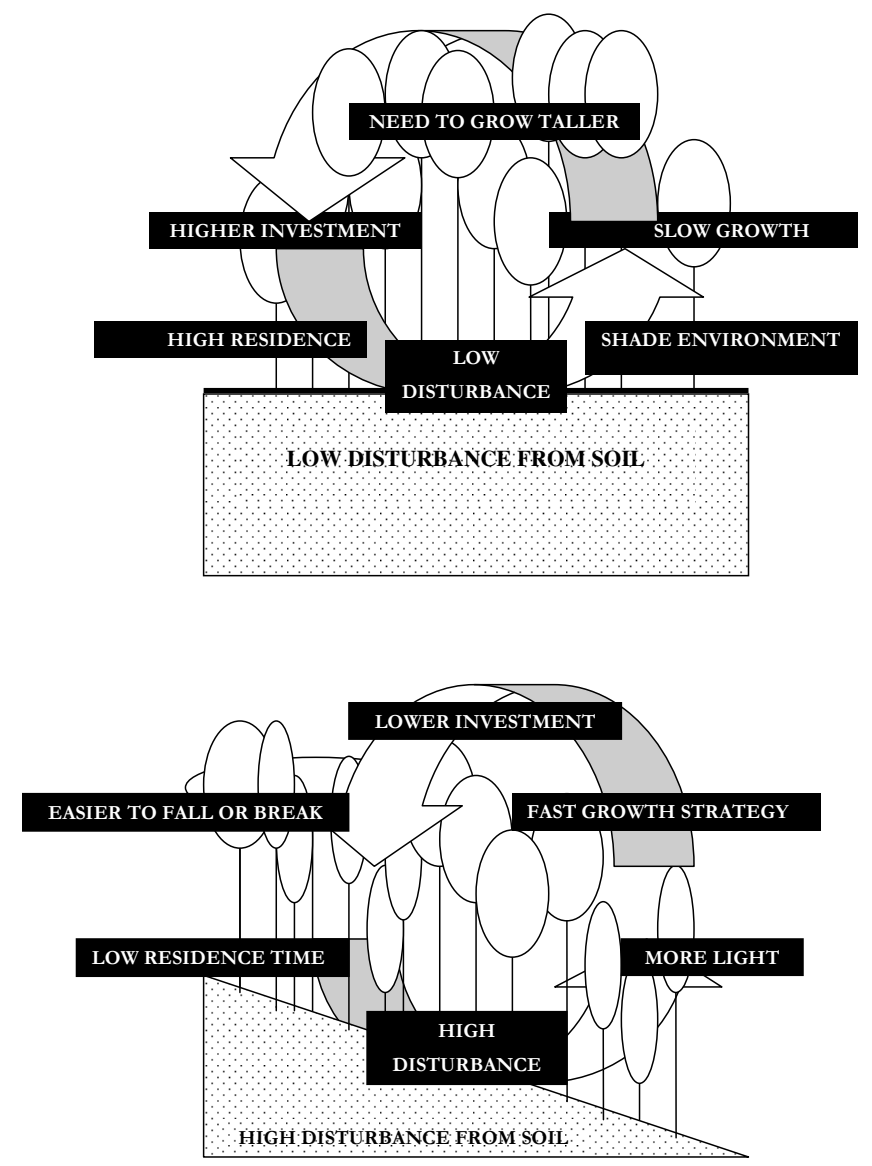

Fig. 17. Positive feedback mechanisms acting over floristic composition and tree turnover rates. In the top the interacting mechanisms tend to select for conservative growth strategies and structural investment, whilst in the bottom they tend to select for limited structural investment but a rapid completion of the life-cycle.

\subsection{Feedbacks affecting stand structure and composition}

Developing on the arguments presented in Sect. 4.5, Fig. 17 shows how soil physical and chemical conditions might take part in positive feedback mechanisms which would maintain the large-scale patterns of slow growth and long residence times in the eastern and central areas of the Amazon Basin (top) as well as a dominance of fast diameter growth/light demanding species in the western and southern parts (bottom).

The strong relationships between soil physical quality and turnover as well as its coincident pattern with $\varrho_{\mathrm{w}}$ are interpreted in this scheme to suggest that soil physical structure may be a key factor directing the mechanisms that regulate Amazon forest floristic composition, $\varrho_{\mathrm{w}}$ and stem turnover rates. Specifically, soil physical quality is proposed to initiate a positive feedback mechanism that maintains the spatial patterns of forest growth dynamics across the Amazon Basin. In other words, the absence of disturbance promoted by soil physical properties on generally older soils is intrinsically 
a key component in a self-maintaining system. Where low disturbance leads to shade environments, these together with a limited nutrient supply favour species with a slow growth strategy (in terms of both $G_{\mathrm{B}}$ and $W_{\mathrm{P}}$ ). This in turn increases investment in structures to support taller and bigger trees; this then increasing residence times, with reduced disturbance levels and so on. Low nutrient availability in soils also influence forest growth rates as clearly demonstrated here, with the opposite system often found in the western part of the Basin where high disturbance levels are initiated by soil physical constraints, thus increasing mortality rates, gap formation and higher light levels lower down inside the forest. Together with greater nutrient availability, this favours high diameter increment species with a lower investment in structures (low $\varrho_{\mathrm{w}}$ ) favoured. This then reduces mean tree lifetimes, increasing disturbance frequencies and so on.

Systematic differences in mode of death and associated gap formation characteristics, themselves related to soil physical properties, also support this idea of feedbacks controlling forest growth and dynamics at an Amazon Basin wide scale. For example, gaps from fragmentation of standing dead trees, more usual in sites with favourable physical conditions, are usually smaller and formed over a more extended period than gaps formed by uprooted and snapped trees (Chao et al., 2009). The latter are mostly found in association with poor soil physical conditions, these gaps being larger and with much higher disturbance levels (Gale and Barfod, 1999; Carey et al., 1994; Sugden et al., 1985). This is thought to favour low $\varrho_{\mathrm{w}}$ pioneer-type species (Gale and Hall, 2001) and maybe lianas as well (van der Heijden and Phillips, 2008). High liana infestation is itself in turn a strong predictor of tree mortality (Phillips et al., 2005), suggesting that liana-disturbance positive feedbacks could be a further significant stand-level process that tends to lock-in fast turnover behaviour in some tropical forests.

The effects of $\varrho_{\mathrm{w}}$ in affecting turnover rates can then be interpreted as being due to the interacting effects of environmental conditions and stand floristic composition. First, high $\varrho_{\mathrm{w}}$ species should obviously be favoured on soils of little disturbance as such trees are expected to have a higher investment in long-term structures resistant to mechanical and biotic damage to support taller and large and heavy canopies. For water transport in taller trees, stronger vessels walls may also be needed to cope with lower tensions. The residence time of such structures must naturally be higher and all those features clearly fit with having a good physical soil environment to grow in for a long period of time. On the other hand, low $\varrho_{\mathrm{w}}$ is argued to be part of the fast turnover strategy suggesting an adaptation to highly disturbed environments. In such forests, there is a need to rapidly complete one's lifecycle and generally higher fertility levels should fulfill nutrient requirements for fast growth despite the negative cation effects mentioned in Sect. 4.4. Overall, this results in low wood density species characterised by a lower level of invest- ment in woody structures and a lower residence time having a comparative advantage on such soils.

Forest floristic composition is, in turn, a key factor influencing turnover rates. Forests in the western part of the Basin are dominated by light demanding taxa while the central and eastern parts are dominated by slower growing, shadetolerant species (Phillips et al., 2004; Baker et al., 2004a). This implies that these forests have different "life cycles", with their species composition indirectly affected by soil physical conditions. One example of this process could be the maintenance of light-demanding taxa through favoured recruitment after disturbance events; such as those induced by a limited rooting depth and steep topography or other combinations of processes. This in turn would affect the turnover rates due to intrinsically higher mortality rates, resulting in a wave-like continuum driven both by soil and species composition (Phillips et al., 2004). Thus, soil physical limitations may short-circuit the successional process by promoting a continued pattern of high disturbance, with forest succession never proceeding towards a climax state unless dramatic changes in the landscape and species composition occur.

\section{Conclusions}

Despite the complications imposed by dealing with spatially autocorrelated data, we have found strong evidence for soil chemical and physical properties being the main factors causing variations in forest structure and dynamics across the Amazon Basin. Our results point to total soil phosphorus concentration as the single most important factor directly influencing wood production rates but with a negative effect of soil exchangeable potassium. The latter is argued to emerge from a negative association between soil potassium and stand level wood density, which may in turn be associated with the abundance of low wood-density species being greater on soils with high exchangeable cation concentrations.

In addition, soil physical properties, indirectly correlated with soil fertility through common dependencies on pedogenic processes, directly influence forest disturbance levels. This effect ultimately determines tree turnover rates; with differences in stand level floristic composition and associated variations in stand-level wood density an inevitable consequence. Complex interactions also occur and are argued to propagate and interact, influencing forest structure through a series of positive feedback mechanisms. Otherwise enigmatic variations in stand-level biomass then become accountable in terms of different mixes of stem growth rates and turnover times, with the stand equilibrium biomass thus shaped through the combined effects of soil phosphorus status, soil physical properties and to a lesser extent, soil cation availability and climate.

Since soil chemical and physical properties are ultimately controlled by geology and geomorphology, spatial patterns 
in Amazon forest structure and dynamics can thus be considered to be primarily accountable through edaphic variations arising as a consequence of the diverse and complex geological history of the region.

\section{Supplementary material related to this article is available online at: http://www.biogeosciences.net/9/ 2203/2012/bg-9-2203-2012-supplement.pdf.}

Acknowledgements. We thank J. O. Moraes Filho, F. P. Carvalho, R. N. Araujo Filho, J. E. Chavez, O. F. Cruz Jr. , and T. P. Pimentel for their help during laboratory analysis at INPA, and I. Hilke, I. Kuhlmann, and M. Raessler for their help in the laboratory at the Max-Planck Institute for Biogeochemistry in Jena, Germany. Carlos A. Quesada was funded by a scholarship from the School of Geography, University of Leeds. The final stages of data analysis and manuscript preparation were funded by the Gordon and Betty Moore Foundation through the RAINFOR project (www.rainfor.org). Much of the soil sampling and many of the forest plot dynamics measurements were funded by the European Union Fifth Framework Programme through CARBONSINKLBA, which is part of the European contribution to the Large-Scale Biosphere/Atmosphere Experiment in Amazonia (LBA). Shiela Lloyd helped with manuscript and figure preparation. We also thank the Copernicus Office staff for their extreme patience in dealing with this manuscript over an extended period of time.

Edited by: J. Grace

\section{References}

Ackerley, D. D.: Canopy structure and dynamics; integration of growth processes in tropical pioneer trees, in: Tropical Forest Plant Physiology, edited by: Mulkey, S. S., Chazdon, R. I., and Smith, A. P., Chapman and Hall, London, 619-658, 1996.

Adepetu, J. A. and Corey, R. B.: Organic phosphorus as a predictor of plant-available phosphorus in soils of Southern Nigeria, Soil Sci., 122, 159-164, 1976.

Alexander, I.: Mycorrhizas in tropical forests, in: Mineral nutrients in tropical forests and savanna ecosystems, Blackwell, Oxford, 1989.

Angiosperm Phylogeny Group: An ordinal classification for the families of flowering plants, Ann. Missouri Bot. Gard., 85, 53153, 1998.

Anhuf, D., Ledru, M. P., Behling, H., Da Cruz, F. W., Cordeiro, R. C., Van Der Hammen, T., Karmann, I., Marengo, J. A., De Oliveira, P. E., Pessenda, L., Siffedine, A., Albuquerque, A. L., and Dias, P. L. D.: Paleo-environmental change in Amazonian and African rainforest during the LGM, Palaeogeogr. Palaeocl., 239, 510-527, 2006.

Anten, N. P. R. and Schieving, F.: The role of wood mass density and mechanical constraints in the economy of tree architecture, The Amer. Nat., 175, 250-260, 2010.
Anten, N. P. R. and During, H. J.: Is analysing the nitrogen use at the plant canopy level a matter of choosing the right optimization criterion?, Oecologia, 167, 293-303, 2011.

Aragão, L. E. O. C., Malhi, Y., Metcalfe, D. B., Silva-Espejo, J. E., Jiménez, E., Navarrete, D., Almeida, S., Costa, A. C. L., Salinas, N., Phillips, O. L., Anderson, L. O., Alvarez, E., Baker, T. R., Goncalvez, P. H., Huamán-Ovalle, J., Mamani-Solórzano, M., Meir, P., Monteagudo, A., Patiño, S., Peñuela, M. C., Prieto, A., Quesada, C. A., Rozas-Dávila, A., Rudas, A., Silva Jr., J. A., and Vásquez, R.: Above- and below-ground net primary productivity across ten Amazonian forests on contrasting soils, Biogeosciences, 6, 2759-2778, doi:10.5194/bg-6-2759-2009, 2009.

Arshad, M. A., Lowery, B., and Grossman, B.: Physical tests for monitoring soil quality, in: Methods for Assessing Soil Quality, edited by: Doran, J. W. and Jones, A. J., Soil Science Society of America, Madison, SSSA Special Publication, 49, 123-141, 1996.

Ashton, P. S.: Crown characteristics of tropical trees, in: Tropical Trees as Living systems, edited by: Tommlinson, P. B. and Zimmermann, M. H., Cambridge University Press, Cambridge, 591615, 1978.

Baker, T. R., Phillips, O. L., Malhi, Y., Almeida, S., Arroyo, L., Di Fiore, A., Erwin, T., Killeen, T. J., Laurance, S. G., Laurance, W. G., Lewis, S., Lloyd, J., Monteagudo, A., Neill, D. A., Patiño, S., Pitman, N. C. A., Silva, J. M. N., and Martínes, R. V.: Variation in wood density determines spatial patterns in Amazonian forest biomass, Glob. Change Biol., 10, 545-562, 2004a.

Baker, T. R., Phillips, O. L., Malhi, Y., Almeida, S., Di Fiori, A., Erwin, T., Higuchi, N., Killeen, T. J., Laurance, S. G., Laurance, W. F., Lewis, S. L., Monteagudo, A., Neil, D. A., Vargas, P. N., Pitman, N. C. A., Silva, J. N. M., and Martínez, R. V.: Increasing biomass in Amazonian forest plots, Philos. T. Roy. Soc. B, 359, 353-365, 2004b.

Baker, T. R., Phillips, O. L., Laurance, W. F., Pitman, N. C. A., Almeida, S., Arroyo, L., DiFiore, A., Erwin, T., Higuchi, N., Killeen, T. J., Laurance, S. G., Nascimento, H., Monteagudo, A., Neill, D. A., Silva, J. N. M., Malhi, Y., López-González, G., Peacock, J., Quesada, C. A., Lewis, S. L., and Lloyd, J.: Do species traits determine patterns of wood production in Amazonian forests?, Biogeosciences, 6, 297-307, doi:10.5194/bg-6297-2009, 2009.

Baraloto, C., Rabaud, S., Molto, Q., Blanc, L., Fortunel1, C., Hérault, B., Dãvila, N., Mesones, I., Rios. M., Valderrama, E., and Fine, P. V. A.: Disentangling stand and environmental correlates of aboveground biomass in Amazonian forests, Glob. Change Biol., 17, 2677-2688, 2011.

Bazzaz, F. A.: Dynamics of wet tropical forests and their species strategies, in: Physiological Ecology of Plants in the Wet Tropics, edited by: Medina, E, Mooney, H. A., and Vaázquez-Yanes, C., Junk, The Hague, 233-243, 1984.

Bazzaz, F. A. and Pickett, S. T. A.: The physiological ecology of tropical succession: a comparative review, Ann. Rev. Ecol. System., 11, 287-310, 1980.

Bazzaz, F. A. and Reekie. E. G.: The meaning and measurement of reproductive effort in plants, in: Studies on Plant Demography: A Festschrift for John L. Harper, edited by: White, J., Academic Press, London, 373-387, 1985.

Beale, C. M., Lennon, J. J., Yearsley, J. M., Brewer, N. J., and Elston, D. A.: Regression analysis of spatial data, Ecol. Lett., 13, 
246-264, 2010

Bertrand, I., Hinsinger, P., Jaillard, B., and Arvieu, J. C.: Dynamics of phosphorus in the rhizosphere of maize and rape grown on synthetic, phosphated calcite and goethite, Plant Soil, 211, 111119, 1999.

Bini, L. M., Diniz, J. A. F., Rangel, T. F. L. V., Akre, T. S. B., Albaladejo, R. G., Albuquerque, F. S. Aparicio, A., Araújo, M. B., Baselga, A., Beck, J., Bellocq, I. M., Böhning-Gaese, K. Borges, P. A. V., Castro-Parga, I., Khen Chey, V., Chown, S. L., De Marco, Jr, P., Dobkin, D. S., Ferrer-Castin, D., Field, R., Filloy, J., Fleishman, E., Gómez, J. F., Hortal, J., Iverson, J. B., Kerr, J. T., Kissling, D. W., Kitching, I. J., León-Corés, Jorge L., Lobo, J. M., Montoya, D., Morales-Castilla, I., Moreno, J. C., Oberdorff, T., Olalla-Táarraga, M., Pausas, J. G., Qian, H., Rahbek, C., Rodriguez, M. Rueda, M., Ruggiero, A., Sackmann, P., Sanders, N. J., Terribile, L. C., Vetaas, O. R., and Hawkins, B. A.: Coefficient shifts in geographical ecology: an empirical evaluation of spatial and nonspatial regression, Ecography, 32, 193-204, 2009

Bochert, R. and Pockman, W. T.: Water storage and xylem function in isolated branches on temperate and tropical trees, Tree Physiol., 25, 457-466, 2005.

Borcard, D. and Legendre, P.: All-scale spatial analysis of ecological data by means of principal coordinates of neighbour matrices, Ecol. Model., 153, 51-68, 2002.

Butt, N., Malhi, Y., Phillips, O. L., and New, N.: Floristic and functional affiliations of woody plants with climate in western Amazonia, J. Biogeog., 35, 939-950, 2008.

Cannel, R. Q.: Effects of soil drainage on root growth and crop production, in: Soil Physical Properties and Crop Production in the Tropics, edited by: Lal, R. and Greenland, D. J., John Wiley and Sons, New York, 183-195, 1979.

Carey, E. V., Brown, S., Gillespie, A. J. R., and Lugo, A. E.: Tree mortality in mature lowland tropical moist and tropical lower montane moist forests of Venezuela, Biotropica, 26, 255-265, 1994.

Chambers, J. Q., Santos, J.D., Ribeiro, R. J., and Higuchi, N.: Tree damage, allometric relationships, and above-ground net primary production in central Amazon forest, Forest Ecol. Manag., 152, 73-84, 2001.

Chao, K. J., Phillips, O. L., Gloor, E., Monteagudo, A., TorresLezama, A., and Vásquez Martínez, R.: Growth and wood density predict tree mortality in Amazon forests, J. Ecol., 96, 281292, 2008

Chao, K. J., Phillips, O. L., Monteagudo, A., Torres-Lezama, A., and Vásquez Martínez, R.: How do trees die? Mode of death in northern Amazonia, J. Veg. Sci., 20, 260-268, 2009.

Chave, J., Riera, B., and Bubois, M.: Estimation of biomass in a Neotropical forest of French Guiana: spatial and temporal variability, J. Trop. Ecol., 17, 79-96, 2001.

Chave, J., Coomes, D., Jansen, S., Lewis, S. L., Swenson, N. G., and Zanne, E. R.: Towards a worldwide wood economic spectrum, Ecol. Lett., 12, 351-366, 2009.

Chave, J., Navarrete, D., Almeida, S., Álvarez, E., Aragão, L. E. O. C., Bonal, D., Châtelet, P., Silva-Espejo, J. E., Goret, J.-Y., von Hildebrand, P., Jiménez, E., Patiño, S., Peñuela, M. C., Phillips, O. L., Stevenson, P., and Malhi, Y.: Regional and seasonal patterns of litterfall in tropical South America, Biogeosciences, 7, 43-55, doi:10.5194/bg-7-43-2010, 2010.
Clark, D. A. and Clark, D. B.: Landscape scale variation in forest structure and biomass in a tropical forest, Forest Ecol. Manag., 14, 185-198, 2000.

Clark, D. B., Clark, D. A., and Oberbauer, S. F.: Annual wood production in a tropical rain forest in NE Costa Rica linked to climatic variation but not to increasing $\mathrm{CO}_{2}$, Glob. Change Biol., 16, 747-759, doi:10.1111/j.1365-2486.2009.02004.x, 2010.

Cleveland, C. C., Townsend, A. R., Taylor, P., Alvarez-Clare, S., Bustamante, M. M. C., Chuyong, G., Dobrowski, S. Z., Grierson, P., Harms, K. E., Houlton, B. Z., Marklein, A., Parton, W. J., Porder, S., Reed, S. C., Sierra, C. A., Silver, W. L., Tanner, E. V. J., and Weider, W. R.: Relationships among net primary productivity, nutrients and climate in tropical rain forest: a pantropical analysis, Ecol. Lett., 14, 939-947, doi:10.1111/j.14610248.2011.01658.x, 2011a.

Cleveland, C. C., Townsend, A. R., Taylor, P., Alvarez-Clare, S., Bustamante, M. M. C., Chuyong, G., Dobrowski, S. Z., Grierson, P., Harms, K. E., Houlton, B. Z., Marklein, A., Parton, W. J., Porder, S., Reed, S. C., Sierra, C. A., Silver, W. L., Tanner, E. V. J., and Weider, W. R.: Erratum to Relationships among net primary productivity, nutrients and climate in tropical rain forest: a pan-tropical analysis, Ecol. Lett., 14, 1313-1317, doi:10.1111/j.1461-0248.2011.01711.x, 2011b.

Costa, A. C. L., Galbraith, D., Almeida, S., Portela, B. T. T., da Costa, M., Silva Junior, J. D. A., Braga, A. P., de Goncalves, P. H. L., de Oliveira, A. A. R., Fisher, R., Phillips, O. L., Metcalfe, D. B., Levy, P., and Meir, P.: Effect of 7 years of experimental drought on vegetation dynamics and biomass storage of an eastern Amazonian rainforest, New Phytol., 187, 579-591, 2010.

Crews, T. E., Kitayama, K., Fownes, J. H., Riley, R. H., Herbert, D. A., Mueller-Dombois, D., and Vitousek, P. M.: Changes in soil phosphorus fractions and ecosystem dynamics across a long chronosequence in Hawaii, Ecology, 76, 1407-1424, 1995.

Cross, A. F. and Schlesinger, W. H.: A literature review and evaluation of the Hedley fractionation: Applications to the biogeochemical cycle of soil phosphorus in natural ecosystems, Geoderma, 64, 197-214, 1995.

Cuevas, E. and Medina, E.: Nutrient dynamics within Amazonian forest ecosystems, Oecologia, 68, 466-472, 1986.

Dedecek, R. A., Bellote, A. F. J., Gava, J. L., and Menegol, O.: Site characterisation and the effects of harvesting on soil tillage on the productivity of Eucalyptus grandis plantations in Brazil, in: Rehabilitation of Degraded Tropical Forest Ecosystems: Workshop Proceedings, 2-4 November 1999, Bogor, Indonesia, edited by: Kobayashi, S., Turnbull, J. W., Toma, T., Mori, T., and Majid, N. M. N. A., 157-164, CIFOR, Bogor, Indonesia, 2001.

Davies, S. J. and Ashton, P. S.: Phenology and fecundity in 11 sympatric pioneer species of Macaranga (Euphorbiaceae) in Borneo, Am. J. Bot., 86, 1786-1795, 1999.

Dayton, C. M.: Model comparisons using information measures, J. Mod. Appl. Stat. Meth., 2, 281-292, 2003.

DeWalt, S. J. and Chave, J.: Structure and biomass of four lowland Neotropical forests, Biotropica, 36, 7-19, 2004.

Dietrich, W. E., Windsor, D. M., and Dunne, T.: Geology, climate and hydrology of Barro Colorado Island, in: The Ecology of a Tropical Rain Forest: Seasonal Rhythms and Long Term Changes, 2nd Edn., edited by: Leigh, E. G., Rand, A. S., and Windsor, D. M., Smithsonian Institution Press, Washington DC, 101-108, 1996. 
Diniz-Filho, J. A. F. and Bini, L. M.: Modelling geographical patterns in species richness using eigenvector-based spatial filters, Global Ecol. Biogeogr., 14, 177-185, 2005.

Diniz-Filho, J. A. F. Bini, L. M., and Hawkins. B. A: Spatial autocorrelation and red herrings in geographical ecology, Glob. Ecol. Biogeog., 12, 53-64, 2003.

Diniz-Filho, J. A. F., Rangel, T. F. L. V. B., and Bini, L. M.: Model selection and information theory in geographical ecology, Glob. Ecol. Biogeog., 17, 479-488, 2008.

Domingues, T. F., Meir, P., Feldpausch, T. R., Saiz, G., Veenendaal, E. M., Schrodt, F., Bird, M., Djagbletey, G., Hien, F., Compaore, H., Diallo, A., Grace, J., and Lloyd, J.: Co-limitation of photosynthetic capacity by nitrogen and phosphorus in West Africa woodlands, Plant Cell Environ., 33, 959-980, 2010.

Dutilleul, P.: Spatial heterogeneity and the design of ecological field experiments, Ecology, 74, 1646-1658, 1993.

Eschenbach, C., Glauner, R., Kleine, M., and Kappen, L.: Photosynthesis rates of selected tree species in lowland dipterocarp rainforest in Sabah, Malaysia, Trees, 12, 356-365, 1998.

Feeley, K. J., Wright, S. J., Supardi, M. N. N., Kassim, A. R., and Davies, S. J.: Decelerating growth in tropical forest trees, Ecol. Lett., 10, 1-9, doi:10.1111/j.1461-0248.2007.01033.x, 2007.

Feldpausch, T. R., Banin, L., Phillips, O. L., Baker, T. R., Lewis, S. L., Quesada, C. A., Affum-Baffoe, K., Arets, E. J. M. M., Berry, N. J., Bird, M., Brondizio, E. S., de Camargo, P., Chave, J., Djagbletey, G., Domingues, T. F., Drescher, M., Fearnside, P. M., França, M. B., Fyllas, N. M., López-González, G., Hladik, A., Higuchi, N., Hunter, M. O., Iida, Y., Salim, K. A., Kassim, A. R., Keller, M., Kemp, J., King, D. A., Lovett, J. C., Marimon, B. S., Marimon-Junior, B. H., Lenza, E., Marshall, A. R., Metcalfe, D. J., Mitchard, E. T. A., Moran, E. F., Nelson, B. W., Nilus, R., Nogueira, E. M., Palace, M., Patiño, S., Peh, K. S.H., Raventos, M. T., Reitsma, J. M., Saiz, G., Schrodt, F., Sonké, B., Taedoumg, H. E., Tan, S., White, L., Wöll, H., and Lloyd, J.: Height-diameter allometry of tropical forest trees, Biogeosciences, 8, 1081-1106, doi:10.5194/bg-8-1081-2011, 2011.

Ferry, B., Morneau, F., Bontemps, J.-D., Blanc, L., and Freycon, V.: Higher treefall rates on slopes and waterlogged soils result in lower stand biomass and productivity in a tropical rain forest, $\mathrm{J}$. Ecol., 98, 106-116, 2010.

Fine, P. V. A., Daly, D. C., Munõz, G. V., Mesones, I., and Cameron, K. M.: The contribution of edaphic heterogeneity to the evolution and diversity of Burseraceae trees in the western Amazon, Evolution, 59, 1464-1478, 2005.

Fromm, J.: Wood formation in trees in relation to potassium and calcium nutrition, Tree Physiol., 30, 1140-1147, 2010.

Frossard, E., Condron, L. M., Oberson, A., Sinaj, S., and Fardeau, J. C.: Processes governing phosphorus availability in temperate soils, J. Environ. Qual., 29, 15-23, 2000.

Fyllas, N. M., Patiño, S., Baker, T. R., Bielefeld Nardoto, G., Martinelli, L. A., Quesada, C. A., Paiva, R., Schwarz, M., Horna, V., Mercado, L. M., Santos, A., Arroyo, L., Jiménez, E. M., Luizzão, F. J., Neill, D. A., Silva, N., Prieto, A., Rudas, A., Silviera, M., Vieira, I. C. G., López-González, G., Malhi, Y., Phillips, O. L., and Lloyd, J.: Basin-wide variations in foliar properties of Amazonian forest: phylogeny, soils and climate, Biogeosciences, 6 , 2677-2708, doi:10.5194/bg-6-2677-2009, 2009.

Fyllas, N. M., Lloyd, J., and Quesada, C. A.: Deriving plant functional types for Amazonian forests for use in vegetation dynam- ics models, Persp. Plant Ecol. Evol. System., 14, 97-100, 2012.

Gahoonia, T. S., Claassen, N., and Jungk, A.: Mobilization of residual phosphate of different phosphate fertilizers in relation to $\mathrm{pH}$ in the rhizosphere of ryegrass, Nutr. Cycl. Agroecosys., 33, 229 237, 1992.

Galbraith, D., Malhi, Y., Castanho, A. D. A., Quesada, C. A., Doughty, C., Peh, K. S.-H., Affum-Baffoe, K., Lewis, S. L., Sonké, B., Phillips. O. L., Lloyd, J., and Fisher, R. A.: The residence time of woody biomass in tropical forests, Plant Ecol. Divers., submitted, 2012.

Gale, N.: The relationship between canopy gaps and topography in a western Ecuadorian rain forest, Biotropica, 32, 653-661, 2000.

Gale, N. and Barford, A. S.: Canopy tree mode of death in western Ecuadorian forests, J. Trop. Ecol., 15, 415-436, 1999.

Gale, N. and Hall, P.: Factors determining the mode of tree death in three Bornean rain forests, J. Veg. Sci., 12, 337-346, 2001.

Gee, G. W. and Bauder, J. W.: Particle-size analysis, in: Methods in Soil Analysis. Part 1. Physical and Mineralogical Methods, edited by: Klute, A., American Society of Agronomy and Soil Science Society of America, Madison, Wisconsin, USA, 383409, 1986.

Gentry, A. H. and Emmons, L. H.: Geographical variation in fertility, phenology, and composition of the understory of Neotropical forest, Biotropica, 19, 216-227, 1987.

Gonzalez, E. and Fisher, R. F.: Variation in selected wood properties of Vochysia guatemalensis from four sites in Costa Rica, Forest Sci., 44, 185-191, 1998.

Grace, J. B and Bollen, K. A.: Interpreting the results from multiple regression and structural equation models, Bull. Ecol. Soc. Amer., 86, 283-294, 2005.

Griffith, D. A. and Peres-Neto, P. R.: Spatial modeling in ecology: the flexibility of eigenfunction spatial analyses, Ecology, 87, 2603-2613, 2006.

Guo, F. and Yost, R. S.: Partitioning soil phosphorus into three discrete pools of differing availability, Soil Sci., 163, 822-833, 1998.

Hammond, D. S.: Guianan forest dynamics: geomorphological control and tropical forest change across diverging landscapes, in: Tropical Forests of the Guiana Shield: Ancient Forests in a Modern World, edited by: Hammond, D. S., CABI Publishing, Wallingford, UK, 343-379, 2005.

Hardin, G.: The tragedy of the commons, Science, 162, 1243-1248, 1968.

Hart, M. R. and Cornish, P.: Comparison of bicarbonate-extractable soil phosphorus measured by ICP-AES and colourimetry in soils of south-eastern New South Wales, Aust. J. Soil Res., 47, 742746, 2009.

Hawkins, B. A., Diniz, J. A. F., Bini, L. M., De Marco, P., and Blackburn, T. M.: Red herrings revisited: spatial autocorrelation and parameter estimation in geographical ecology, Ecography, 30, 375-384, 2007.

Hedley, M. J., Stewart, J. W. B., and Chauhan, B. S.: Changes in inorganic and organic soil phosphorus fractions induced by cultivation practices and by laboratory incubations, Soil Sci. Soc. Am. J., 46, 970-976, 1982.

Hedley, M. J., Kirk, G. J. R., and Santos, M. B.: Phosphorus efficiency and the forms of soil phosphorus utilized by upland rice cultivars, Plant Soil, 158, 53-62, 1994. 
Herbert, D. A. and Fownes, J. H.: P limitation on forest leaf area and net primary productivity on highly weathered tropical montane soils in Hawaii, Biogeochemistry, 29, 223-235, 1995.

Hernández, R. A. and Restrepo, G.: Natural variation in wood properties of Alnus acuminata grown in Colombia, Wood Fiber Sci., 27, 41-48, 1995.

Herrera, R., Jordan, C. F., Klinge, H., and Medina, E.: Amazon ecosystems: Their structure and functioning with particular emphasis on nutrients, Interciencia, 3, 223-232, 1978.

Higgins, M. A., Ruokolainen, K., Tuomisto, H., Llerena, N., Cardenas, G., Phillips, O. L., Vásquez, R., and Räsänen, M.: Geological control of floristic composition in Amazonian forests, J. Biogeog., 38, 2136-2149, 2011.

Hingsinger, P.: Bioavailability of soil inorganic P in the rhizosphere as affected by root-induced chemical changes: a review, Plant Soil, 237, 173-195, 2001.

Hinsinger, P. and Gilkes, R. J.: Mobilization of phosphate from phosphate rock and alumina-sorbed phosphate by the roots of ryegrass and clover as related to rhizosphere $\mathrm{pH}$, Eur. J. Soil Sci., 47, 533-544, 1996.

Hirai, K., Ferraz, J. B. S., Kobayashi, M., Ferreira, S. J. F., Sales, P. C., Lopes, M. C., and Hotta, I.: Physical properties of the soils under degraded areas in the Central Amazon, in: Projecto Jacaranda Fase II: Pesquisas Florestais na Amazonia Central, CPST-INPA, Manaus, Brazil, 153-167, 2003.

Hodnett, M. G. and Tomasella, J.: Marked differences between Van Genuchten soil-water retention parameters for temperate and tropical soils: A new water-retention pedo-transfer functions developed for tropical soils, Geoderma, 108, 155-180, 2002.

Holbrook, N. M.: Stem water storage, in: Plant Stems: Physiology and Functional Morphology, edited by: Gartner, B. L., Academic Press, San Diego, 151-174, 1995.

Holbrook, N. M., Whitbeck, J. L., and Mooney, H. A.: Drought responses of Neotropical deciduous forest trees, in: Tropical Deciduous Forests, edited by: Mooney, H. A., Medina, E., and Bullock, S. H., Canbridge Univerisity Press, Cambridge, UK, 243276, 1995.

Honorio Coronado, E. N., Baker, T. R., Phillips, O. L., Pitman, N. C. A., Pennington, R. T., Vásquez Martínez, R., Monteagudo, A., Mogollón, H., Dávila Cardozo, N., Ríos, M., García-Villacorta, R., Valderrama, E., Ahuite, M., Huamantupa, I., Neill, D. A., Laurance, W. F., Nascimento, H. E. M., Soares de Almeida, S., Killeen, T. J., Arroyo, L., Núñez, P., and Freitas Alvarado, L.: Multi-scale comparisons of tree composition in Amazonian terra firme forests, Biogeosciences, 6, 2719-2731, doi:10.5194/bg-62719-2009, 2009.

Hurlbert, S. H.: Pseudoreplication and the design of ecological field experiments, Ecol. Monogr., 54, 187-211, 1984.

Irion, G.: Soil infertility in the Amazonian rain forest, Naturwissenschaften, 65, 515-519, 1978.

Joly, C. A.: Flooding tolerance in tropical trees, in: Plant Life Under Oxygen Deprivation, edited by: Jackson, M. B., Davies, D. D., and Lambers, H., SPB Academic, The Hague, 23-34, 1991.

Johnson, A. H., Frizano, J., and Vann, D. R.: Biogeochemical implications of labile phosphorus in forest soils determined by the Hedley fractionation procedure, Oecologia, 135, 487-499, 2003.

Keeling, H. C., Baker, T. R., Vasquez Martinez, R., Monteagudo A., and Phillips, O. L.: Contrasting patterns of diameter and biomass increment across tree functional groups in Amazonian forests,
Oecologia, 158, 521-534, 2008.

Kitajima, K.: Relative importance of photosynthetic traits and allocation patterns as correlates of seedling shade tolerance of 13 tropical trees, Oecologia, 98, 419-428, 1994.

Kitajima, K., Mulkey, S. S., and Wright, S. J.: Variation in crown light utilization characteristics among tropical canopy trees, Ann. Bot-London, 95, 535-547, 2005.

Kitayama, K., Majalap-Lee, N., and Aiba, S.-I.: Soil phosphorus fractionation and phosphorus-use efficiencies of tropical rain forests along altitudinal gradients of Mount Kinabalu, Borneo, Oecologia, 123, 342-349, 2000.

Kitayama, K., Aiba, S.-I., Takyu, M., Majalap, N., and Wagai, R.: Soil phosphorus fractionation and phosphorus-use efficiency of a Bornean tropical montane rain forest during soil aging with podzolization, Ecosystems, 7, 259-274, 2004.

Korning, J., Thomsen, K., Dalsgaard, K., and Nornberg, P.: Characters of three Udults and their relevance to the composition and structure of virgin rain forest of Amazonian Ecuador, Geoderma, 63, 145-164, 1994.

Larjavaara, M. and Muller-Landau, H. C.: Rethinking the value of high wood density, Funct. Ecol., 24, 701-705, 2010.

Laurance, W. F., Fearnside, P. M., Laurance, S. G., Delamônica, P., Lovejoy, T., Merona, J. R., Chambers, J. Q., and Gascon, C.: Relationship between soils and Amazon forest biomass: a landscape study, Forest Ecol. Manag., 118 127-138, 1999.

Legendre, P.: Spatial autocorrelation: trouble or new paradigm?, Ecology, 74, 1659-1673, 1993.

Legendre, P. and Legendre, L.: Numerical Ecology, 2nd Edn., Elsevier, Amsterdam, 1998.

Leigh, R. A. and Wyn Jones, R. G.: A hypothesis relating critical potassium concentrations for growth to the distribution and function of this ion in the plant cell, New Phytol., 97, 1-13, 1984.

Lennon, J. J.: Red-shifts and red herrings in geographical ecology, Ecography, 23, 101-113, 2000.

Lewis, S. L., Phillips, O. L., Baker, T. R., Lloyd, J., Malhi, Y., Almeida, S., Higuchi, N., Laurance, W. F., Neill, D., Silva, N., Terborgh, J., Torres-Lezama, A., Brown, S., Chave, J., Kuebler, C., Nunez, P., Vasquez, M. R., and Vinceti, B.: Concerted changes in tropical forest structure and dynamics: evidence from 50 South American long-term plots, Philos. T. Roy. Soc. B., 359, 421-436, 2004a.

Lewis, S. L., Phillips, O. L., Sheil, D., Vinceti, B., Baker, T. R., Brown, S., Graham, A. W., Higuchi, N., Hilbert, D. W., Laurance, W. F., Lejoly, J., Malhi, Y., Monteagudo, A., Nunez, P., Sonke, B., Nur Supardi, M. N., Terborgh, J. W., and Vasquez, M. R.: Tropical forest tree mortality, recruitment and turnover rates: calculation, interpretation, and comparison when census intervals vary, J. Ecol., 92, 929-944, 2004b.

Lieberman, D. and Lieberman, M.: Forest tree growth and dynamics at La Selva, Costa Rica (1969-1982), J. Trop. Ecol., 3, 347-369, 1987.

Lloyd, J.: The $\mathrm{CO}_{2}$ dependence of photosynthesis, plant growth responses to elevated $\mathrm{CO}_{2}$ concentrations and their interaction with soil nutrient status, II. Temperate and boreal forest productivity and the combined effects of increasing $\mathrm{CO}_{2}$ concentrations and increased nitrogen deposition at a global scale, Funct. Ecol., 13, 439-459, 1999.

Lloyd, J. and Farquhar, G. D.: The $\mathrm{CO}_{2}$ dependence of photosynthesis, plant growth responses to elevated atmospheric $\mathrm{CO}_{2}$ concen- 
trations and their interaction with soil nutrient status. I. General principles and forest ecosystems, Funct. Ecol., 10, 4-32, 1996.

Lloyd, J. and Farquhar, G. D.: Effects of rising temperatures and $\left[\mathrm{CO}_{2}\right]$ on the physiology of tropical forest trees, Phil. Trans. Roy. Soc., 363, 1811-1817, 2008.

Lloyd, J., Bird, M. I., Veenendaal, E. M., and Kruijt, B.: Should phosphorus availability be constraining moist tropical forest responses to increasing $\mathrm{CO}_{2}$ concentrations? In: Global Biogeochemical Cycles in the Climate System, edited by Schulze, E., Heimann, M., Harrison, S., Holland, E., Lloyd, J., Prentice, I. C., and Schimel, D., Academic Press, San Diego, 95-114, 2001.

Lloyd, J., Patiño, S., Paiva, R. Q., Nardoto, G. B., Quesada, C. A., Santos, A. J. B., Baker, T. R., Brand, W. A., Hilke, I., Gielmann, H., Raessler, M., Luizão, F. J., Martinelli, L. A., and Mercado, L. M.: Optimisation of photosynthetic carbon gain and within-canopy gradients of associated foliar traits for Amazon forest trees, Biogeosciences, 7, 1833-1859, doi:10.5194/bg-71833-2010, 2010.

López-González, G., Lewis, S. L., Burkitt, M., and Phillips, O. L.: ForestPlots.net: a web application and research tool to manage and analyse tropical forest plot data, J. Veg. Sci., 22, 610-613, 2011.

Magid, J., Tiessen, H., and Condron, L. M.: Dynamics of organic phosphorus in soils under natural and agricultural ecosystems, in: Humic Substances in Terrestrial Ecosystems, edited by: Piccolo, H., Elsevier, Amsterdam, 429-466, 1996.

Malhi, Y. and Wright, J. A.: Spatial patterns and recent trends in the climate of tropical forest regions, Phil. T. Royal Soc. Lond., 359B, 311-329, 2004.

Malhi, Y., Baker, T., Phillips, O. L., Almeida, S., Alvarez, E., Arroyo, L., Chave, J., Czimczik, C., Di Fiore, A., Higuchi, N., Killeen, T., Laurance, S. G., Laurance, W. F., Lewis, S., Montoya, L. M. M., Monteagudo, A., Neill, D., Núñez Vargas, P., Panfil, S. N., Patiño, S., Pitman, N., Quesada, C. A., Salomão, R., Silva, N., Lezama, A. T., Vasquez Martínez, R., Terborgh, J., Vinceti, B., and Lloyd, J.: The above-ground coarse wood productivity of 104 Neotropical forest plots, Glob. Change Biol., 10, 1-29, 2004.

Malhi, Y., Wood, D., Baker, T. R., Wright, J., Phillips, O. L., Cochrane, T., Meir, P., Chave, J., Almeida, S., Arroyo, L., Higuchi, N., Killeen, T. J., Laurance, S. G., Laurance, W. F., Lewis, S. L., Monteagudo, A., Neill, D. A., Núñez Vargas, P., Pitman, N. C. A., Quesada, C. A., Salomão, R., Silva J. N. M., Torres Lezama, A., Terborgh, J., Vásquez Martínez, R., and Vinceti, B.: The regional variation of aboveground live biomass in oldgrowth Amazonian forests, Glob. Change Biol., 12, 1107-1138, 2006.

Markesteijn, L., Poorter, L., Frans Bongers, F., Paz, H., and Sack, L.: Hydraulics and life history of tropical dry forest tree species: coordination of species' drought and shade tolerance, New Phytol., 191, 480-495, 2011.

Mayle, F. E., Burbridge, R., and Killeen, T. J.: Millennial-scale dynamics of southern Amazonian rain forests, Science, 290, 22912294, 2000.

McCulloch, K. A., Meinzer, F. C., Sperry, J. S., Lachenbruch, B., Voelker, S. L., Woodruff, D. R., and Domec, J-C.: Comparative hydraulic architecture of tropical tree species representing a range of successional stages and wood density, Oecologia, 167, 27-37, 2011.
McGrath, D. A., Smith, C. K., Gholz, H. L., and Oliveira, F. A.: Effects of land-use change on soil nutrient dynamics in Amazonia, Ecosystems, 4, 625-645, 2001.

McDowell, N. G.: Mechanisms linking drought, hydraulics, carbon metabolism, and vegetation mortality, Plant Physiol., 155, 10511059, 2011.

Meinzer, F. C., James, S. A., Goldstein, G., and Woodruff, D.: Whole-tree water transport scales with sapwood capacitance in tropical forest canopy trees, Plant Cell Environ., 26, 1147-1155, 2003.

Meinzer, F. C., Johnson, D. M., Lachenbruch, B., McCulloh, K. A., and Woodruff, D. R.: Xylem hydraulic safety margins in woody plants: coordination of stomatal control of xylem tension with hydraulic capacitance, Funct. Ecol., 23, 922-930, 2009.

Meir, P. and Grace, J.: Scaling relationships for woody tissue respiration in two tropical rain forests, Plant Cell Environ, 25, 963 973, 2002.

Mercado, L. M., Patiño, S., Domingues, T. F., Fyllas, N. M., Weedon, G. P., Sitch, S., Quesada, C. A., Phillips, O. L., Aragão, L. E. O. C, Malhi, Y., Dolman, A. J., Restrepo-Coupe, N., Saleska, S. R., Baker, T.R., Almeida, S., Higuchi, N., and Lloyd, J.: Variations in Amazon forest productivity correlated with foliar nutrients and modelled rates of photosynthetic carbon supply, Phil Trans. R. Soc. B, 366, 3316-3329, 2011.

Miao, S., Carstenn, S., and Nungesser, M. K.: Real World Ecology: Large-Scale and Long-Term Case Studies and Method, Springer, New York, 2009.

Moles, A. T. and Westoby, M.: Seed size and plant strategy over the whole life cycle, Oikos, 11, 91-115, 2006.

Mosse, B., Hayman, D. S., and Arnold, D. J.: Plant growth responses to VA mycorrhizas, New Phytol., 72, 809-815, 1973.

Muchena F. N.: Use of soil physical characteristics, for land evaluation, in: Soil Physical Properties and Crop Production in the Tropics, edited by: Lal, R. and Greenland, D. J., John Wiley and Sons, Bath, UK, 427-437, 1979.

Muller-Landau, H. C., Condit, R. S., Chave, J., Thomas, S. C., Bohlman, S. A., Bunyavejchewin, S., Davies, S., Foster, R., Gunatilleke, S., Gunatilleke, N., Harms, K. E., Hart, T., Hubbell, S. P., Itoh, A., Kassim, A. R., LaFrankie, J. V., Lee, H. S., Losos, E., Makana, J-R., Ohkubo, T., Sukumar, R., Sun, I-F., Nur Supardi, M. N.,, Tan, S., Thompson, J., Valencia, R., Munoz, G. V., Wills, C., Yamakura, T., Chuyong, G., Dattaraja, H. S., Esufali, S., Hall, P., Hernandez, C., Kenfack, D., Kiratiprayoon, S., Suresh, H. S., Thomas, D., Vallejo, M. I., and Ashton, P.: Testing metabolic ecology theory for allometric scaling of tree size, growth and mortality in tropical forests, Ecol. Letts., 9, 575-588, doi:10.1111/j.1461-0248.2006.00904.x, 2006.

Nardoto, G. B., Quesada, C. A., Patiño, S., Baker, T. R., Schwarz, M., Schrodt, F., Feldpausch, T. R., Domingues, T. F., Marimon, B. S., Marimon Junior, B-H., Bird, M. I., Phillips, O.L., Lloyd, J., and Martinelli, L. A.: Nitrogen isotopes suggest soil fertility and climate as prime modulators of forest nitrogen cycling patterns across the Amazon Basin, Plant Ecol. Divers., submitted, 2012.

Nelson, D. W. and Sommers, L. E.: Total carbon and total nitrogen, in: Methods of Soil Analysis: Part 3 - Chemical Methods, edited by: Sparks, D. L., SSSA Book Series No 5, SSSA and ASA, Madison, WI, 961-1010, 1996.

New, M., Lister, D., Hulme, M., and Makin, I.: A high-resolution data set of surface climate over global land areas, Climate Res., 
$21,1-25,2002$.

Nogueira, A., Martinez, C. A., Ferreira, L. L. and Prado, C. H. B. A.: Photosynthesis and water use efficiency in twenty tropical tree species of differing succession status in a Brazilian reforestation, Photosynthetica, 42, 351-356, 2004.

Olalla-Tárraga, M. A., Diniz-Filho, J. A. F., Bastos, R. P., and Rodríguez, M. A.: Geographic body size gradients in tropical regions: Water deficit and anuran body size in the Brazilian Cerrado, Ecography, 32, 581-590, 2009.

Omolodun, O. O., Cutter, B. E., Krause, G. F., and McGinnes, E. A.: Wood quality in Hidegardia berteri (Mast.) Kossern - An African tropical pioneer species, Wood Fiber Sci., 23, 419-435, 1991.

Paoli, G. D. and Curran, L. M.: Soil nutrients limit fine litter production and tree growth in mature lowland forest of southwestern Borneo, Ecosystems, 10, 503-518, 2007.

Paoli, G. D., Curran, L. M., and Slik, J. W. F.: Soil nutrients affect spatial patterns of aboveground biomass and emergent tree density in southwestern Borneo, Oecologia, 155, 287-299, 2008.

Parolin, P., De Simone, O., Haase, K., Waldhoff, D., Rottenberger, S., Kuhn, U., Kesselmeier, J.. Kleiss, B.. Schmidt, W., Pledade, M., and Junk, W.: Central Amazonian floodplain forests: Tree adaptations in a pulsing system, Bot. Rev., 70, 357-380, 2004

Patiño, S., Lloyd, J., Paiva, R., Baker, T. R., Quesada, C. A., Mercado, L. M., Schmerler, J., Schwarz, M., Santos, A. J. B., Aguilar, A., Czimczik, C. I., Gallo, J., Horna, V., Hoyos, E. J., Jimenez, E. M., Palomino, W., Peacock, J., Peña-Cru, A., Sarmiento, C., Sota, A., Turriago, J. D., Villanueva, B., Vitzthum, P., Alvarez, E., Arroyo, L., Baraloto, C., Bonal, D., Chave, J., Costa, A. C. L., Herrera, R., Higuchi, N., Killeen, T., Leal, E., Luizão, F., Meir, P., Monteagudo, A., Neil, D., Núñez-Vargas, P., Peñuela, M. C., Pitman, N., Priante Filho, N., Prieto, A., Panfil, S. N., Rudas, A., Salomão, R., Silva, N., Silveira, M., Soares deAlmeida, S., Torres-Lezama, A., Vásquez-Martínez, R., Vieira, I., Malhi, Y., and Phillips, O. L.: Branch xylem density variations across the Amazon Basin, Biogeosciences, 6, 545-568, doi:10.5194/bg-6545-2009, 2009.

Patiño, S., Fyllas, N. M., Baker, T. R., Paiva, R., Quesada, C. A., Santos, A. J. B., Schwarz, M., ter Steege, H., Phillips, O. L., and Lloyd, J.: Coordination of physiological and structural traits in Amazon forest trees, Biogeosciences, 9, 775-801, doi:10.5194/bg-9-775-2012, 2012.

Peacock, J., Baker, T. R., Lewis, S. L., López-González, G., and Phillips, O. L.: The RAINFOR database: monitoring forest biomass and dynamics, J. Veg. Sci., 18, 535-542, 2007.

Pella, E.: Elemental organic analysis, Part 2, State of the art, Am. Lab., 22, 28-32, 1990.

Peres-Neto, P. R. and Legendre, P.: Estimating and controlling for spatial structure in the study of ecological communities, Global Ecol. Biogeog., 19, 174-184, 2010.

Peres-Neto, P. R., Legendre, P., Dray, S., and Borcard, D.: Variation of partitioning of species data matrices: Estimation and comparison of fractions, Ecology, 87, 2614-2625, 2006.

Phillips, O. L. and Gentry, A. H.: Increasing turnover through time in tropical forests, Science, 263, 954-958, 1994.

Phillips, O. L., Malhi, Y., Higuchi, N., Laurance, W. F., Nuñez, V. P., Vãsquez, M. R., Laurance, S. G., Ferriera, L. V., Stern, M., Brown, S., and Grace, J.: Changes in the carbon balance of tropical forest: evidence from long-term plots, Science, 282, 439-442,
1998.

Phillips, O. L., Núñez Vargas, P., Monteagudo, A. L., Cruz, A. P., Zans, M. E. C., Sañchez, W. G., Yli-Halla, M., and Rose, S. Habitat association among Amazonian tree species: a landscapescale approach, J. Ecol., 91, 757-775, 2003.

Phillips, O. L., Baker, T., Arroyo, L., Higuchi, N., Killeen, T., Laurance, W. F., Lewis, S. L., Lloyd, J., Malhi, Y., Monteagudo, A., Neill, D., Núñez Vargas, P., Silva, N., Terborgh, J., Vásquez Martínez, R., Alexiades, M., Almeida, S., Brown, S., Chave, J., Comiskey, J. A., Czimczik, C. I., Di Fiore, A., Erwin, T., Kuebler, C., Laurance, S. G., Nascimento, H. E. M., Olivier, J., Palacios, W., Patiño, S., Pitman, N., Quesada, C. A., Saldias, M., Torres Lezama, A., and Vinceti, B.: Patterns and process in Amazon tree turnover, 1976-2001, Philos. T. Roy. Soc. B., 359, 437-46, 2004.

Phillips, O. L., Martínez, R. V., Mendoza, A. M., Baker, T. R., and Núñez Vargas, P.: Large lianas as hyperdynamic elements of the tropical forest canopy, Ecology, 86, 1250-1258, 2005.

Phillips, O. L., Aragão, L. E., Lewis, S. L., Fisher, J. B., Lloyd, J., López-González, G., Malhi, Y., Monteagudo, A., Peacock, J., Quesada, C.A., van der Heijden, G., Almeida, S., Amaral, I., Arroyo, L., Aymard, G., Baker, T. R., Bánki, O., Blanc, L., Bonal, D., Brando, P., Chave, J., de Oliveira, A. C., Cardozo, N. D., Czimczik, C. I., Feldpausch, T. R., Freitas, M. A., Gloor, E., Higuchi, N., Jiménez, E., Lloyd, G., Meir, P., Mendoza, C., Morel, A., Neill, D. A., Nepstad, D., Patiño, S., Peñuela, M. C., Prieto, A., Ramrez, F., Schwarz, M., Silva, J., Silveira, M., Thomas, A. S., ter Steege, H., Stropp, J., Vásquez, R., Zelazowski, P., Alvarez Dávila, E., Andelman, S., Andrade, A., Chao, K. J., Erwin, T., Di Fiore, A., Honorio, C. E, Keeling, H., Killeen, T. J., Laurance, W. F., Peña Cruz, A., Pitman, N. C., Núñez Vargas, P., Ramírez-Angulo, H., Rudas, A., Salamão, R., Silva, N., Terborgh, J., and Torres-Lezama, A.: Drought sensitivity of the Amazon rainforest, Science, 323, 1344-1347, 2009.

Pleysier, J. L. and Juo, A. S. R.: A single-extraction method using silver-thiourea for measuring exchangeable cations and effective CEC in soils with variable charges, Soil Sci., 129, 205-211, 1980.

Poorter, L.: Growth responses of 15 rain-forest tree species to a light gradient: the relative importance of morphological and physiological traits, Funct. Ecol., 13, 396-410, 1999.

Poorter, L., McDonald, I., Alarcón, A., Fichtler, E., Licona, J.-C., Penã-Claros, M. M., Sterck, F., Villegas, Z., and Sass-Klaassen, U.: The importance of wood traits and hydraulic conductance for the performance and life history strategies of 42 rainforest tree species, New Phytol., 185, 481-492, 2010.

Posada, J. M., Lechowicz, M. J., and Kitajima, K.: Optimal photosynthetic use of light by tropical tree crowns achieved by adjustment of individual leaf angles and nitrogen content, Ann. Bot., 103, 795-805, 2009.

Proctor, J., Anderson, J. M., Chai, P., and Vallack, H. W.: Ecological studies in four contrasting lowland rain forests in Gunung Mulu National Park, Sarawak, J. Ecol., 71, 237-260, 1983.

Quesada, C. A., Lloyd, J., Schwarz, M., Patiño, S., Baker, T. R., Czimczik, C., Fyllas, N. M., Martinelli, L., Nardoto, G. B., Schmerler, J., Santos, A. J. B., Hodnett, M. G., Herrera, R., Luizão, F. J., Arneth, A., Lloyd, G., Dezzeo, N., Hilke, I., Kuhlmann, I., Raessler, M., Moraes Filho, J., Paiva, F., Araujo Filho, R., Chaves, E., Cruz, O. Junior, Pimentel, T. P., and Paiva, R.: Vari- 
ations in chemical and physical properties of Amazon forest soils in relation to their genesis, Biogeosciences, 7, 1515-1541, doi:10.5194/bg-7-1515-2010, 2010.

Quesada, C. A., Lloyd, J., Anderson, L. O., Fyllas, N. M., Schwarz, M., and Czimczik, C. I.: Soils of Amazonia with particular reference to the RAINFOR sites, Biogeosciences, 8, 1415-1440, doi:10.5194/bg-8-1415-2011, 2011.

Raaimakers, D., Boot, R. G. A., Dijkstra, P., and Pot, S.: Photosynthetic rates in relation to leaf phosphorus content in pioneer versus climax tropical rain forest trees, Oecologia, 102, 120-125, 1995.

Raich, J. W., Russel, A. E., Crews, T. E., Farrington, H., and Vitousek, P.: Both N and P limit plant production on young Hawaiian lava flows, Biogeochemistry, 32, 1-14, 1996.

Rangel, T. F., Diniz-Filho, J. A., and Bini, L. M.: Towards an integrated computational tool for spatial analysis in macroecology and biogeography, Global Ecol. Biogeogr., 15, 321-327, 2006.

Reich, P. B.: Key canopy traits drive forest productivity, Proc. Roy. Soc. Lond., 7, 2128-2134. 2012.

Reich, P. B., Ellsworth, D. S., and Uhl, C.: Leaf carbon and nutrient assimilation and conservation in species of different successional status in an oligotrophic Amazonian forest, Funct. Ecol., 9, 6576, 1995.

Reich, P. B., Christopher Uhl, C., Walters, M. B., Laura Prugh, L., and Ellsworth, D. S: Leaf demography and phenology in Amazonian rain forest: A census of 40,000 leaves of 23 tree species, Ecol. Mon. 74, 3-23, 2004.

Richards, S. A.: Testing ecological theory using the informationtheoretic approach: Examples and cautionary results, Ecology, 86, 2805-2814, 2005.

Richardson, J. E., Pennington, R. T., Pennington, T. D., and Hollingsworth, P. M.: Rapid diversification of a species- rich genus of Neotropical rain forest trees, Science, 293, 2242-2245, 2001

Riddoch, I., Grace, J., Fasehun, F. E., Riddoch, B., and Ladipo, D. O.: Photosynthesis and successional status of seedlings in a tropical semi-deciduous rain forest in Nigeria, J. Ecol., 79, 491-503, 1991.

Rocha, R. M., Higuchi, N., Santos, J., Nakamura, S., Silva, R. P., Pinto, A. C. M., and Tribuzy, E. S.: Taxas de Recrutamento e mortalidade e mudancas de estoque de fitomassa da floresta primaria na regiao de Manaus-AM, in: Projeto Jacaranda Fase II: Pesquisas Florestais na Amazonia Central, CPST-INPA, Manaus, Brazil, 43-54, 2003.

Roderick, M. L. and Berry, S. L.: Linking wood density with tree growth and environment: a theoretical analysis based on the motion of water, New Phytol., 149, 473-485, 2001.

Roggy, J. C., Prevost, M. F., Garbaye, J., and Domenach, A. M.: Nitrogen cycling in the tropical rain forest of French Guiana: Comparison of two sites with contrasting soil types using ${ }^{15} \mathrm{~N}$, J. Trop. Ecol., 15, 1-22, 1999.

Russo, S. E, Davies, S. J., King, D. A., and Tan, S.: Soil-related performance variation and distributions of tree species in a Bornean rain forest, J. Ecol., 93, 879-889, 2005.

Saleque, M. A. and Kirk, G. J. D.: Root-induced solubilization of phosphate in the rhizosphere of lowland rice, New Phytol., 129, 325-336, 1995.

Sanchez, P. A.: Soil productivity and sustainability in agroforestry systems, in: Agroforestry: a Decade of Development, edited by:
Steppler, H. A. and Nair, P. K. R., International Council for Research in Agroforestry, Nairobi, 205-223, 1987.

Sarmiento, C., Patiño, S., Paine, C. E. P., Beauchêne, J., Thibaut, A., and Baraloto, C.: Within-individual variation of trunk and branch xylem density in tropical trees, Amer. J. Bot., 98, 140149, doi:10.3732/ajb.1000034, 2011.

Sattell, R. R. and Morris, R. A.: Phosphorus fractions and availability in Sri Lankan alfisols, Soil Sci. Soc. Am. J., 56, 1510-1515, 1992.

Schieving, F. and Poorter, H.: Carbon gain in a multispecies canopy: the role of specific leaf area and photosynthetic nitrogen-use efficiency in the tragedy of the commons, New Phytol., 143, 201211, 1999.

Scholz, F. G., Bucci, S. J., Goldstein, G., Meinzer, F. C., Franco, A. C., and Miralles- Wilhelm, F.: Biophysical properties and functional significance of stem water storage tissues in Neotropical savanna trees, Plant Cell Environ., 30, 236-248, 2007.

Schoenholtz, S. H., Van Miegroet, H., and Burger, J. A.: A review of chemical and physical properties as indicators of forest soil quality: challenges and opportunities, Forest Ecol. Manag., 138, 335-356, 2000.

Schuur, E. A. G.: Productivity and global climate revisited: The sensitivity of tropical forest growth to precipitation, Ecology, 84 1165-1170, 2003.

Silver, W. L.: Is nutrient availability related to plant nutrient use in humid tropical forests?, Oecologia, 98, 336-343, 1994.

Slik, J. W. F., Aiba, S.-I., Brearley, F. Q., Cannon, C. H., Forshed, O., Kitayama, K., Nagamasu, H., Nilus, R., Payne, J., Paoli, G., Poulsen, A. D., Raes, N., Seil, D. Sidiyasa, K., Suzuki, E., and van Valkenburg, J. L. C. H.: Environmental correlates of tree biomass, basal area, wood specific gravity and stem density gradients in Borneo's tropical forests, Global Ecol. Biogeog., 1950 60, 2010.

Sombroek, W. G.: A Reconnaissance of the Soils of the Brazilian Amazon Region, Centre for Agricultural Publications and Documentation, Wageningen, 1966.

Stephenson, N. and Van Mantgen, P. J.: Forest turnover rates follow global and regional patterns of productivity, Ecol. Lett., 8, 524531, 2005.

Stephenson, N. L., van Mantgem, P. J., Bunn, A. G., Bruner, M., Harmon, M. E., O'Connell, K. B., Urban, K. L., and Franklin, J. F: Causes and implications of the correlation between forest productivity and tree mortality rates, Ecol. Monog., 8, 527-555, 2011.

Sugden, A. M., Tanner, E. V. J., and Kapos, V.: Regeneration following clearing in a Jamaican montane forest: results of a ten year study, J. Trop. Ecol., 1, 329-351, 1985.

Swaine, M. D. and Whitmore, T. C.: On the definition of ecological species groups in tropical rain forests, Plant Ecol., 75, 81-86, 1988.

Swaine, M. D., Lieberman, D., Putz, F. E.: The dynamics of tree populations in tropical forest: a review, J. Trop. Ecol., 3, 359366, 1987.

Swenson, N.G. and Enquist, B. J: Ecological and evolutionary determinants of a key plant functional trait: Wood density and its community-wide variation across latitude and elevation, Amer. J. Bot., 94, 451-459, 2007.

Swenson, N. G. and Enquist, B. J.: The relationship between stem and branch wood specific gravity and the ability of each measure 
to predict leaf area, Amer. J. Bot., 95, 516-519, 2008.

Tanner, E. V. J., Vitousek, P. M., and Cuevas, E.: Experimental investigation of forest growth on wet tropical mountains, Ecology, 79, 10-22, 1998.

ter Steege, H. and RAINFOR: Contribution of current and historical processes to patterns of tree diversity and composition in the Amazon, in: Amazonia, landscape and species evolution: a look into the past, edited by: Hoorn, C. and Wesselingh, F. P., WileyBlackwell, Oxford, 349-359, 2010.

Thomas, S. C.: Relative size at onset of maturity in rain forest trees: a comparative analysis of 37 Malaysian species, Oikos, 76, 145154, 1996.

Thomas, D. S., Montagu, K. D., and Conroy, J. P.: Changes in wood density of Eucalyptus camaldulensis due to temperature-the physiological link between water viscosity and wood anatomy, Forest Ecol. Manag., 193, 157-165, 2004.

Thomas, M. F.: Geomorphology in the Tropics: A Study of Weathering and Denuation in Low Latitudes, Wiley, Chichester, 1994.

Thomas, S. C.: Age-related changes in tree growth and functional biology: the role of reproduction. In: Size- and age-related changes in tree structure and function, edited by Meinzer F. C., Lachenbruch, B., and Dawson, T. E., Springer, Dordrecht, 33-64, 2011.

Tiessen, H., Stewart, J. W. B., and Cole, C. V.: Pathways of phosphorus transformations in soils of differing pedogenesis, Soil Sci. Soc. Am. J., 48, 853-858, 1984.

Toledo, M., Poorter, L., Peña-Claros, M., Alarcón, A., Balcázar, Chuviña, J., Leaño, C., Licona, J. C., ter Steege, H., and Bongers, F.: Patterns and determinants of floristic variation across lowland forests of Bolivia, Biotropica, 43, 405-413, 2011 a.

Toledo, M., Poorter, L., Peña-Claros, M., Alarcón, A., Balcázar, Leaño, C., Licona, J. C., Llanque, O., Vroomans, V., Zuidema, P., and Bongers, F.: Climate is a stronger driver of tree and forest growth rates than soils and disturbance, J. Ecol., 99, 254-264, $2011 b$.

Trolove, S. N., Hedley, M. J., Caradus, J. R., and Mackay, A. D.: Uptake of phosphorus from different sources by Lotus pedunculatus and three genotypes of Trifolium repens 2 . Forms of phosphate utilised and acidification of the rhizosphere, Aust. J. Soil Res., 34, 1027-1040, 1996.

van der Heijden, G. M. F. and Phillips, O. L.: What controls liana success in Neotropical forests?, Glob. Ecol. Biogeogr., 17, 372383, 2008. van der Werf, A., Poorter, H., and Lambers, H.: Respiration as dependent on a species' inherent growth rate and on the nitrogen supply to the plant, in: A whole plant perspective on carbonnitrogen interactions, edited by: Roy, J. and Garnier, E., SPB Academic Publishing, The Hague, 91-110, 1994.

van Nieuwstadt, M. G. L. and Sheil, D.: Drought, fire and tree survival in a Borneo rain forest, East Kalimantan, Indonesia, J. Ecol., 93, 191-201, 2005.

Van Wambeke, A.: Soils of the Tropics - Properties and Appraisal, McGraw-Hill, New York, 1992.

Vitousek, P. M.: Nutrient cycling and nutrient use efficiency, Am. Nat., 119, 553-572, 1982.

Vitousek, P. M.: Litterfall, nutrient cycling, and nutrient limitation in tropical forests, Ecology, 65, 285-298, 1984.

Vitousek, P. M.: Nutrient Cycling and Limitation: Hawai'i as a Model System, Princeton University Press, 223 pp., New Jersey, USA, 2004.

Vitousek, P. M. and Sanford, R. L.: Nutrient cycling in moist tropical forest, Ann. Rev. Ecol. Syst., 17, 137-167, 1986.

Walker, T. W. and Syers, J. K.: The fate of phosphorus during pedogenesis, Geoderma, 15, 1-19, 1976.

Weber, J. C. and Montes, C. S.: Geographic variation in tree growth and wood density of Guazuma crinita Mart, in the Peruvian Amazon, New Forests, 36, 29-52, 2008. southern Peruvian Amazon, Acta Amazonica (Brasil), 30, 589-599, 2000.

Wright, S. J.: Phenological responses to seasonality on tropical forest plants, in: Tropical Forest Plant Physiology, edited by: Mulkey, S. S., Chazdon, R. I., and Smith, A. P., Chapman and Hall, London, 440-460, 1996.

Wright, S. J., Yavitt, J. B., Wurzburger, N., Turner, B. L., Tanner, E. V. J., Sayer, E. J., Santiago, L. S., Kaspari, M., Hedin, L. O., Harms, K. E., Garcia, M. N., and Corre, M. D.: Potassium, phosphorus, or nitrogen limit root allocation, tree growth, or litter production in a lowland tropical forest, Ecology, 92, 1616-1625, 2011.

Zoysa, A. K. N., Loganathan, P., and Hedley, M. J.: A technique for studying rhizosphere processes in tree crops: soil phosphorus depletion around camellia (Camellia japonica L.) roots, Plant Soil, 190, 253-265, 1997.

Zoysa, A. K. N., Loganathan, P., and Hedley, M. J.: Effect of forms of nitrogen supply on mobilisation of phosphorus from a phosphate rock and acidification in the rhizosphere of tea, Aust. J. Soil Res., 36, 373-388, 1998.

Zoysa, A. K. N., Loganathan, P., and Hedley, M. J.: Phosphorus utilisation efficiency and depletion of phosphate fractions in the rhizosphere of three tea (Camellia sinensis L.) clones, Nutr. Cycl. in Agroecosys., 53, 189-201, 1999. 